\title{
ESTUDIO DE FACTIBILIDAD \\ DE MICROEMPRESAS DE SERVICIO \\ DE COMIDA RÁPIDA
}

Claudia A. Molina Quiroz

Stefany M. Hidalgo Moreira

Karen G. Pinoargote Montenegro

Daniel A. Miranda Ledesma

Lenin A. Párraga Zambrano 
Editado y distribuido por

\section{(c) Casa Editora del Polo}

Sello Editorial: 978-9942-816

Manta, Manabí, Ecuador. 2019

Teléfono: (05) 6053240

https://www.casedelpo.com/

ISBNFisico: 978-9942-980-18-2

\section{(C) Primera edición \\ (c) agosto - 2019}

Impreso en Ecuador

Revisión, Ortografía y Redacción:

Lic. Jessica Mero Vélez

Diseño de Portada:

Ing. Edwin Alejandro Delgado Veliz

Diagramación:

Ing. Edwin Alejandro Delgado Veliz

Director:

Ing. Darwin Alex Roldán Mendoza, Mg.

Todos los libros publicados por la Casa Editora del Polo son sometidos previamente a un proceso de evaluación realizado por árbitros calificados.

Este es un libro digital y físico, destinado únicamente al uso personal y colectivo en trabajos académicos de investigación, docencia y difusión del Conocimiento, donde se debe brindar crédito de manera adecuada al autor.

(c) Reservados todos los derechos. Queda estrictamente prohibida, sin la autorización expresa de los autores, bajo las sanciones establecidas en las leyes, la reproducción 


\section{Constancia de Arbitraje}

La Casa Editora del Polo, hace constar que este libro proviene de una investigación realizada por los autores, siendo sometido a un arbitraje bajo el sistema de doble ciego (peer review), de contenido y forma por jurados especialistas. Además, se realizó una revisión del enfoque, paradigma y método investigativo; desde la matriz epistémica asumida por los autores, aplicándose las normas APA, Sexta Edición, proceso de anti-plagio en línea iThenticate, garantizándose así la cientificidad de la obra.

\section{Comité Editorial}

Abg. Néstor D. Suárez-Montes Casa Editora del Polo (CASEDELPO)

Dra. Juana Cecilia Ojeda Universidad del Zulia, Maracaibo, Venezuela

Ph. D. Marco A. Zaldumbide-Verdezoto Universidad Central del Ecuador, Quito, Ecuador

Ing. Vanessa Quishpe-Morocho Universidad Tecnológica Israel, Quito, Ecuador

Dra. Raquel Zoraya Lamus-García Universidad Bolivariana de Venezuela, Venezuela

Dra. Maritza Berenguer-Gouarnaluses

Universidad Santiago de Cuba, Santiago de Cuba, Cuba

Dr. Víctor Reinaldo Jama-Zambrano

Universidad Laica Eloy Alfaro de Manabí, Ext. Chone

Dra. Tibisay Milene Lamus de Rodríguez

Universidad Nacional Experimental "Francisco de Miranda, Venezuela 


\section{CAPÍTULO I}

ASPECTOS GENERALES DE LAS COMIDAS

\section{CAPITULO II}

\section{ESTUDIO DE MERCADO PARA LA}

IMPLEMENTACIÓN DE LA MICROEMPRESA DE COMIDAS RÁPIDAS EN EL CANTÓN CHONE...33

2.1.- Estructura del mercado de comidas rápidas en el cantón Chone... 
2.2.2.-Distribución geográfica . .34

2.2.3.-Potencial económico. .34

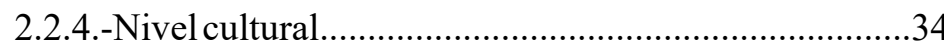

2.3.-Identificación de los productos a comercializar.................34

2.4.-Características del servicio. .35

2.5.-Análisis del tipo de demanda.. . .36

2.5.1.-Tipificación del consumidor.. .36

2.6.-Investigación de mercado .37

2.6.1.-Metodología aplicada al estudio factible para la implementación de microempresa de comidas rápidas en el cantón Chone. . .37

2.7.-Demanda potencial del servicio... . .58

2.8.-Proyección de la población potencial. .58

2.9.-Análisis de la oferta . .61

2.9.1.-Oferta local actual. 661

2.9.2.-Proyección de la oferta estimada.. . .63

2.9.3.-Proyección de la oferta del proyecto.

2.10.-Demanda insatisfecha. .66

2.11.-Análisis de la comercialización de precios actual..........67

2.11.1.-Precios del servicio actual 67

2.11.2.-Análisis del mercado de proveedores.......................68

2.11.3.-Criterio de selección de proveedores......................73

2.12.-Análisis de comercialización.. .75

2.12.1.1.-Estrategias de diferenciación. .75
2.12.1.2.-Promociones.

\section{CAPÍTULO III}

Estudio técnico - administrativo legal y financiero para la implementación de la microempresa de comidas rapidas en la ciudad de Chone.......................79

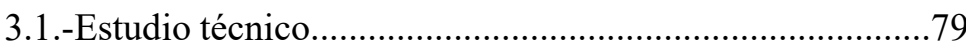

3.1.1.--Localización de la planta.............................................

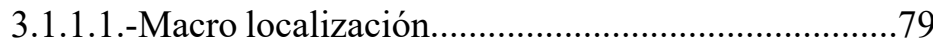

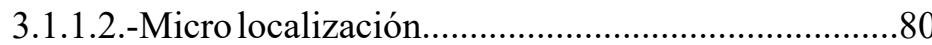

3.1.2.-Tamaño de la planta..........................................................

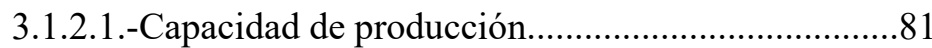

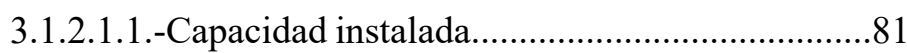

3.1.2.1.2.-Capacidad Ociosa................................................ 83

3.1.3.Proceso de elaboración de productos...............................84

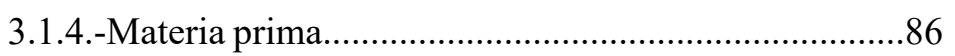

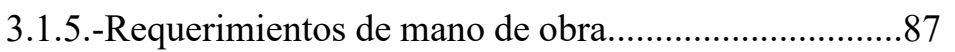

3.1.6.-Estimación de la inversión.............................................

3.1.6.1.-Obras físicas.......................................................91

3.1.7.-Distribución del lugar para la instalación del servicio . .97

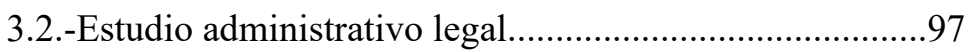

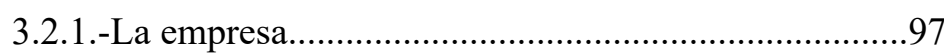

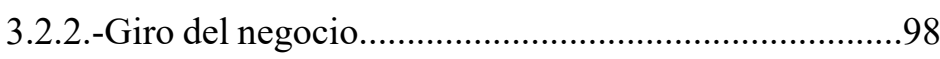

3.2.3.-Objetivos estratégicos.................................................99

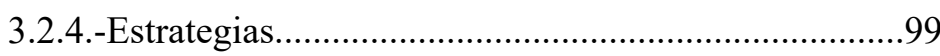

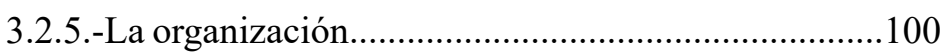

3.2.5.1.-Organigrama estructural...................................... 100 
3.3.-Estudio legal

3.3.1.-Constitución de la empresa.

.. .107

3.3.2.-permisos de funcionamiento.

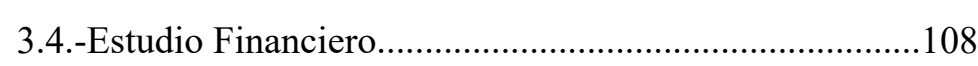

3.4.1.-Presupuesto de inversiones.........................................108

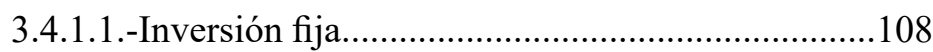

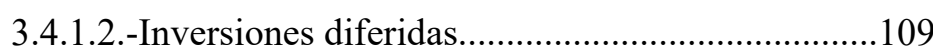

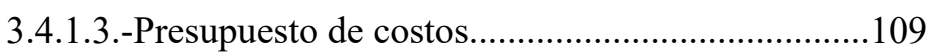

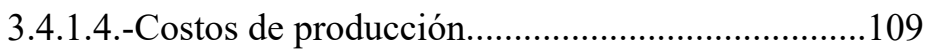

3.4.1.5.-Costos de materia prima.........................................111

3.4.1.6.-Costos de operación................................................113

3.4.1.7.-Capital de operación............................................115

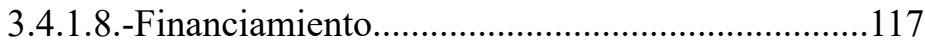

3.4.1.9.-Presupuesto de ingresos.......................................117

3.4.1.10.-Estados financieros............................................118

3.4.1.11.-Balance general....................................................119

3.4.1.12.-Evaluación financiera.............................................. 123

3.4.1.13.-Criterios de evaluación......................................124

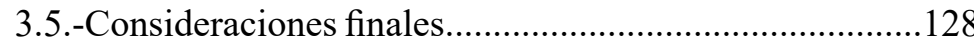

Bibliografía. .129

\section{INTRODUCCIÓN}

La globalización y el desarrollo económico del mundo actual, ha hecho que la población tenga cada vez menos tiempo para actividades no relacionadas directamente con su trabajo por lo que muchas personas se ven obligadas a comer en poco tiempo y consumen alimentos calificados como "comida rápida". El mercado de comida, en la última década ha tendido a dar este tipo de soluciones rápidas, modificando su menú e incluso su ubicación. Adicionalmente, se ha identificado la carencia de espacios diferentes, alternativos y asequibles de entretenimiento en la ciudad de Chone que se ajusten a los estándares de calidad exigidos por los clientes, organismos competentes, en salud, turismo y que satisfagan la necesidad creciente de los consumidores del Cantón Chone, en la Provincia Manabí, hace necesario proponer la ejecución del proyecto de creación de una microempresa de comidas rápidas a ser instalada en dicha ciudad, por ser una zona de gran movilidad humana favorecida por la ubicación de la terminal terrestre y de hoteles, donde existen una fluctuación a diario de personas, que tienen la necesidad de adquirir alimentos, de una forma rápida y de calidad, es así, donde nace la opción, de crear una alternativa que pueda brindar un servicio de venta de comidas rápidas, en un establecimiento que brinde calidad, calidez, confort y satisfacción a los clientes- usuarios.

Cabe destacar que en la ciudad de Chone, la falta de locales de venta de comidas rápidas, en lugares seguros y que brinden el servicio de cafetería- bar, con ambiente climatizado y música 
apropiada, es considerado por sus habitantes y turistas, como un elemento negativo para esta ciudad, a diferencia de otras ciudades de la provincia de Manabí. Chone, por ser una urbe de tránsito obligatorio para las personas que viajan hacia otros cantones de la zona norte de Manabí y las provincia de Santo Domingo de los Tsháchilas y de Pichincha y viceversa hasta otras ciudades de esta jurisdicción provincial, es otra de las causas, por la cual se hace necesaria la creación de una microempresa de comidas rápidas, para satisfacer las necesidades manifiestas en este tipo de servicios dirigidos a colectivos o grupos ocupacionales, así como también a residentes de la ciudad de Chone, generadora de belleza y de riqueza al erario nacional.

Por ello nace la necesidad de elaborar un estudio de factibilidad sobre la creación de un restaurante en la zona Av. Sixto Durán Ballén, ciudad de Chone, que brinde una alternativa sana de comida rápida, así como también alternativas de esparcimiento que contribuirá a satisfacer las necesidades del mercado actual y generará fuentes de empleo. Para lo cual se realizó un estudio de mercado determinando así las tendencias de consumo de comida rápida de la población y el nicho de mercado al que se enfocaría este proyecto. El desarrollo del mismo se presenta en este libro en tres capítulos a saber:

El primer capítulo, refiere los aspectos generales de las comidas rápidas relacionados con su tipología, características y teorías que la sustentan.

En el segundo capítulo se presenta el estudio de mercado para la implementación de la microempresa de comidas rápidas en el cantón Chone, especificándose la estructura del mercado de comidas rápidas en el cantón Chone.

El tercer capítulo presenta el estudio técnico - administrativo legal y financiero para la implementación de la microempresa de comidas rápidas en la ciudad de Chone y las consideraciones finales del estudio. 


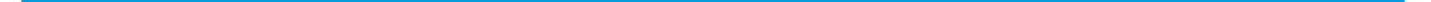




\section{CAPÍTULO I \\ ASPECTOS GENERALES DE LAS COMIDAS RAPIDAS}

El concepto de comida rápida es un estilo de alimentación, donde el alimento se prepara y sirve para consumir rápidamente en establecimientos especializados o para llevar su consumo, generalmente, fuera del local de expendio.

Aunque ya desde la antigua Roma se servía en puestos callejeros panes con olivas en el Medio Oriente, no es hasta el año 1912, cuando se abre el primer automático, un local que ofrecía comida detrás de una ventana de vidrio y una ranura para pagar. Los cambios en los hábitos de alimentación de la población, provocados por un ritmo de vida muy acelerado y estresante, han hecho que muchas personas se vean obligadas a mayormente o muy frecuentemente a alimentarse a partir de comida como: "fast food", comida rápida o comida chatarra, hasta llegar a casos en los que una persona, ni desciende del vehículo para ingerirla.

Antes de que existieran las franquicias internacionales de comidas rápidas en el Ecuador, las personas realizaban su consumo en pequeños negocios que no estaban a la altura de los estándares de las franquicias. A partir del ingreso al mercado ecuatoriano de varias cadenas de comidas rápidas, estas en poco tiempo logran posesionarse, circunstancias por las cuales los negocios nacionales, se ven obligados a mejorar sus estándares de servicio para poder competir con estas cadenas, lo que ha 
provocado que los consumidores tengan un mayor grado de exigencias al momento de recibir un servicio y productos.

Entre las cadenas de comidas rápidas que han ingresado al Ecuador podemos citar: KFC, Burger King, Mc Donald's, Amercian Deli, Pizza Hut, Rock and Roll, las que han captado con sus variadas producciones, que las personas consuman sus productos en grandes cantidades. De allí que comidas rápidas, como hamburguesas, hot-dogs, papas fritas, aros de cebolla fritos, pollo frito, pizzas y demás snacks, forman parte de la alimentación diaria de una inmensa mayoría de personas, entro los que se encuentran niños y adolescentes.

\section{1.-Tipos de comida rápida}

Considerándose que la comida rápida, se encuentra elaborada en su mayoría con almidones de maíz, papas o harinas de trigo y frituras de toda índole, entre las comunes se encuentran:

- Hamburguesas: es un tipo de sándwich hecho a base de carne molida aglutinada en forma de filete, cocinado a la parrilla o a la plancha.

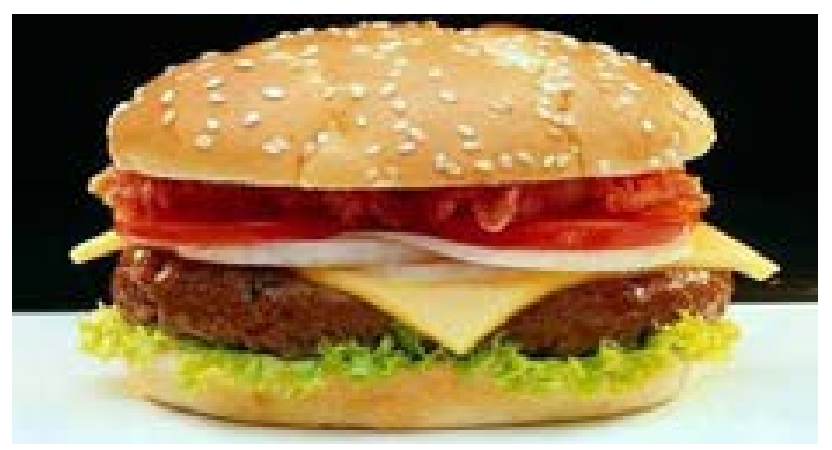

- Hot dog: es un alimento en forma de bocadillo que se genera con la combinación de una salchicha del tipo salchicha de Frankfurt (frankfurter), o vienesa (wiener) hervida, o frita, servida en un pan con forma alargada que suele acompañarse con algún aderezo como salsa de tomate, mostaza y cebolla.

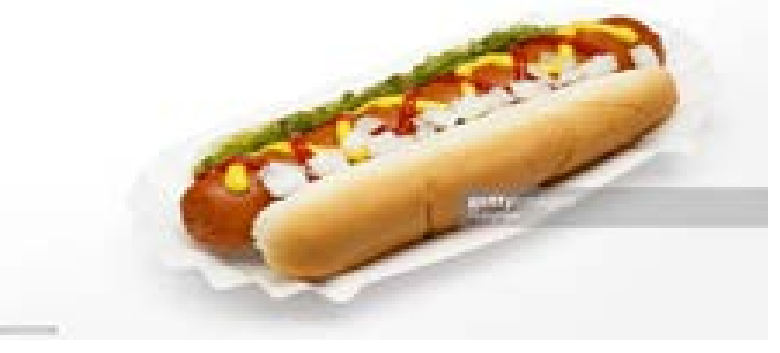

- Pollo frito: es originaria del sur de los Estados Unidos. La harina lleva un toque de páprika, la cual se puede sustituir por un chile en polvo favorito.

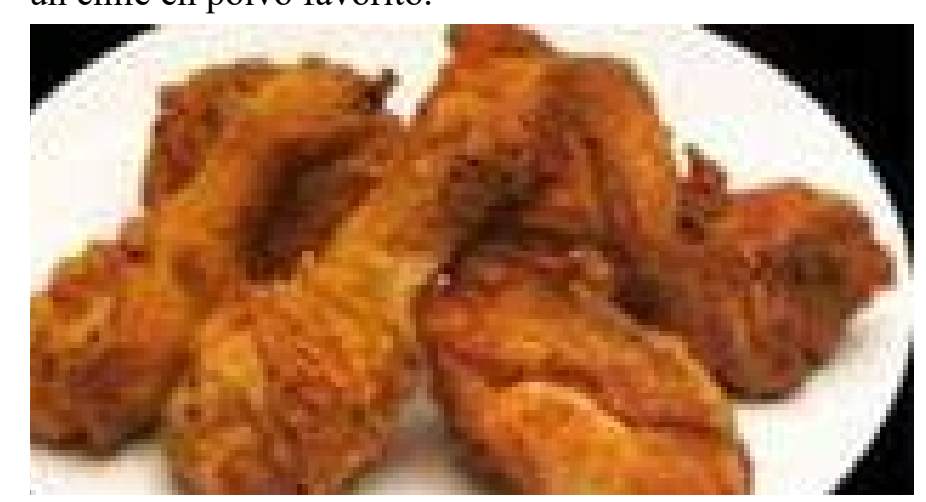

- Papas fritas: también conocidas como papas a la francesa o patatas a la francesa, son las papas que se preparan cortándose 
en rodajas o en forma de bastones y friéndolas en aceite caliente hasta que queden doradas, retirándolas del aceite y luego sazonándolas con sal.

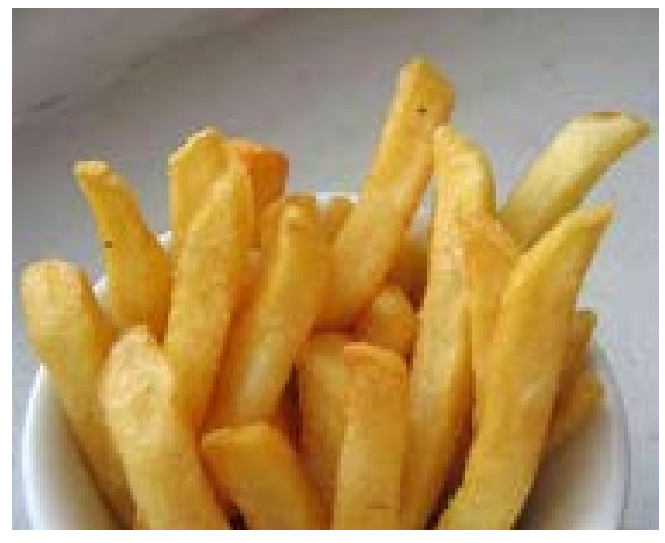

- Salchipapas: Consiste en rodajas fritas de salchicha y papas fritas, acompañadas de diferentes salsas, como ketchup, mostaza, crema de aceituna y de chile/ají

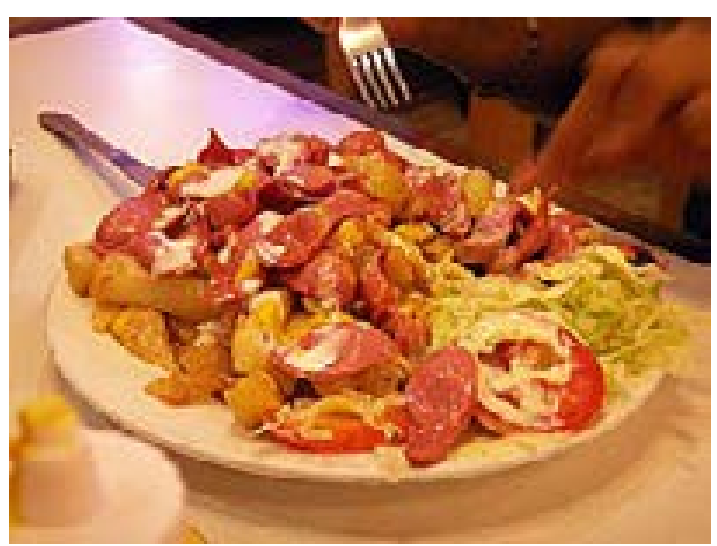

- Bocadillos: es un trozo de pan o un panecillo - un bollo- en cuyo centro se coloca algún tipo de alimento. Normalmente se suele abrir el pan longitudinalmente en dos mitades.

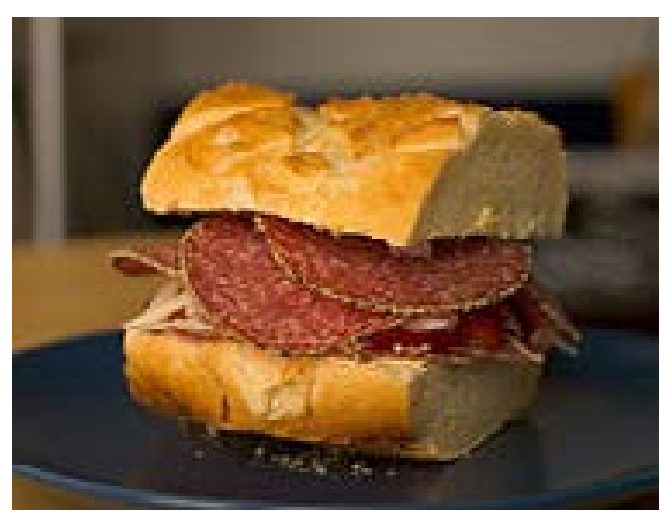

- Pinchos: también conocidos como chuzos o pinchos, se prepara usando filetes de carne de res, pollo o cerdos cortados finamente, y adobados con naranja, ajo, achiote, y comino

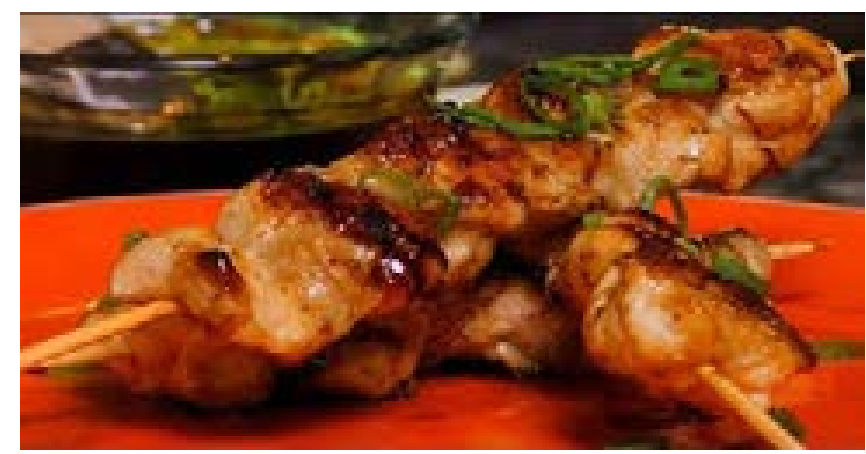

- Pizzas: es un pan plano horneado, habitualmente de forma redonda, elaborado con harina de trigo, sal, agua y levadura, cubierto con salsa de tomate y queso. 

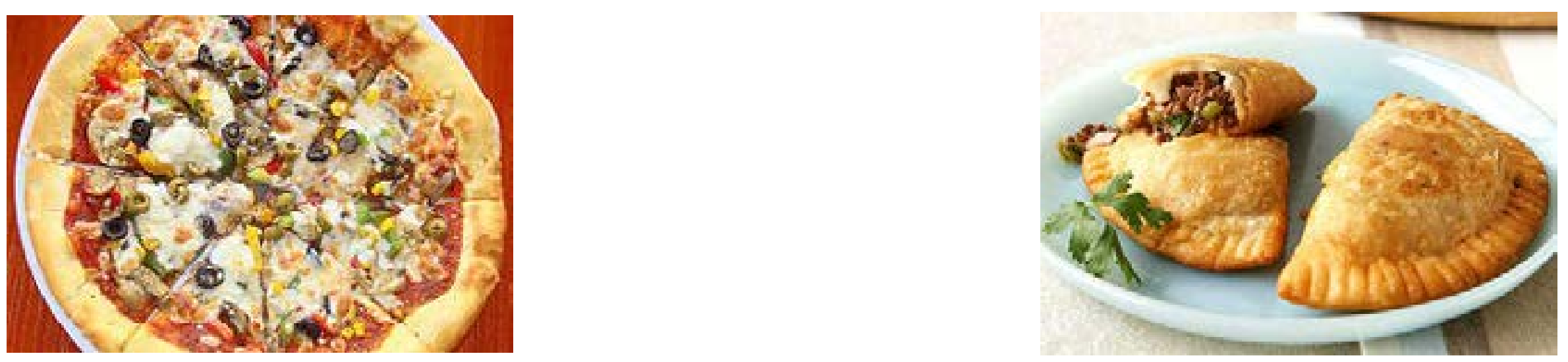

- Sándwich: sánduche o emparedado es una comida, a modo de tentempié, aperitivo o la comida que se suele hacer a diario.

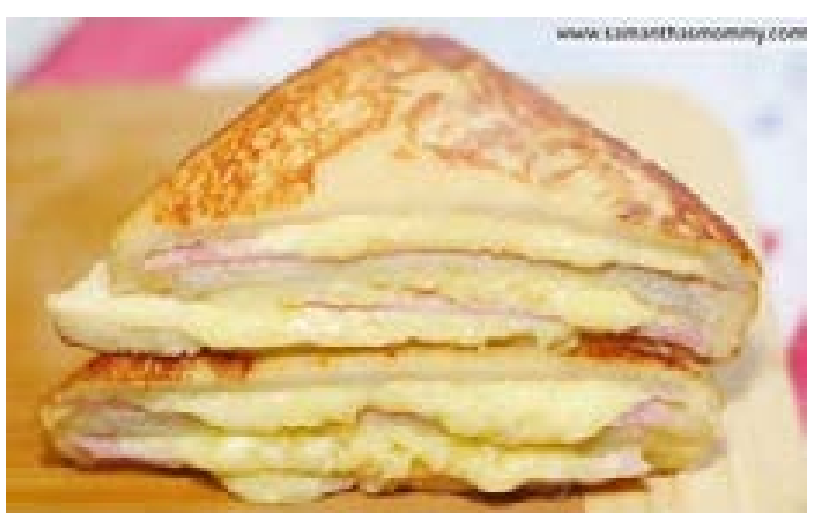

\section{2.-Características de la comida rápida}

La comida rápida se caracteriza principalmente por lo siguiente:

- Es de fácil preparación.

- Entrega .

- La comida se prepara a menudo con ingredientes formulados para alcanzar un cierto sabor o consistencia para preservar la frescura.

- No se usan cubiertos para consumirlo.

- Ofrece diferentes tipos de servicio como el consumo en el local, recogerlo en el local, en la calle o domicilio y la entrega domiciliaria.

- Empanadas: es una fina masa de pan, masa quebrada u hojaldre rellena con una preparación salada o dulce y cocida al horno o frita. El relleno puede incluir carnes rojas o blancas, pescado, verduras o fruta. La masa, generalmente, es de harina de trigo -aunque también puede usarse harina de maíz u otros cereales- y suele llevar alguna grasa, aceite o manteca.

- Precios moderados.

- Son platillos prácticos cuando no se dispone de tiempo para comer.

- Se manejan bajo estándares y procesos de preparación similares. 
Un negocio que presta el servicio de comida rápida, también presenta varias ventajas como:

- Las personas en caso de emergencia alimentaria, la primera opción son las comidas rápidas.

- La comida rápida, es consumida por personas de cualquier edad, por lo que los locales que se dedican a esta actividad siempre cuentan con clientes.

- No se necesita un lugar amplio.

- Se puede prestar varios servicios a la vez.

- En su mayoría cuentan con horarios accesibles de acuerdo a la zona.

- Tienen una alta capacidad de distribución.

Lo anteriormente expuesto, se justifica al considerar la actividad de alimentarse como la propia existencia del ser humano. Sin este proceso sería imposible la subsistencia de la vida humana. El proceso de alimentación que surgió como una necesidad inherente a los seres vivos, ha dejado de ser un proceso limitado a la subsistencia humana, para convertirse en una actividad que es fuente de placer, unido a los procesos de socialización del ser humano.

Varias son las formas y características que ha adoptado el proceso de comercialización de alimentos. Sus orígenes se remota a la tradición primitiva de los festines comunitarios y que en la actualidad se ha convertido en una de las principales actividades como parte del desarrollo turístico contemporáneo.

La creación de servicios de comidas rápidas, han pasado de ser sencillas opciones de comercialización, hasta convertirse en grandes empresas trasnacionales de comercialización de alimentos. Sin embargo el rescate de las culturas tradicionales en la elaboración de alimentos, ha perdido su esencia, con el desarrollo de este servicio.

En la actualidad existe un importante movimiento por el rescate de los procesos de elaboración de alimentos, apegados a los mejores estándares de preparación, con la utilización de alimentos y procesos saludables, dentro de esta dimensión se incluye, las pequeñas empresas de elaboración de alimentos ajustadas a las características, necesidades y demandas del ser humano y su entorno.

Chone es un Cantón de la provincia de Manabí, en la cual se evidencia la falta de establecimientos donde se comercialicen alimentos como en las grandes ciudades del país, en términos de calidad en los servicios que se brindan. Por otro lado existe una amplia gama de áreas de expendio de comida tradicional, sin embargo estos establecimientos, carecen de un estudio y una planificación que les permitan evaluar y proyectar la visión de la empresa en función de las necesidades de los clientes y las demandas de los usuarios. Problemas como la carencia en insumos necesarios para la elaboración adecuada de los alimentos, el confort, la calidad de la atención, entre otros, son aspectos que constituyen limitaciones en una población creciente y con demandas en este sentido.

Con el propósito de brindar un servicio que supere las dificultades que se presentan en la mayoría de los locales de expendio de alimentos, en este libro se determina la factibilidad de crear 
una microempresa de comidas rápidas en la ciudad de Chone, cantón del mismo nombre, en la provincia de Manabí, para ello más adelante se presenta un análisis del comportamiento de factibilidad, un estudio técnico y administrativo, y los requerimientos de inversión para una empresa de comida rápida.

\section{3.-Teorías que sustentan la creación de una empresa de comida rápida.}

Dentro de las teorías que permiten sustentar teóricamente la factibilidad de crear una microempresa de comidas rápidas en la ciudad de Chone, se pueden distinguir las siguientes:

\subsection{1.-Beneficio costo $(B / C)$}

Es un indicador de rentabilidad entre los ingresos y los egresos de un proyecto y cuya utilización es muy frecuente en estudios de grandes proyectos. El cálculo se apoya en el método del valor actual Neto - VAN.

\subsection{2.-Comercialización}

Es la acción de poner a la venta un producto o crear las vías y condiciones para su venta.

\subsection{3.-Costos}

Representan una porción del precio de adquisición de artículos, propiedades o servicios, que ha sido diferida o que todavía no se ha aplicado a la realización de ingresos.+

\subsection{4.-Demanda}

Es la cantidad de bienes o servicios que los consumidores están dispuestos a comprar a un precio dado, en un tiempo determinado. La demanda se determina por el precio del bien o servicio, el nivel de ingresos personal y las preferencias de los consumidores

\subsection{5.-Gastos}

Es la salida de dinero que realiza una empresa, o persona natural, con el objetivo de administrar adecuadamente un proceso productivo o un negocio, así como también ejecutar las labores de venta, promoción y distribución de los productos manufacturados, los servicios prestados y las mercancías adquiridas para vender.

El gasto produce una doble circulación económica: por un lado sale dinero y, por el otro, entran bienes y servicios con los cuales podrán obtener ingresos derivados de la actividad económica con lo que se conseguirá recuperar los desembolsos iniciales.

\subsection{6.-Inversiones}

Representan colocaciones de dinero sobre las cuales una empresa espera obtener algún rendimiento a futuro, ya sea, por la realización de un interés, dividendo o mediante la venta a un mayor valor a su costo de adquisición. Estas operaciones se producen cuando un ente tiene un sobrante de fondos y desea utilizarlos para obtener un resultado proveniente de una actividad ajena al mismo.

\subsection{7.-Oferta}

Es la cantidad que los productores están dispuestos a ofrecer en 
el mercado en un precio dado, en un tiempo determinado.

\subsection{8.-Precio}

Es la expresión de valor que tiene un producto o servicio, manifestado en términos monetarios, que el comprador debe pagar al vendedor para acceder al producto o servicio que esté ofertando.

\subsection{9.-Rentabilidad}

Es una relación porcentual que dice cuanto se obtiene a través del tiempo por cada unidad de recurso invertido.

\subsubsection{0.-Tasa interna de retorno (TIR)}

Indicador financiero que se utiliza para medir el rendimiento de las inversiones por periodo. Se expresa porcentualmente; $\mathrm{y}$, es la tasa de interés que iguala a cero, los beneficios netos descontados a una tasa de interés.

\section{TIR $=$ TIO Proyecto indiferente para el inversionista}

TIR $<$ TIO Proyecto no recomendable.

TIR > TIO Proyecto recomendable, porque la TIR cubre sus expectativas de ganancia representada a través de la Tasa Interna de Oportunidad-TIO.

\subsubsection{1.-Tasa verdadera de rentabilidad (TVR)}

Indicador financiero que se utiliza para medir el rendimiento de las inversiones, considerando todo el periodo de vida útil del proyecto. Se expresa porcentualmente (\%) y representa la combinación de la TIR y de la TIO, que son las expectativas de ganancia del inversionista.

TVR > TIO Es recomendable en razón que el rendimiento de TVR, es mayor que la expectativa de ganancia.

$\mathrm{TVR}=0 \mathrm{El}$ proyecto es indiferente ya que cubre en igual cuantía las expectativas de ganancia del inversionista.

TVR $<0$ El proyecto no es recomendable, porque las expectativas de ganancia no son superiores a las que muestra la TVR.

\subsubsection{2.-Valor actual neto (VAN)}

Es un indicador financiero que mide el dinero de hoy en flujos futuros de ingresos- egresos. El resultado se expresa en valores absolutos y se compara con las expectativas de ganancias.

VAN $>0$ Ganancia por encima de la inversión a una tasa dada.

$\mathrm{VAN}=0$ Ganancia esperada.

VAN $<0$ Ganancia por debajo de lo esperado. 


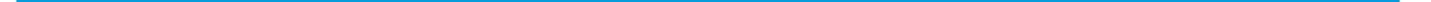




\section{CAPITULO II}

ESTUDIO DE MERCADO PARA LA

IMPLEMENTACIÓN DE LA MICROEMPRESA DE COMIDAS RÁPIDAS EN EL CANTÓN CHONE.

El estudio de mercado que permitió conocer la viabilidad comercial de la implementación de la microempresa de comidas rápidas en el cantón Chone, develo la demanda insatisfecha del proyecto de inversión, los competidores actuales y potenciales competidores, el precio promedio de los competidores en los productos que se consumen con mayor frecuencia y cuales estrategias comerciales se han de proponer para consolidar el mercado de las comidas rápidas en la región.

\section{1.- Estructura del mercado de comidas rápidas en el cantón chone}

Los productos alimentarios que se comercializan en la actualidad, en los locales de expendio de comidas rápidas, se desarrollan en un mercado de competencia monopolística, sustentado en las siguientes características:

- Existen muchos ofertantes

- Los productos y servicios que se ofrecen son variados.

- Alta facilidad de ingreso de competidores.

- La demanda potencial disminuye a medida que entran más competidores. 


\subsection{1.-Segmentación}

La segmentación del mercado se basó en su distribución geográfica, su potencial económico y su nivel de cultura.

\subsection{2.-Distribución geográfica}

Los productos que se comercializarán tendrán como principal mercado objetivo a las personas que se encuentran dentro de la población económicamente activa (PEA) y que realizan sus actividades dentro del área urbana del cantón Chone.

\subsection{3.-Potencial económico}

En función del crecimiento económico local así como también de una mejora sustancial en el nivel de ingresos de la población y sumado a una disminución en los niveles de desempleo, en el mediano plazo se espera que exista un crecimiento de la demanda del servicio que se pretende implementar.

\subsection{4.-Nivel cultural}

El compartir en familia, con amigos o personas allegadas de momentos de sano esparcimiento mientras se saborea algún alimento, es parte de la cultura del manabita a nivel general y de los residentes de la ciudad de Chone en lo particular, por este motivo se pretende satisfacer dicha necesidad arraigada en la cultura local.

\section{3.-Identificación de los productos a comercializar}

El estudio de la factibilidad del proyecto busca convertirse en una alternativa de alimentación y diversión para la población de la ciudad de Chone, tratando de ofrecer un servicio de calidad que permitirá brindar:

- Comidas rápidas: hamburguesas, papas fritas, sanduches, tostadas, pizza, alitas de sabores, lasaña, fritadas, tablitas de carne - maricos, humitas, torta de choclo, bollos, horneado, patacones rellenos, empanadas, bocadillos de jamón y queso.

- Postres: torta mojada de chocolate, cheescakes, tiramisú, frutas picadas, tres leches, queso de piña, helados.

- Bebidas calientes y frías: te aromático, café, té, cappuccino, mocaccinos, batidos, frappé, jugos naturales y gaseosas.

- Cocteles: margaritas, piña colada, cuba libre, tequila sonrise.

\section{4.-Características del servicio}

- Servicio de bar: Los fines de semanas donde se podrá encontrar bebidas con contenido de grados de alcohol, y con música en vivo los sábados y fechas conmemorativas.

- Servicio de catering: consiste en brindar el servicio de comidas preparadas a grupos de personas como por ejemplo: instituciones públicas y privadas.

- Servicio adicional de parqueadero: el espacio físico del proyecto estará respectivamente diseñado para ofertar este tipo de servicios, ubicado en la planta baja del Hotel Chuno, de la Ciudad de Chone, con una capacidad de 35 personas.

- USO: El servicio de cafetería es de consumo final, porque sus productos son para que se los consuma de manera directa. 


\section{5.-Análisis del tipo de demanda}

- Considerando la oportunidad: la demanda a la que está dirigido el proyecto es demanda insatisfecha por cuanto los locales de comida rápida existentes brindan un servicio que no cumple las expectativas de los consumidores.

- De acuerdo a su necesidad: la demanda es suntuaria porque no es un servicio que se considere de primera necesidad.

- De acuerdo a su temporalidad: el tipo de demanda es continua ya que los consumidores necesitan el servicio en cualquier momento.

- De acuerdo a su destino: el servicio es final puesto que los consumidores utilizaran el servicio de manera directa.

- De acuerdo a su permanencia: la demanda es de flujo porque es de carácter permanente.

\subsection{1.-Tipificación del consumidor}

Se consideró como potenciales consumidores a las personas que se encuentran dentro de la población económicamente activa (PEA) de la zona urbana del cantón Chone. Sin discriminación del género y la edad se consideró a aquella mayor a 12 años, la cual pertenece a la población económicamente activa, pues son ellos quienes en su gran mayoría son consumidores del servicio que ofrece el presente proyecto.

\section{6.-Investigación de mercado}

2.6.1.-Metodología aplicada al estudio factible para la implementación de microempresa de comidas rápidas en el cantón Chone.

Para la realización del estudio de mercado se utilizaron un conjunto de métodos y técnicas tales como la observación, análisis cualitativo y cuantitativo, que permitieron lograr la consolidación del estudio de factibilidad. Es de indicar que durante el mismo, se consultó el universo de la población económicamente activa $(45,4 \%)$ del área urbana $(42 \%)$ del cantón Chone, la cual según datos proporcionados por el Instituto Ecuatoriano de Estadísticas y Censos (INEC) para el año 2010 dio como resultado una PEA de 24.007 habitantes (INEC, 2010). De la población reportada que asciende a 24007 sujetos, se seleccionó una muestra, para ello se utilizó la fórmula de población finita que se detalla a continuación:

$n=\frac{Z^{2} P Q N}{E^{2}(N)+Z^{2} P Q} ;$ donde:

$\mathrm{n}=$ Tamaño de la muestra

$\mathrm{N}=$ Número de elementos de la población

$\mathrm{P}-\mathrm{Q}=$ Probabilidad de la presentación del fenómeno

$Z=$ Valor crítico correspondiente al nivel de significación $(5 \%)$

$\mathrm{E}=$ Margen de error permitido, para la presente propuesta se 
consideró el 7\%.

Esto permitió obtener el siguiente resultado:

$$
n=\frac{(1,96)^{2} * 0,5 * 0,5 * 24.007}{0,07^{2}(24.007)+(1,96)^{2} * 0,5 * 0,5}=\frac{23.056,32}{118,59} \cong 195
$$

Para obtener información veraz del funcionamiento de las microempresas de comidas rápidas, se elaboró un instrumento tipo cuestionario que permitió recabar la información referente a los gustos y preferencias de las personas que consumen los productos y servicios que ofrece las comidas rápidas. La información solicitada indicaban: lugares a los que acude, frecuencia, el consumo, horario y precio que estarían dispuestos a pagar por los productos y servicios ofrecidos, así como también cuales son aquellas características y productos que prefiere. La información obtenida se puede resumir en las siguientes tablas:

1.¿Le satisface el servicio de comidas rápidas que se ofrece en la ciudad?

Tabla 1: Satisfacción del servicio

\begin{tabular}{l|rr}
\hline Satisfaccion & Frecuencia & Porcentaje \\
\hline Si & 179 & $65 \%$ \\
\hline A veces & 70 & $26 \%$ \\
\hline Nunca & 4 & $1 \%$ \\
\hline Sin Resp & 21 & $8 \%$ \\
\hline Total & $\mathbf{2 7 4}$ & $\mathbf{1 0 0 \%}$
\end{tabular}

Fuente: Elaboración propia.

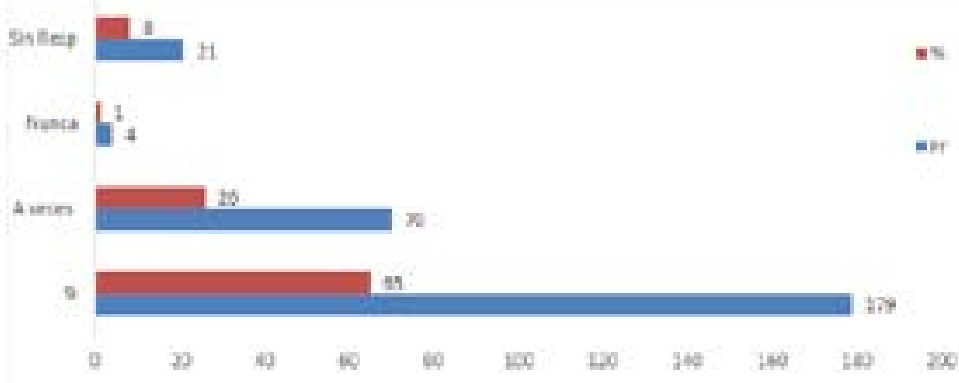

Grafico 1: Satisfacción del servicio

Fuente: Elaboración propia.

A esta pregunta, de las 274 personas encuestadas, 179 personas que equivalen al $64 \%$ respondieron que si les satisface; a 70 persona que equivale el $25 \%$ respondieron que a veces se sentían satisfechas y 4 que nunca se sentían satisfechas. A esta pregunta 21 personas no respondieron.

2.¿Se siente bien atendido en esos lugares?

Tabla 2: Atención al público.

\begin{tabular}{|lrr|}
\hline Atendido & Frecuencia & Porcentaje \\
\hline Si & 131 & $48 \%$ \\
\hline A veces & 114 & $42 \%$ \\
\hline Nunca & 4 & $1 \%$ \\
\hline Sin Resp & 25 & $9 \%$ \\
\hline Total & $\mathbf{2 7 4}$ & $\mathbf{1 0 0 \%}$
\end{tabular}

Fuente: Elaboración propia. 


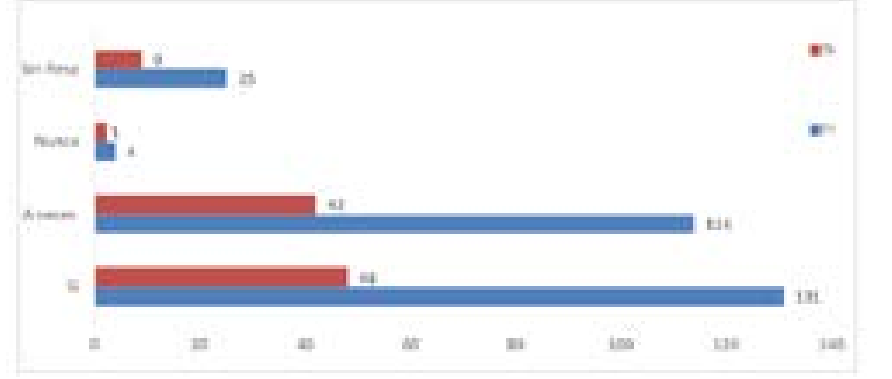

Grafico 2: Atención al público.

Fuente: Elaboración propia.

Las personas encuestadas al ser cuestionadas sobre la atención brindada en los lugares donde se expende comida rápida, en un número de 134 personas equivalente al 47\%, dijeron si se sentían bien atendidas, un numero de 114 personas que representa el $41 \%$ dijo que a veces se sentía bien atendido; 4 personas respondieron que nunca se sintieron bien atendidas y 25 personas equivalentes al $9 \%$ no respondieron esta pregunta.

3.¿Los precios se adecuan a la calidad del servicio?

Tabla 3: Precios y calidad del servicio.

\begin{tabular}{lrr}
$\begin{array}{l}\text { Precios acordes } \\
\text { al servicio }\end{array}$ & Frecuencia & Porcentaje \\
\hline Si & 166 & $61 \%$ \\
\hline A veces & 70 & $26 \%$ \\
\hline Nunca & 8 & $3 \%$ \\
\hline Sin Resp & 30 & $11 \%$ \\
\hline Total & 274 & $100 \%$ \\
\hline
\end{tabular}

Fuente: Elaboración propia. 


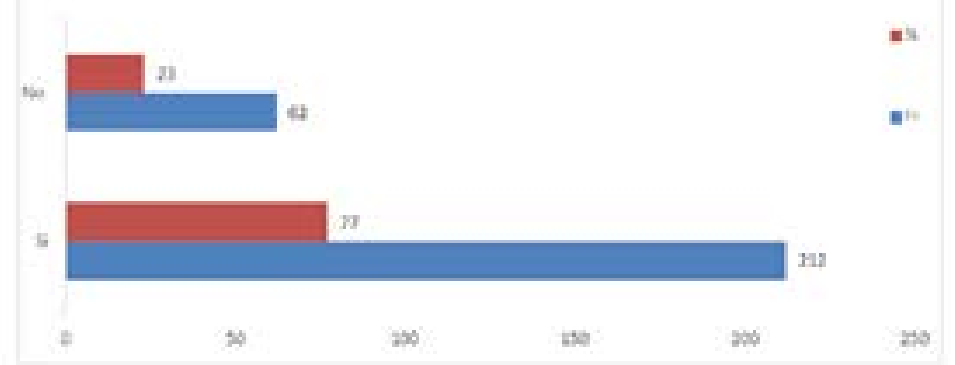

Grafico 4: Horarios adecuados a necesidades del usuario.

Fuente: Elaboración propia.

A esta pregunta 212 personas, que equivalen el $77 \%$, respondieron que los horarios de atención de los locales donde se expende comida rápida tenia horarios adecuados, mientras que 62 personas que representan el 23\% dijeron que los horarios no eran adecuados.

5.¿Cuántas veces a la semana Ud. consume comidas rápidas?

Tabla 5: Frecuencia de consumo de comidas rápidas.

\begin{tabular}{l|rr}
\begin{tabular}{c} 
Consume comidas \\
\multicolumn{1}{c}{ rapidas }
\end{tabular} & Frecuencia & Porcentaje \\
\hline 1 vez por semana & 154 & $56 \%$ \\
\hline 2 veces / semana & 80 & $29 \%$ \\
3 o mas veces & 20 & $7 \%$ \\
\hline Sin Resp & 20 & $\mathbf{7 \%}$ \\
\hline Total & $\mathbf{2 7 4}$ & $\mathbf{1 0 0 \%}$ \\
\hline
\end{tabular}

Fuente: Elaboración propia.
En lo que respecta a la pregunta concerniente a la frecuencia con la que los encuestados consumen comidas rápidas se pudo observar que el $55 \%$ de ellos al menos una vez a la semana lo realizan, el $29 \%$ lo hacen dos veces por semana mientras un $7 \%$ lo realiza al menos tres veces por semana.

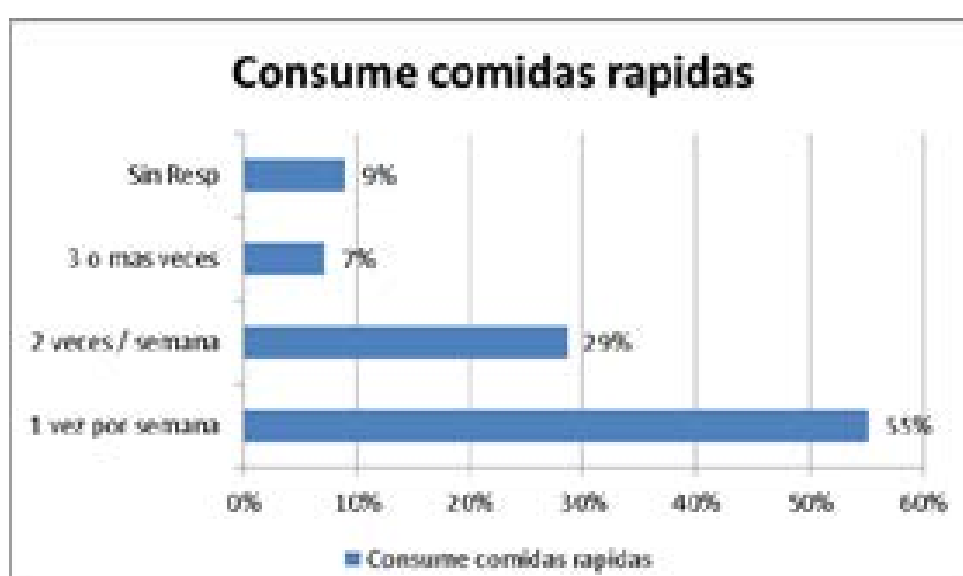

Grafico 5: Frecuencia de consumo de comidas rápidas. Fuente: Elaboración propia.

6.¿Prefiere un nuevo local de comida rápida?

Tabla 6: Preferencia de un nuevo local.

\begin{tabular}{l|rr}
$\begin{array}{c}\text { Prefiere nuevo } \\
\text { local }\end{array}$ & Frecuencia & Porcentaje \\
\hline Si & 241 & $88 \%$ \\
\hline No & 33 & $12 \%$ \\
\hline Total & 274 & $100 \%$ \\
\hline
\end{tabular}

Fuente: Elaboración propia. 


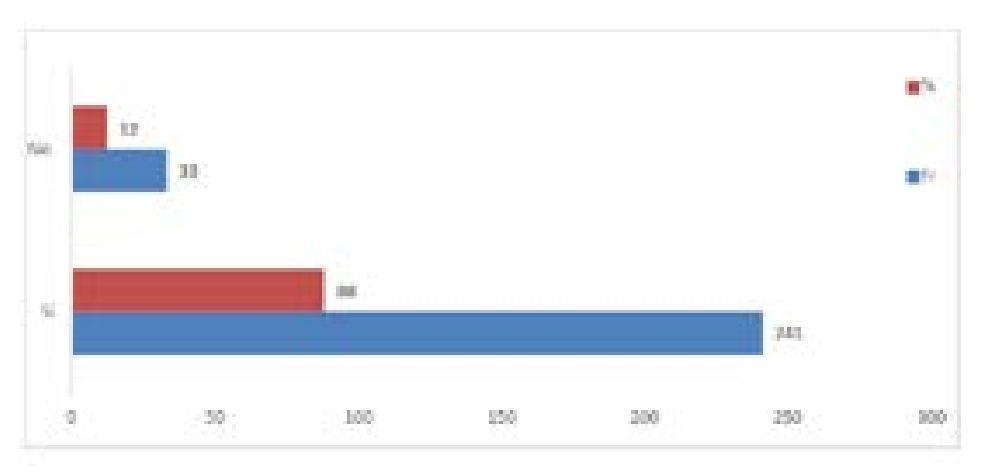

Grafico 6: Preferencia de un nuevo local.

Fuente: Elaboración propia.

Los encuestados en un total de 241 personas respondieron que desearían un nuevo local, mientras que 33 encuestados que representan el $12 \%$ dijeron que no prefieren un nuevo local. Esto muestra que de manera mayoritaria la población preferiría un nuevo local de expendio de comidas rápidas.

7.¿Qué características prefiere en este nuevo local?

Tabla 7: Características del nuevo local.

\begin{tabular}{l|rr}
$\begin{array}{c}\text { Caracteristicas nuevo } \\
\text { local }\end{array}$ & Frecuencia & Porcentaje \\
\hline Atencion personalizada & 178 & $65 \%$ \\
\hline Ambiente climatizado & 157 & $57 \%$ \\
\hline Garaje & 74 & $27 \%$ \\
\hline Diversión & 97 & $35 \%$ \\
\hline Musica tradicional & 95 & $35 \%$ \\
\hline Musica internacional & 50 & $18 \%$ \\
\hline Otro tipo & 12 & $4 \%$ \\
\hline Total & $\mathbf{2 7 4}$ & \\
\hline
\end{tabular}

Fuente: Elaboración propia.
De la información que se pudo recabar de las personas encuestadas se pudo observar que el $65 \%$ de las personas encuestadas desean preferentemente una atención personalizada. Otra característica del nuevo local debería ser el que posea un ambiente climatizado con el 57\%. En tercer lugar con un 35\%, el nuevo local, debería tener como característica actividades de diversión; de igual manera, con un 35\%, los encuestados consideran que debería ofrecer música tradicional seguida de un $27 \%$ ofrecer servicio de garaje, un $18 \%$ considera que debería ofrecer música internacional; mientras que un $4 \%$ considera que debería ofrecer otro tipo de música.

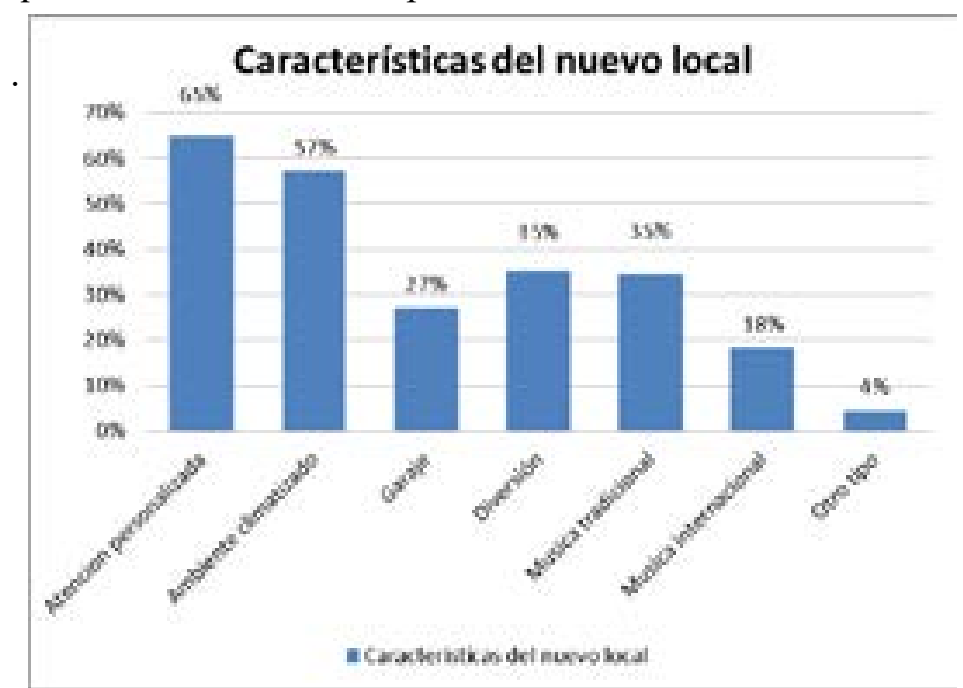

Grafico 7: Preferencias de los consumidores

Fuente: Elaboración propia. 


\section{8.¿Qué horarios de atención prefiere?}

Tabla 8: Horarios diurnos de preferencia.

\begin{tabular}{|l|r|r|}
\hline \multicolumn{1}{|c}{ Horario diurno } & Frecuencia & Porcentaje \\
\hline $07 \mathrm{HOO}-11 \mathrm{HOO}$ & 51 & $18,6 \%$ \\
\hline $07 \mathrm{HOO}-13 \mathrm{HOO}$ & 92 & $33,6 \%$ \\
\hline 07H00 - 15HOO & 93 & $33,9 \%$ \\
\hline Sin Resp & 38 & $13,9 \%$ \\
\hline Total & $\mathbf{2 7 4}$ & $\mathbf{1 0 0 \%}$ \\
\hline
\end{tabular}

Fuente: Elaboración propia.

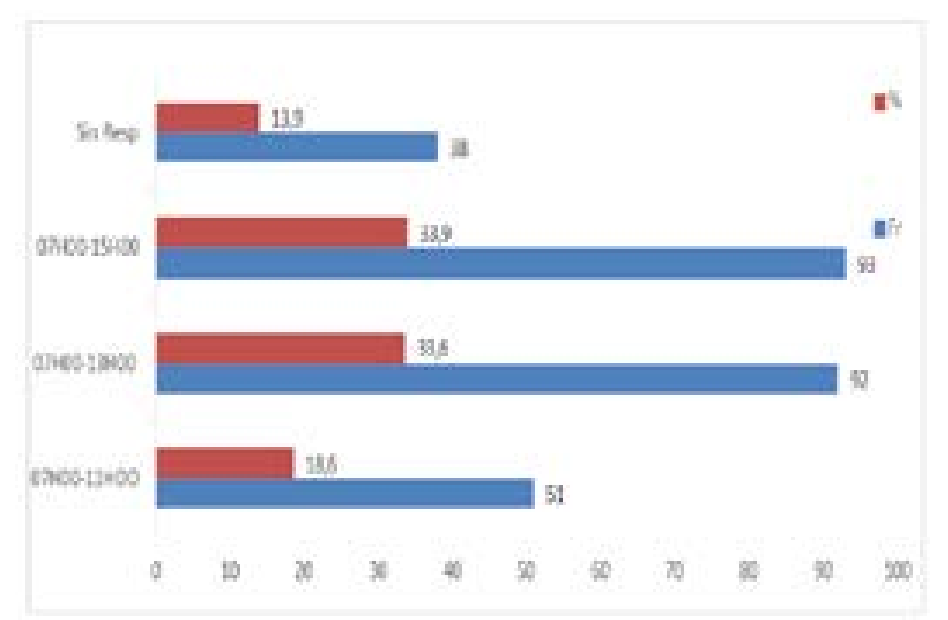

Grafico 8: Horarios diurnos de preferencia.

Fuente: Elaboración propia.

En lo referente a las preferencias de los usuarios por los horarios de atención durante el día, se pudo establecer que el 33,9\% considera que éste debería ser desde las $07 \mathrm{H} 00$ hasta las $15 \mathrm{H} 00$; un $33,6 \%$ prefiere de $07 \mathrm{H} 00-13 \mathrm{H} 00$ y un $18,6 \%$ considera de esta bien de $07 \mathrm{H} 00$ - 11H00. Cabe señalar que un $13,9 \%$ no respondieron a la pregunta.

Tabla 9: Horarios de preferencia nocturnos.

\begin{tabular}{|l|r|r|}
\hline $\begin{array}{c}\text { Horario por la tarde y } \\
\text { noche }\end{array}$ & Frecuencia & Porcentaje \\
\hline $18 \mathrm{HOO}-21 \mathrm{HOO}$ & 40 & $14,6 \%$ \\
\hline $18 \mathrm{HOO}-23 \mathrm{HOO}$ & 79 & $28,8 \%$ \\
\hline $18 \mathrm{H} 00$ - $24 \mathrm{H} 00$ & 66 & $24,1 \%$ \\
\hline $18 \mathrm{H} 00-02 \mathrm{HOO}$ & 58 & $21,2 \%$ \\
\hline Sin Resp & 31 & $11,3 \%$ \\
\hline Total & 274 & $100 \%$ \\
\hline
\end{tabular}

Fuente: Elaboración propia.

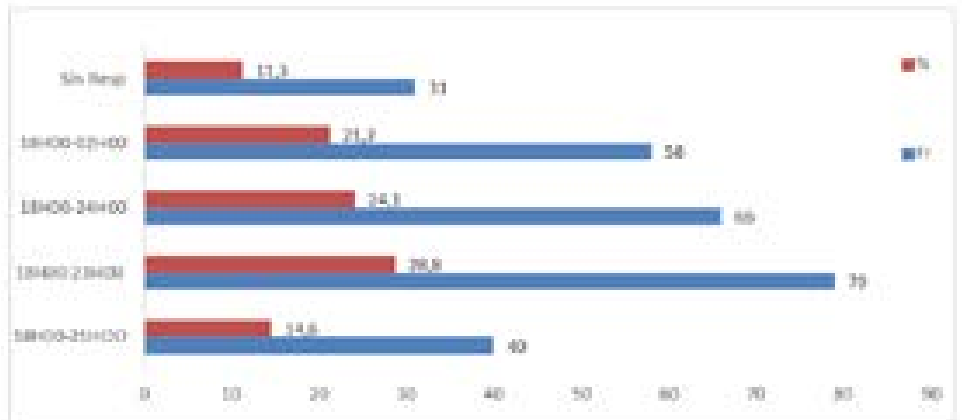

Grafico 9: Horarios de preferencia nocturnos.

Fuente: Elaboración propia.

Con respecto a los horarios de preferencia de los consumidores de comida rápida durante la noche, se pudo observar que en su mayor porcentaje $(28,8 \%)$ prefieren de $18 \mathrm{H} 00$ - $23 \mathrm{H} 00$; le sigue un $24,1 \%$ que prefiere el horario de $18 \mathrm{H} 00$ - $24 \mathrm{H} 00$; un $21,2 \%$ prefiere de $18 \mathrm{H} 00-02 \mathrm{H} 00$ y un $14,6 \%$ prefiere el horario de $18 \mathrm{H} 00-21 \mathrm{H} 00$. 
9.¿Considera necesario que este nuevo establecimiento incluya servicio de bar con música en vivo los fines de semana, días festivos / conmemorativos?

De la información recabada en las encuestas se obtuvo que la gran mayoría, el $81 \%$, considera que de haber un nuevo local este debería ofrecer el servicio de música en vivo durante los fines de semana o en días festivos o conmemorativos.

Tabla 10: Servicio de música en vivo fines de semana.

\begin{tabular}{l|rr}
\multicolumn{1}{r}{ Bar y música en vivo } & Frecuencia & Porcentaje \\
\hline Si & 221 & $81 \%$ \\
\hline No & 53 & $19 \%$ \\
\hline Total & 274 & $100 \%$ \\
\hline
\end{tabular}

Fuente: Elaboración propia.

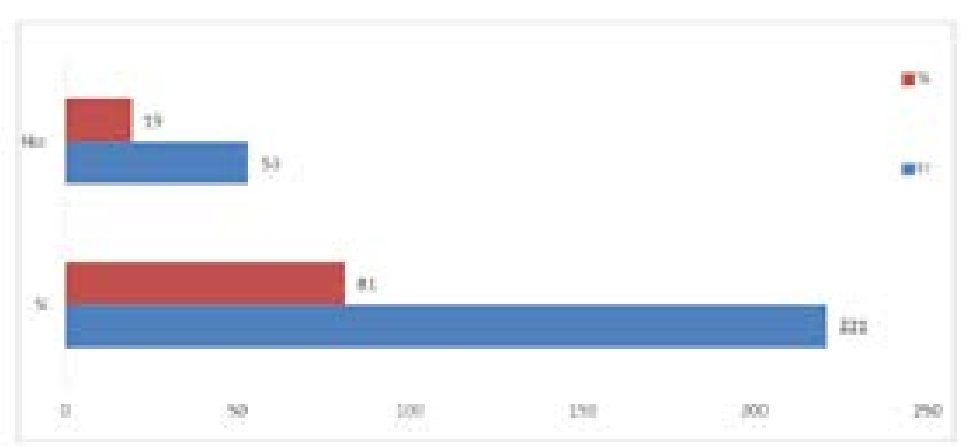

Grafico 10: Servicio de música en vivo fines de semana.

Fuente: Elaboración propia.
10. ¿Cuánto tiempo permanece en el lugar seleccionado durante su consumo?

A ésta pregunta la mayoría de las personas encuestadas (37\%) respondió que no permanecen más allá de los 30 minutos, un $20,8 \%$ respondió que no sobrepasa los 45 minutos; mientras que no sobrepasan los 15 minutos respondieron un $15,3 \%$, siendo el mismo porcentaje para aquellos que no sobrepasan la hora de permanencia en un local de comida rápida. De estos datos se puede concluir que el $90 \%$ de los usuarios no sobrepasa la hora de permanencia en este tipo de locales.

Tabla 11: Permanencia de los usuarios en el local.

\begin{tabular}{lrr}
\hline Permanencia en el lugar & Frecuencia & Porcentaje \\
\hline 15 minutos & 42 & $15,3 \%$ \\
\hline 30 minutos & 103 & $37,6 \%$ \\
\hline 45 minutos & 57 & $20,8 \%$ \\
\hline Una hora & 42 & $15,3 \%$ \\
\hline Dos horas & 17 & $6,2 \%$ \\
\hline No responde & 13 & $4,7 \%$ \\
\hline Total & $\mathbf{2 7 4}$ & $\mathbf{1 0 0} \%$
\end{tabular}

Fuente: Elaboración propia. 


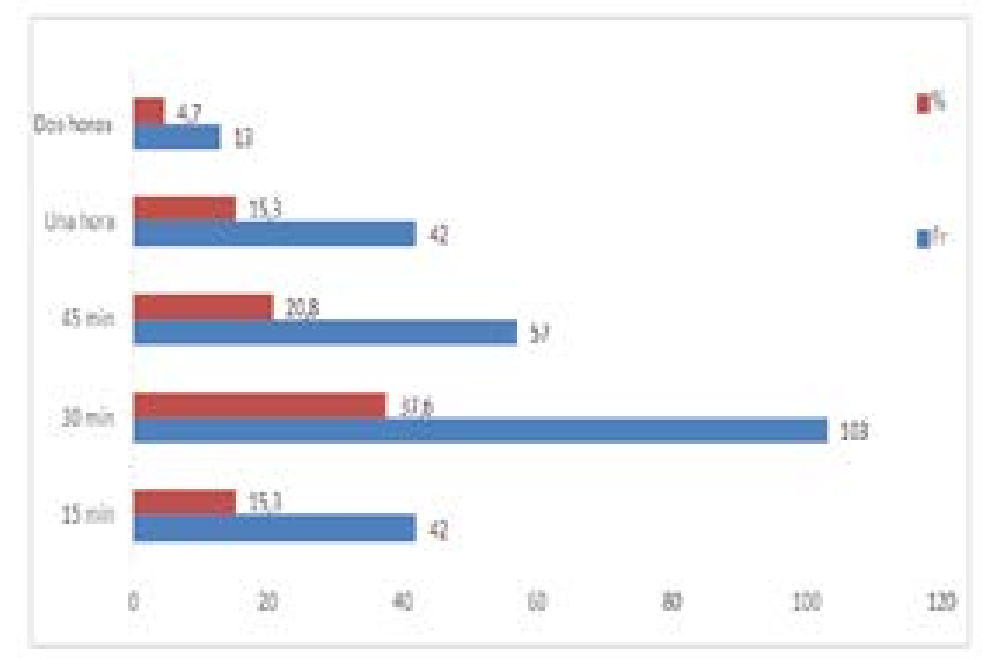

Grafico 11: Permanencia de los usuarios en el local.

Fuente: Elaboración propia

11. ¿Cuánto suele gastar en un establecimiento de comidas rápidas?

La encuesta realizada permitió determinar que un $43,4 \%$ de los usuarios consume entre 6 a 10 dólares; el 32,1\% tiene un consumo inferior a 5 dólares; mientras que un $12,4 \%$ tiene un consumo entre 11 y 15 dólares. Cabe notar que estas tres categorías de usuarios equivalen aproximadamente al $88 \%$ de los consumidores.
Tabla 12: Consumo de los usuarios en locales de comida rápida.

\begin{tabular}{|lrr}
\multicolumn{1}{c}{ Cuánto consume } & Frecuencia & Porcentaje \\
\hline De 1 - 5 dólares & 88 & $32,1 \%$ \\
\hline De 6 - 10 dólares & 119 & $\mathbf{4 3 , 4 \%}$ \\
\hline De 11 - 15 dólares & 34 & $12,4 \%$ \\
\hline De 16 - 20 dólares & 12 & $4,4 \%$ \\
\hline Mas de 20 dólares & 10 & $3,6 \%$ \\
\hline No responde & 11 & $4,0 \%$ \\
\hline Total & $\mathbf{2 7 4}$ & $\mathbf{1 0 0 \%}$
\end{tabular}

Fuente: Elaboración propia.

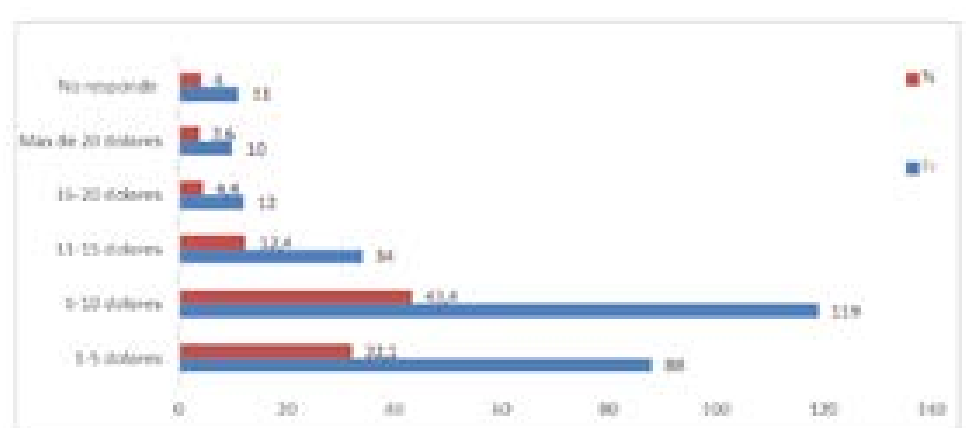

Gratico 12: Consumo de los usuarios en locales de comida rápida.

Fuente: Elaboración propia.

12.- ¿Cuáles son sus productos preferidos?

Con base en las repuestas expuestas por las personas encuestadas se pudo obtener lo siguiente:

Los productos de mayor aceptación por parte de los consumidores son: las hamburguesas $(53,3 \%)$; las fritadas $(50 \%)$; los sándwich 
(48,9\%); tostadas $(47,4 \%)$; las pizzas $(44,5 \%)$; las papas fritas $(42 \%)$ y las alitas el $(41,2 \%)$.

Entre los productos de mediana aceptación se tiene: Torta de choclo (38,3\%); la lasaña $(35,4 \%)$; y las empanadas (35\%).

Los de baja aceptación: bollos (28,8\%); humitas (27,4\%); tablitas (26,6\%); Bolones de jamón y queso (23\%); horneado $(20,4 \%)$ y patacones $(20,8 \%)$.

Tabla 13: Productos preferidos por los usuarios.

\begin{tabular}{|l|r|r|}
\hline \multicolumn{1}{|c|}{ Comida rápida } & Frecuencia & Porcentaje \\
\hline Hamburguesas & 146 & $53,3 \%$ \\
\hline Papas & 115 & $42,0 \%$ \\
\hline Sanduches & 134 & $48,9 \%$ \\
\hline Tostadas & 130 & $47,4 \%$ \\
\hline Pizza & 122 & $44,5 \%$ \\
\hline Alitas & 113 & $41,2 \%$ \\
\hline Lasaña & 97 & $35,4 \%$ \\
\hline Fritadas & 137 & $50,0 \%$ \\
\hline Tablitas & 73 & $26,6 \%$ \\
\hline Humitas & 75 & $27,4 \%$ \\
\hline Torta de choclo & 105 & $38,3 \%$ \\
\hline Bollos & 79 & $28,8 \%$ \\
\hline Hornados & 56 & $20,4 \%$ \\
\hline Patacones & 57 & $20,8 \%$ \\
\hline Empanadas & 96 & $35,0 \%$ \\
\hline B de jamón y queso & 63 & $23,0 \%$ \\
\hline
\end{tabular}

Fuente: Elaboración propia.

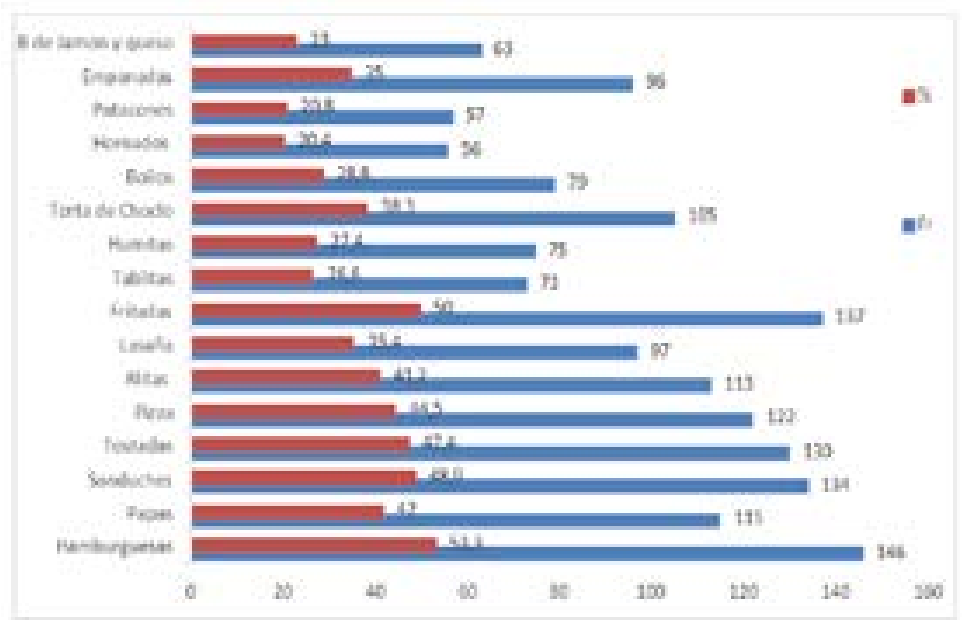

Grafico 13: Productos preferidos por los usuarios. Fuente: Elaboración propia.

13.-Seleccione los productos de su preferencia en el grupo de bebidas calientes y frías.

Del estudio realizado se obtuvo que las bebidas de mayor preferencia por parte de los consumidores, en orden de preferencia son: Jugos naturales $(75,9 \%)$; Batidos $(68,2 \%)$; Chocolate (59,5\%); Capuccino (57,7\%); Café (54,7\%);Té aromático (53,3\%); Té helado (41,2\%) y Mocaccino (32,5\%). 
Tabla 14: Bebidas de preferencia por los consumidores.

\begin{tabular}{|l|r|r|}
\hline Bebidas calientes y frias & Frecuencia & Porcentaje \\
\hline Té aromatico & 146 & $53,3 \%$ \\
\hline Capuccino & 158 & $57,7 \%$ \\
\hline Café & 150 & $54,7 \%$ \\
\hline Té helado & 113 & $41,2 \%$ \\
\hline Chocolate & 163 & $59,5 \%$ \\
\hline Mocaccino & 89 & $32,5 \%$ \\
\hline Batidos & 187 & $68,2 \%$ \\
\hline Jugos naturales & 208 & $75,9 \%$ \\
\hline
\end{tabular}

Fuente: Elaboración propia.

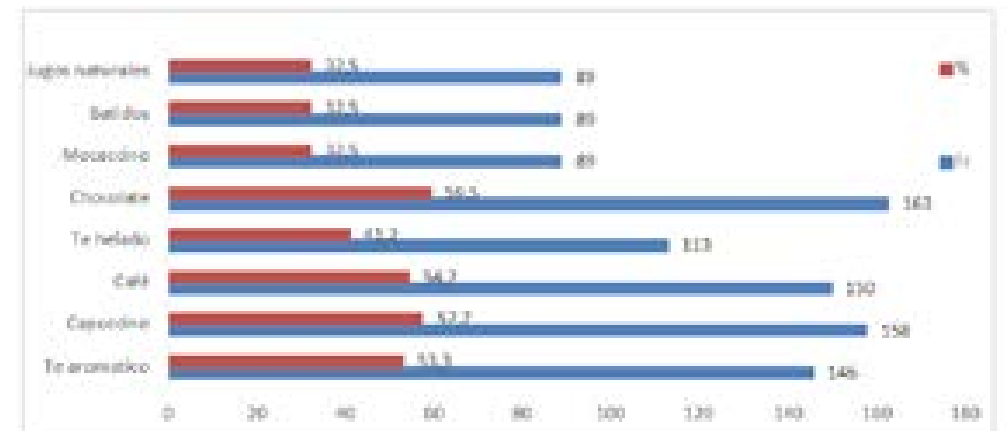

Grafico 14: Bebidas de preferencia por los consumidores.

Fuente: Elaboración propia.

14.-Seleccione los productos de su preferencia en el grupo de postres.
Tabla 15: Postres de preferencia por parte de los usuarios.

\begin{tabular}{|l|r|r|}
\hline \multicolumn{1}{|c|}{ Postres } & Frecuencia & Porcentaje \\
\hline Tres leches & 213 & $77,7 \%$ \\
\hline Tiramisu & 90 & $32,8 \%$ \\
\hline Queso de piña & 153 & $55,8 \%$ \\
\hline Chesscake & 86 & $31,4 \%$ \\
\hline Torta mojada de chocolate & 176 & $64,2 \%$ \\
\hline Frutas picadas & 207 & $75,5 \%$ \\
\hline Helados & 172 & $62,8 \%$ \\
\hline
\end{tabular}

Fuente: Elaboración propia.

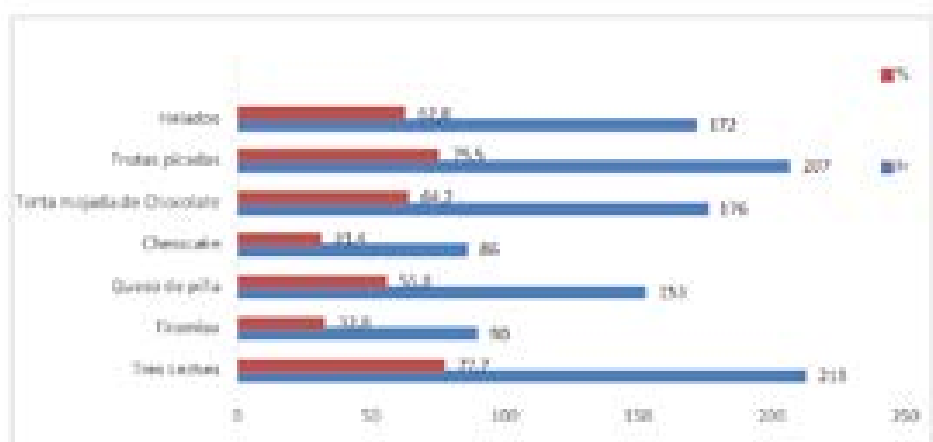

Grafico 15: Postres de preferencia por parte de los usuarios. Fuente: Elaboración propia.

A la pregunta referente a los postres de preferencia por parte de los consumidores se pudo recabar que en orden de preferencia los más apetecidos son: Tres leches (77,7\%); frutas picadas (75,5\%); torta mojada de chocolate $(64,2 \%)$; helados $(62,8 \%)$; queso de piña $(55,8 \%)$; tiramisú $(32,8 \%)$ y chesscake $(31,4 \%)$. 
15.-Seleccione tres productos del siguiente grupo de bebidas alcohólicas según su preferencia.

Con respecto a las bebidas alcohólicas de preferencia se pudo obtener que las bebidas más apetecidas por parte de los usuarios en orden descendente de preferencia son: piña colada $(62,4 \%)$; micheladas $(51,8 \%)$; margaritas $(48,5 \%)$; cuba libre $(46 \%)$ y tequila shot $(32,1 \%)$, esto se muestra en la tabla a continuación.

Tabla 16: Bebidas alcohólicas de preferencia por los consumidores.

\begin{tabular}{|l|r|r|}
\hline \multicolumn{1}{|c|}{ Bebidas alcohólicas } & Frecuencia & Porcentaje \\
\hline Margaritas & 133 & $48,5 \%$ \\
\hline Piña colada & 171 & $62,4 \%$ \\
\hline Cuba libre & 126 & $46,0 \%$ \\
\hline Tequila (shot) & 88 & $32,1 \%$ \\
\hline Micheladas & 142 & $51,8 \%$ \\
\hline Otros & 28 & $10,2 \%$ \\
\hline
\end{tabular}

Fuente: Elaboración propia.

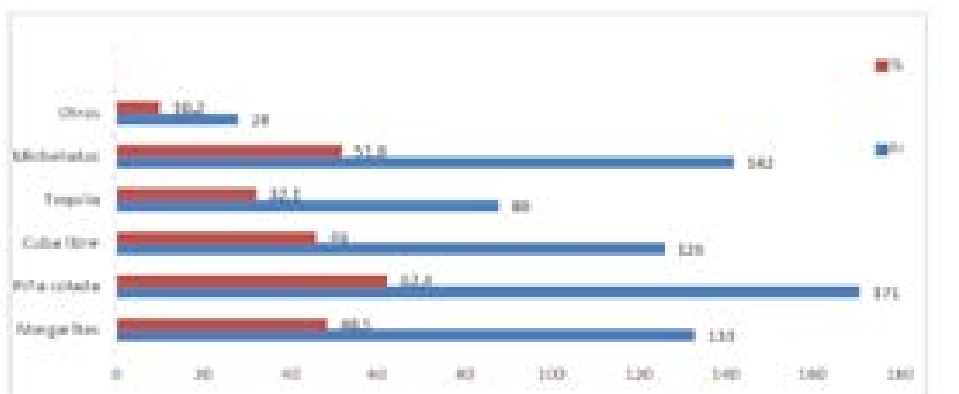

Gratico 16: Bebıdas alcohólıcas de preterencia por los consumidores.

Fuente: Elaboración propia.
16.- ¿Qué precio estaría dispuesto a pagar por las bebidas con grados de alcohol ofertadas?

Al analizar los datos proporcionados por los encuestados, se reveló que la gran mayoría $(50,7 \%)$ no está dispuesta a pagar más allá \$2,50; un 36,5\% estaría dispuesto a pagar un máximo de $\$ 3,50$. De esta información se concluye que el $87 \%$ no está dispuesto a pagar más de $\$ 3,50$.

Tabla 17: Disposición a pagar por bebidas alcohólicas.

\begin{tabular}{lrr}
\multicolumn{1}{c}{ Precio por bebidas } & Frecuencia & Porcentaje \\
\hline Hasta $\$ 2,50$ & 139 & $50,7 \%$ \\
\hline Hasta $\$ 3,50$ & 100 & $36,5 \%$ \\
\hline Otros & 14 & $5,1 \%$ \\
\hline No responde & 21 & $7,7 \%$ \\
\hline Total & 274 & $100,0 \%$
\end{tabular}

Fuente: Elaboración propia.

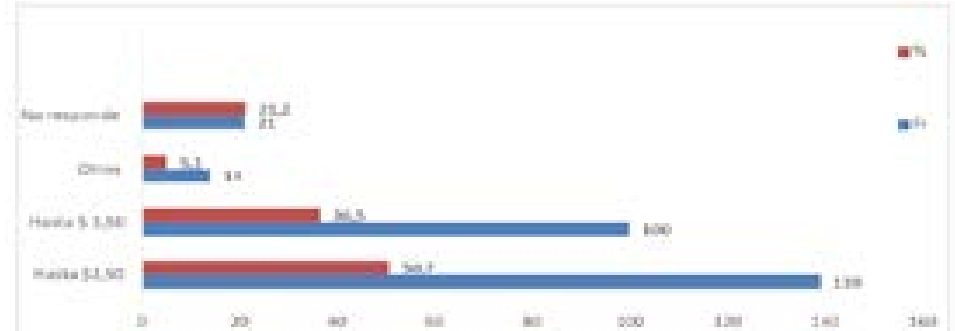

Grafico 17: Disposición a pagar por bebidas alcohólicas. Fuente: Elaboración propia. 


\section{7.-Demanda potencial del servicio}

En este apartado se estimó las características del consumidor y el volumen de consumo, posterior a los datos obtenidos en la encuesta a los consumidores, la cual determino que al menos una vez por semana los encuestados, realizan en promedio un consumo de $\$ 5$ en comida rápida por semana, lo que resulta en un consumo de \$20 dólares mensuales en este servicio. De esta manera se pudo inferir que en promedio anualmente las personas consumen en promedio $\$ 240$.

\section{8.-Proyección de la población potencial}

Para realizar la proyección se consideró la tasa de crecimiento poblacional y se utilizó la siguiente fórmula: $P_{f}=P_{0}(1+k)$

$P_{f}=P_{0}(1+k)$; Donde:

$\mathrm{Pf}=$ Población final

Po $=$ Población inicial

$\mathrm{K}=$ Tasa de crecimiento poblacional

$\mathrm{N}=$ periodos
Tabla 18: Población potencial del proyecto.

\begin{tabular}{|r|c|r|}
\hline \multicolumn{2}{|c|}{ Añctor } & $\begin{array}{r}\text { Población } \\
\text { potencial }\end{array}$ \\
\hline 2015 & $P_{f}=24007(1+0,016)^{1}$ & 24391 \\
\hline 2016 & $P_{f}=24007(1+0,016)^{2}$ & 24781 \\
\hline 2017 & $P_{f}=24007(1+0,016)^{3}$ & 25178 \\
\hline 2018 & $P_{f}=24007(1+0,016)^{4}$ & 25581 \\
\hline 2019 & $P_{f}=24007(1+0,016)^{5}$ & 25990 \\
\hline 2020 & $P_{f}=24007(1+0,016)^{6}$ & 26406 \\
\hline 2021 & $P_{f}=24007(1+0,016)^{7}$ & \\
\hline 2022 & $P_{f}=24007(1+0,016)^{8}$ & 26828 \\
\hline 2023 & $P_{f}=24007(1+0,016)^{9}$ & 27694 \\
\hline 2024 & $P_{f}=24007(1+0,016)^{10}$ & 28137 \\
\hline & & \\
\hline 208
\end{tabular}

Fuente: Elaboración propia.

Considerando la población potencial se procedió a proyectar la demanda potencial del proyecto teniendo en cuenta que al menos una vez por semana los encuestados hacen uso del servicio de comidas rápidas y un consumo mínimo de $\$ 5$ semanal por persona. Con base a los resultados, se puede inferir que este estudio tiene un horizonte de 10 años de vida útil del proyecto analizado en relación a la población consumidora de 
comidas rápidas.

Tabla 19: Proyección de la demanda potencial del proyecto.

\begin{tabular}{|r|r|r|r|}
\hline \multicolumn{1}{|c|}{ Año } & $\begin{array}{c}\text { Poblacion } \\
\text { potencial } \\
\text { anual }\end{array}$ & $\begin{array}{c}\text { Demanda } \\
\text { potencial anual }\end{array}$ & $\begin{array}{c}\text { Consumo } \\
\text { total anual } \\
\text { (en dólares) }\end{array}$ \\
\hline 2015 & 24391 & 1170773 & $\$ 5.853 .867$ \\
\hline 2016 & 24781 & 1189506 & $\$ 5.947 .529$ \\
\hline 2017 & 25178 & 1208538 & $\$ 6.042 .689$ \\
\hline 2018 & 25581 & 1227874 & $\$ 6.139 .372$ \\
\hline 2019 & 25990 & 1247520 & $\$ 6.237 .602$ \\
\hline 2020 & 26406 & 1267481 & $\$ 6.337 .404$ \\
\hline 2021 & 26828 & 1287760 & $\$ 6.438 .802$ \\
\hline 2022 & 27258 & 1308365 & $\$ 6.541 .823$ \\
\hline 2023 & 27694 & 1329298 & $\$ 6.646 .492$ \\
\hline 2024 & 28137 & 1350567 & $\$ 6.752 .836$ \\
\hline
\end{tabular}

Fuente: Elaboración propia.

\section{9.-Análisis de la oferta}

La oferta es la cantidad de bienes o servicios que un cierto número de productores o prestadores de servicios, están decididos a poner a la disposición del mercado a un precio determinado.

El propósito que se busca, mediante el análisis de la oferta, es definir y medir las cantidades y condiciones en que se pone a disposición del mercado un bien o un servicio. La oferta, al igual que la demanda, está en función de una serie de factores, cómo es el precio en el mercado del producto o servicio, el precio de las materias primas; entre otros. La investigación de campo que se utilizó tomó en cuenta todos estos factores junto con el entorno económico en que se desarrolla el proyecto.

Para ello se consideró el número de oferentes del servicio, el volumen de ventas y las limitaciones referentes a los horarios de funcionamiento de los competidores directos del presente proyecto.

\subsection{1.-Oferta local actual}

Se pudo determinar de acuerdo a los datos obtenidos en la encuesta que existen ocho locales que se consideran competencia directa al presente proyecto. 
Tabla 20: Establecimientos que ofrecen servicios de comidas

ESTABLECIMIENTOS QUE OFRECEN SERVICIO DE COMIDAS

\begin{tabular}{|l|l|l|}
\hline \multicolumn{1}{|c|}{ NOMBRES } & \multicolumn{1}{c|}{ TIPO DE SERVICIO } & \multicolumn{1}{c|}{ DIRECCIÓN } \\
\hline BOLON PATACON & VENTA DE DESAYUNOS & SALINAS Y BOLIVAR \\
\hline CAFÉ COLIBRI & SERVICIO DE CAFETERIA & 7 DE AGOSTO Y SALINAS \\
\hline BAR CEBOLLITA & CAFETERIA & CALLE BOLIVAR \\
\hline BAR MICHITA & CAFETERIA & CALLE MERCEDES Y BOLIVAR \\
\hline EE FERIADO & SODA AAR & PIIHINCHA Y ROCAFUERTE \\
\hline XOCO & SODA BAR & SUCRE ESQUINA \\
\hline BAR CAFETERIA "MARÍA BELEN" & CAFETERIA & AV. AMAZONAS \\
\hline Fuente: Elaboracion la Autora & \multicolumn{2}{|l}{} \\
\hline
\end{tabular}

Fuente: Elaboración propia.

\subsection{2.-Proyección de la oferta estimada.}

Al no existir barreras para el ingreso de nuevos locales para ofrecer el mismo servicio, se ha considerado la tasa de crecimiento de locales comerciales a nivel nacional, la cual según datos del Censo Económico fue del 17,86\% (INEC, 2010).

Para realizar la proyección se consideró la tasa de crecimiento anteriormente señalada y se utilizó la siguiente fórmula: $P_{f}=P_{0}(1+k)$

$P_{f}=P_{0}(1+k)^{N} ;$ Donde:

Pf = Población final

Po $=$ Población inicial

$\mathrm{K}=$ Tasa de crecimiento de establecimientos comerciales

$\mathrm{N}=$ periodos
Tabla 21: Oferta potencial del proyecto (establecimientos).

\begin{tabular}{|c|c|c|}
\hline Año & Factor & $\begin{array}{l}\text { Población } \\
\text { potencial }\end{array}$ \\
\hline 2015 & $P_{f}=8(1+0,1786)^{1}$ & 9 \\
\hline 2016 & $P_{f}=8(1+0,1786)^{2}$ & 11 \\
\hline 2017 & $P_{f}=8(1+0,1786)^{3}$ & 13 \\
\hline 2018 & $P_{f}=8(1+0,1786)^{4}$ & 15 \\
\hline 2019 & $P_{f}=8(1+0,1786)^{5}$ & 18 \\
\hline 2020 & $P_{f}=8(1+0,1786)^{6}$ & 21 \\
\hline 2021 & $P_{f}=8(1+0,1786)^{7}$ & 25 \\
\hline 2022 & $P_{f}=8(1+0,1786)^{8}$ & 30 \\
\hline 2023 & $P_{f}=8(1+0,1786)^{9}$ & 35 \\
\hline 2024 & $P_{f}=8(1+0,1786)^{10}$ & 41 \\
\hline
\end{tabular}

Fuente: Elaboración propia.

De la información recabada en los locales, que actualmente ofrecen comidas rápidas en la ciudad de Chone, se obtuvo el promedio de personas que visitan cada uno de los establecimientos que se consideran competencia directa del presente proyecto, los resultados se muestran en la tabla que se muestra a continuación: 
Tabla 22: Cuantificación de la oferta anual actual.

\begin{tabular}{|l|r|r|}
\hline \multicolumn{1}{|c|}{ ESTABLECIMIENTO } & \multicolumn{1}{c|}{$\begin{array}{c}\text { Clientes } \\
\text { diarios }\end{array}$} & $\begin{array}{c}\text { Oferta } \\
\text { anual actual }\end{array}$ \\
\hline BOLON PATACON & 80 & 29200 \\
\hline CAFÉ COLIBRI & 40 & 14600 \\
\hline BAR CEBOLLITA & 30 & 10950 \\
\hline BAR MICHITA & 50 & 18250 \\
\hline EL FERIADO & 120 & 43800 \\
\hline XOCO HELADERIA & 100 & 36500 \\
\hline BAR TRIVIÑO & 300 & 109500 \\
\hline BAR CAFETERIA "MARÍA BELI & 60 & 21900 \\
\hline TOTALES & $\mathbf{7 8 0}$ & $\mathbf{2 8 4 7 0 0}$ \\
\hline
\end{tabular}

Fuente: Elaboración propia.

Para la elaboración de la tabla anterior se consideró la información recabada en la encuesta a los locales que son competencia directa al proyecto. En dicha encuesta se obtuvo el número de clientes que acuden a cada uno de los locales encuestados (en promedio), así como también los días y horarios de atención de cada uno de ellos.

En esta tabla se puede observar en la segunda columna el promedio diario de visitantes que consumen diariamente en referidos locales. En la segunda columna se determinó las oferta anual que realiza cada uno de dichos locales suponiendo que trabajan los 365 días del año y mantiene diariamente el mismo número de clientes (clientes diarios * 365).

\subsection{3.-Proyección de la oferta del proyecto}

De igual manera que para el caso de la demanda, la presente investigación consideró un crecimiento anual de la oferta de los locales, considerados como competidores directos del proyecto actual, suponiendo que este incremento será igual a la tasa de crecimiento poblacional del cantón Chone (1,6\%). Por lo tanto la estimación para la oferta estimada durante el periodo analizado quedaría:

Tabla 23: Proyección de la oferta del proyecto

\begin{tabular}{|c|c|c|}
\hline \multicolumn{2}{|c}{ Factor } & $\begin{array}{c}\text { Oferta } \\
\text { estimada } \\
\text { anual }\end{array}$ \\
\hline 2015 & $P_{f}=284.700(1+0,016)^{1}$ & 289.255 \\
\hline 2016 & $P_{f}=284.700(1+0,016)^{2}$ & 293.883 \\
\hline 2017 & $P_{f}=284.700(1+0,016)^{3}$ & 298.585 \\
\hline 2018 & $P_{f}=284.700(1+0,016)^{4}$ & 303.363 \\
\hline 2019 & $P_{f}=284.700(1+0,016)^{5}$ & 308.217 \\
\hline 2020 & $P_{f}=284.700(1+0,016)^{6}$ & 313.148 \\
\hline 2021 & $P_{f}=284.700(1+0,016)^{7}$ & 318.158 \\
\hline 2022 & $P_{f}=284.700(1+0,016)^{8}$ & 323.249 \\
\hline 2023 & $P_{f}=284.700(1+0,016)^{9}$ & 328.421 \\
\hline 2024 & $P_{f}=284.700(1+0,016)^{10}$ & 333.676 \\
\hline
\end{tabular}

Fuente: Elaboración propia.

Para la elaboración de la proyección de la oferta se procedió a utilizar la formula $P_{f}=P_{0}(1+k)^{N}$ donde:

$\mathrm{Pf}=$ Oferta proyectada en el periodo 
Po $=$ Oferta inicial (oferta actual anual $=284.700)$

$\mathrm{K}=$ Tasa de crecimiento de la población en el cantón Chone $(1,6 \%)$

$\mathrm{N}=$ Periodo observado

\subsection{0.-Demanda insatisfecha}

Para la cuantificación de aquella demanda que no ha sido cubierta por el mercado se procedió a determinar la diferencia entre demanda potencial anual y la oferta estimada anual, obteniéndose los siguientes resultados:

Tabla 24: Demanda insatisfecha del proyecto.

\begin{tabular}{|r|r|r|r|r|}
\hline \multicolumn{1}{|c|}{ Año } & \multicolumn{1}{c|}{$\begin{array}{c}\text { Demanda } \\
\text { potencial } \\
\text { anual }\end{array}$} & \multicolumn{1}{c|}{$\begin{array}{c}\text { Oferta } \\
\text { estimada } \\
\text { anual }\end{array}$} & $\begin{array}{c}\text { Demanda } \\
\text { insatisfecha } \\
\text { anual }\end{array}$ & $\begin{array}{c}\text { Demanda del } \\
\text { proyecto (10\%) }\end{array}$ \\
\hline 2015 & 1.170 .773 & 289.255 & 881.518 & 88.152 \\
\hline 2016 & 1.189 .506 & 293.883 & 895.622 & 89.562 \\
\hline 2017 & 1.208 .538 & 298.585 & 909.952 & 90.995 \\
\hline 2018 & 1.227 .874 & 303.363 & 924.512 & 92.451 \\
\hline 2019 & 1.247 .520 & 308.217 & 939.304 & 93.930 \\
\hline 2020 & 1.267 .481 & 313.148 & 954.333 & 95.433 \\
\hline 2021 & 1.287 .760 & 318.158 & 969.602 & 96.960 \\
\hline 2022 & 1.308 .365 & 323.249 & 985.116 & 98.512 \\
\hline 2023 & 1.329 .298 & 328.421 & 1.000 .878 & 100.088 \\
\hline 2024 & 1.350 .567 & 333.676 & 1.016 .892 & 101.689 \\
\hline
\end{tabular}

Fuente: Elaboración propia.
Como se puede observar en la tabla anterior, existe una gran demanda insatisfecha para el presente proyecto, sin embargo se pretende atender únicamente un $10 \%$ de la demanda insatisfecha existente, exponiendo un escenario pesimista para el mismo.

\subsection{1.-Análisis de la comercialización de precios actual}

\subsection{1.-Precios del servicio actual}

De la información obtenida, por los oferentes de comida rápida en la ciudad de Chone, se pudo determinar los siguientes precios de los diferentes productos que se ofrecen en el mercado:

Tabla 25. Precios del servicio actual del oferente; bolón patacón

\begin{tabular}{|c|c|c|}
\hline NOMBRES & \multicolumn{2}{|c|}{ PRECIO \$ } \\
\hline \multicolumn{3}{|c|}{ BOLON PATACON } \\
\hline BOLONES & $\$ 1,75$ & $\$ 2,75$ \\
\hline TIGUIILLOS & $\$ 2,50$ & $\$ 3,50$ \\
\hline PATACONES RELLENOS & $\$ 2,00$ & $\$ 3,00$ \\
\hline TORTILLA DE HUEVO & $\$ 1,50$ & $\$ 3,00$ \\
\hline TORTITAS DE PLATANO & \multicolumn{2}{|c|}{$\$ 1.50$} \\
\hline CAFÉ & \multicolumn{2}{|c|}{$\$ 0.50$} \\
\hline CHOCOLATE & \multicolumn{2}{|c|}{$\$ 0.75$} \\
\hline JUGOS NATURALES & \multicolumn{2}{|c|}{$\$ 1.00$} \\
\hline COLAS & \multicolumn{2}{|c|}{$\$ 0.50$} \\
\hline
\end{tabular}

Tabla 26. Precios del Servicio Actual del oferente; Bar Cafetería "María Belén“ 


\begin{tabular}{|lc|}
\hline \multicolumn{1}{|c|}{ NOMBRES } & \multicolumn{1}{c|}{ PRECIO $\$$} \\
\hline \multicolumn{1}{|c|}{ BAR CAFETERIA “MARIA BELEN" } \\
\hline PAN DE ALMIDON & $\$ 0.20$ \\
\hline TORTILLA DE MAIZ & $\$ 0.20$ \\
\hline TORTILLA DE YUCA & $\$ 0.20$ \\
\hline BOLONES & $\$ 0.50$ \\
\hline CORVICHE & $\$ 0.20$ \\
\hline DEDITOS DE HARINA & $\$ 0.10$ \\
\hline CAFÉ & $\$ 0.35$ \\
\hline YOGURT - GRANIZADO & $\$ 0.50$ \\
\hline JUGOS NATURALES & $\$ 0.75$ \\
\hline COLAS & $\$ 1.00$ \\
\hline
\end{tabular}

\begin{tabular}{|ll|}
\hline TORTILLA DE YUCA & $\$ 0.40$ \\
\hline BOLONES & $\$ 1.00$ \\
\hline CAFÉ & $\$ 0.40$ \\
\hline CHOCOLATE & $\$ 0.60$ \\
\hline JUGOS NATURALES & $\$ 0.50$ \\
\hline COLAS & $\$ 0.50$ \\
\hline Fuente: Elaboración propia. &
\end{tabular}

Tabla 27. Precios del Servicio Actual del oferente; Bar Cebollita“

\begin{tabular}{|c|c|}
\hline NOMBRES & PRECIO \$ \\
\hline \multicolumn{2}{|c|}{ BAR CEBOLLITA } \\
\hline PAN DE ALMIDONES & $\$ 0.30$ \\
\hline FRITADAS & $\$ 1.75$ \\
\hline TOSTADAS & $\$ 0,50-\$ 0,75$ \\
\hline BATIDOS & $\$ 1,50-\$ 3,50$ \\
\hline GRANIZADOS & $\$ 0.50$ \\
\hline JUGOS NATURALES & $\$ 0.50$ \\
\hline ENSALADAS DE FRUTAS & $\$ 1.00$ \\
\hline COLAS & $\$ 0.50$ \\
\hline DULCES DE HARINA & $\$ 0.50$ \\
\hline PAN DE ALMIDON & $\$ 0.40$ \\
\hline TORTITTA DE MAIZ & $\$ 0.40$ \\
\hline
\end{tabular}

\begin{tabular}{|lc|}
\hline \multicolumn{1}{|c|}{ NOMBRES } & PRECIO $\$$ \\
\hline \multicolumn{1}{|c|}{ VENDEDORES INFORMALES DE COMIDAS } \\
\hline HAMBURGUESAS & $\$ 1.00-\$ 3.00$ \\
\cline { 2 - 2 } CHUZOZ & $\$ 1.25$ \\
PAPI POLLOS & $\$ 1.00-\$ 1.50$ \\
SALCHIPAPAS & $\$ 1.00-\$ 1.50$ \\
HOD DOG & $\$ 1.00$ \\
EMPANADAS & $\$ 0.50$ \\
ARROZ COLORADO & $\$ 0.50-\$ 1.50$ \\
FRITADAS & $\$ 1.00-\$ 2.00$ \\
PIZZA & $\$ 1.25$ \\
JUGOS NATURALES & $\$ 0.50$ \\
COLAS PERSONALES & $\$ 0.50$ \\
\hline Fuente: Elaboración propia. &
\end{tabular}


Tabla 27. Precios del Servicio Actual de los vendedores informales de comidas

\begin{tabular}{|lc|}
\hline \multicolumn{1}{|c|}{ NOMBRES } & PRECIO $\$$ \\
\hline ARROZ, MENESTRA Y POLLO & $\$ 4.50$ \\
\hline ARROZ MENESTRA Y CARNE & $\$ 4.50$ \\
\hline ARROZ MENESTRA Y CARNE DE RES & $\$ 4.50$ \\
\hline ARROZ MENESTRA Y COSTILLA & $\$ 4.50$ \\
\hline ARROZ MENESTRA Y UBRE & $\$ 4.50$ \\
\hline ARROZ MENESTRA Y PESCADO ASADO & $\$ 4.50$ \\
\hline PARRILLADA FAMILIAR PEQUEÑA & $\$ 17.50$ \\
\hline PARRILADA FAMILIAR & $\$ 30.00$ \\
\hline CHUZOZ & $\$ 1.50$ \\
\hline Pollo asado & $\$ 2.50-\$ 12.00$ \\
\hline JUGOS NATURALES & $\$ 0.75$ \\
\hline JARRAS DE JUGOS NATURALES & $\$ 3.00$ \\
\hline COLAS PERSONALES & $\$ 0.50$ \\
\hline TE HELADO & $\$ 1.00$ \\
\hline
\end{tabular}

Tabla 28. Precios del Servicio Actual en establecimientos de asados

\begin{tabular}{|c|c|}
\hline NOMBRES & PRECIO \$ \\
\hline \multicolumn{2}{|c|}{ XOCO HELADERIA } \\
\hline FRITADAS & $\$ 1.75$ \\
\hline TOSTADAS & $\$ 1.00$ \\
\hline HELADOS & $\$ 0,30-\$ 3,50$ \\
\hline BATIDOS & $\$ 1,50-\$ 2,00$ \\
\hline JUGOS NATURALES & $\$ 1.00$ \\
\hline COLAS & $\$ 0,35-\$ 0,50$ \\
\hline
\end{tabular}

Tabla 29. Precios del servicio actual en el establecimiento Coco Heladería

Tabla 30. Precios del Servicio Actual en el establecimiento Café Colibrí

\begin{tabular}{|lr|}
\hline \multicolumn{2}{|c|}{ NOMBRES } \\
\hline \multicolumn{2}{|c|}{ CAFECIO $\$$} \\
\hline Sanduche de pavo & $\$ 4.00$ \\
\hline Sanduche de pavo Ligth & $\$ 4.00$ \\
\hline Sanduche de pollo & $\$ 2.50$ \\
\hline Sanduche de pernil & $\$ 3.50$ \\
\hline Sanduche especial de embutidos & $\$ 3.50$ \\
\hline Sanduche sugerido & $\$ 3.50$ \\
\hline Pastelon colibri & $\$ 3.50$ \\
\hline Torta de choclo & $\$ 2.00$ \\
\hline Conchas mexicanas & $\$ 5.00$ \\
\hline Dulce de las tres leches & $\$ 1.50$ \\
\hline Suspiron de mora & $\$ 1.50$ \\
\hline
\end{tabular}




\begin{tabular}{|l|r|}
\hline Suspiron de ciruela & $\$ 1.50$ \\
\hline Brownie con helado & $\$ 2.50$ \\
\hline Mojada de chocolate & $\$ 2.00$ \\
\hline Flan de coco & $\$ 1.50$ \\
\hline Torta de caramelo con nueces & $\$ 2.00$ \\
\hline Café americano (pasado) & $\$ 1.00$ \\
\hline café tostado & $\$ 1.00$ \\
\hline Café con leche & $\$ 1.00$ \\
\hline Café con amaretto & $\$ 1.00$ \\
\hline Capuccino & $\$ 1.50$ \\
\hline Mocaccino & $\$ 1.50$ \\
\hline Chocolate caliente & $\$ 1.50$ \\
\hline Jugos naturales & $\$ 1.50$ \\
\hline Té helado & $\$ 1.00$ \\
\hline Agua con gas & $\$ 1.50$ \\
\hline Copa de vino & $\$ 3.00$ \\
\hline Colas & $\$ 1.00$ \\
\hline Agua & $\$ 1.00$ \\
\hline Poni malta & $\$ 1.00$ \\
\hline
\end{tabular}

dos opciones: A través de proveedores locales o proveedores de ciudades aledañas (Manta y Portoviejo).

Al realzar el análisis respectivo, de las variables anteriormente expuestas se pudo determinar que por cantidad de proveedores, costos de materias primas y calidad de los insumos necesarios el abastecimiento de insumos para el presente proyecto se realizará a través de proveedores locales, los cuales existen en gran cantidad y por lo tanto no existe mayor dificultad para la obtención de las materias primas necesarias para brindar los productos que se ofrecerá desde este trabajo. La existencia de mercado de abastos, supermercado, así como distribuidores mayoristas de diferentes productos garantiza la entrega oportuna de los mismos para su utilización.

Para la elección de los proveedores locales se consideraron algunas variables, entre ellas:

- Precio de las materias primas.

- Calidad de los insumos.

- Costos de transporte.

- Experiencia y reputación en el mercado.

- Situación económica.

- Descuentos por volúmenes de compras.

- Cumplimiento de normas de calidad requeridas.

- Condiciones de pago al proveedor.

- Ubicación del proveedor. (Emprende PYME, 2015).

- Cantidad de proveedores.

- Costos de las materias primas.

- Calidad de los insumos.

En lo que respecta a la cantidad de proveedores se supusieron

\subsection{3.-Criterio de selección de proveedores}

Teniendo en consideración las variables anteriormente citadas 
y debido a las características y servicios que contempla el proyecto, se procedió a realizar un listado de proveedores que cumplen con los estándares de calidad y de cumplimiento para la entrega de sus productos y elaborados. Entre los que destacan, en conformidad a los análisis efectuados:

- Procesadora Nacional de Alimentos - PRONACA: Empresa ecuatoriana, que procesa y comercializa alimentos de los sectores cárnicos, agroindustrial y acuacultura, a través de los años se ha convertido en líder de producción y distribución de alimentos en el Ecuador. Los productos que ofrecen son: Pollo, Chancho, Pavo, Embutidos, Conservas, Congelados, Huevos, Carnes, Pescado y Maricos (PRONACA, 2015).

- La Fabril S.A: Es una de las principales empresas a nivel nacional, refinadora de aceites, grasas vegetales, así como también, elabora productos de limpieza.

- Supan S.A: Empresa nacional, dedicada a la elaboración de productos de panadería, que poseen 74 productos en esta línea, encontrándose entre sus principales: pan de moldes, bollería, rosquitas, pan tostado, apanadura, etc.

- Nestlé: Elabora y comercializa productos alimenticios. La gama de productos ofertada por Nestlé, incluye desde chocolate, café, lácteos, bebidas sin gas, dulces y postres.

- Coca Cola: Multinacional de producción de bebidas con y sin gas. A escala mundial, es el primer proveedor de bebidas carbonatadas, zumos y bebidas a base de zumo, así como de tés, listos para su consumo.

Por otro lado, cabe destacar que del sector agropecuario de la zona en la que se implantará el proyecto, como proveedores locales y en forma directa, están: queso, leche, mantequilla, requesón, carnes, chicharrón, longaniza, choclo, plátano, cítricos, y vegetales (COCA COLA, 2015).

\subsection{2.-Análisis de comercialización}

En lo referente a comercialización, la competencia directa del presente proyecto no cuenta con entrega a domicilio, por lo que la venta se realiza de manera directa al consumidor final, considerando esto, el proyecto tampoco contempla la entrega a domicilio en la comercialización de sus productos, por lo tanto únicamente se tiene en consideración la venta directa a los consumidores.

\subsection{1.-Propuestas de comercialización del proyecto}

Las estrategias que se consideran van acordes a la investigación de campo realizada a los consumidores pudiéndose anotar las siguientes:

- Estrategias para la diferenciación del servicio

- Promociones de introducción al mercado

\subsubsection{1.-Estrategias de diferenciación}

Para este tipo de estrategias se han considerado las preferencias de los consumidores en lo referente al servicio que desearía tener el consumidor, considerando los horarios de preferencia, tipo de música, servicio climatizado, servicio de parqueadero entre otros. 


\subsubsection{2.-Promociones}

Inicialmente es pertinente dar a conocer a los consumidores de la existencia de una nueva opción para el consumidor de comidas rápidas, $\mathrm{y}$ de estimular el consumo en aquellos horarios en los cuales la afluencia disminuye, por lo tanto se han considerado estrategias de precios bajos de introducción al mercado y para incrementar los volúmenes de ventas.

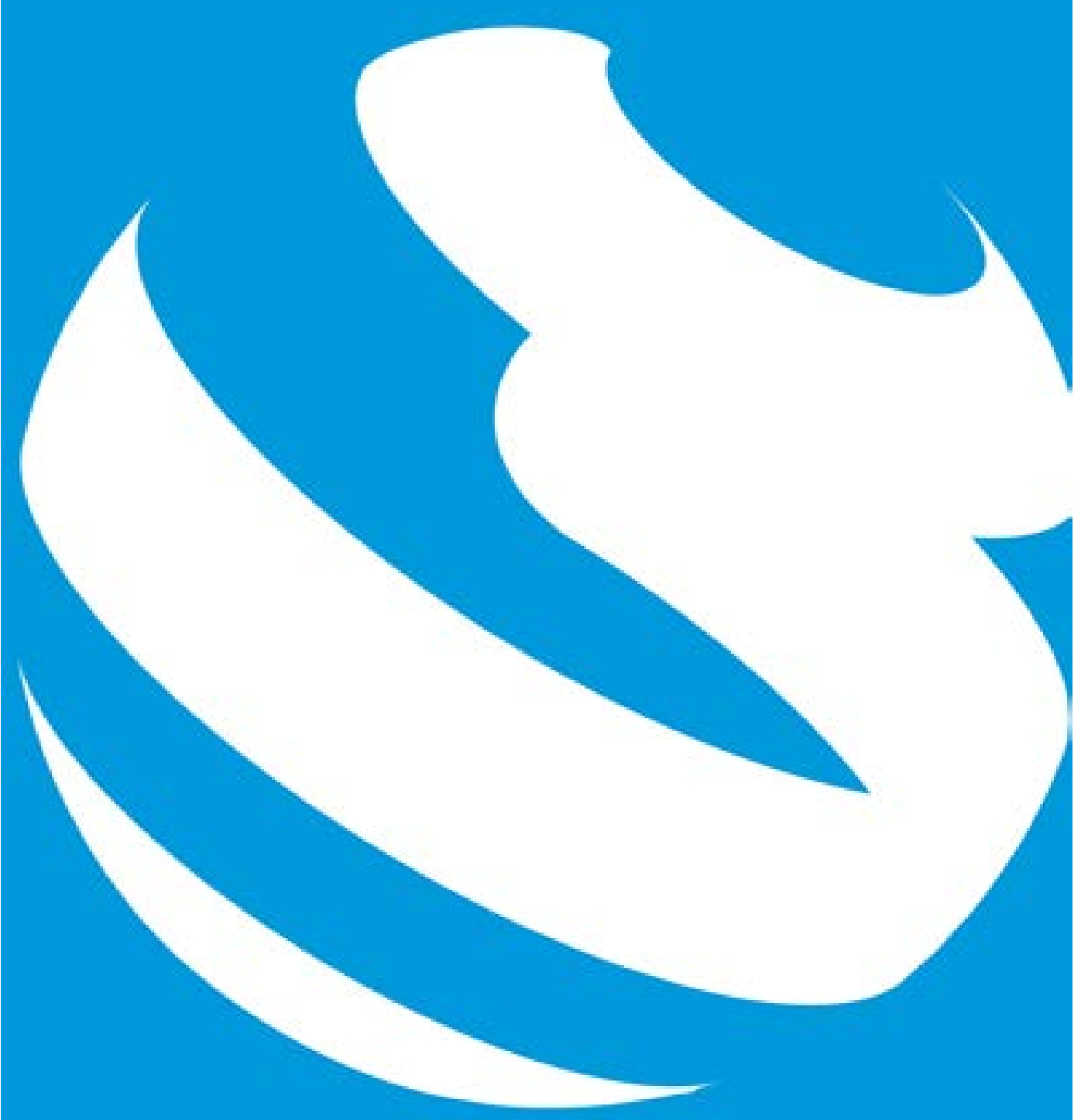




\section{CAPÍTULO III}

Estudio técnico - administrativo legal y financiero para la implementación de la microempresa de comidas rapidas en la ciudad de Chone

\section{1.-Estudio técnico}

Posee como objetivo el plantear el proceso técnico - operativo más adecuado para la ejecución de la microempresa de comidas rápidas en la ciudad de Chone, para ello se abordaron los siguientes aspectos:

\subsection{1.--Localización de la planta}

\subsubsection{1.-Macro localización}

El presente proyecto se implementará en el área urbana de la ciudad de Chone, en la provincia de Manabí, siendo los factores que determinaron su ubicación los siguientes:

\section{Factores determinantes de la Macro localización}

- Chone es una de las ciudades de mayor población de la provincia de Manabí.

- Es una ciudad de gran movimiento económico debido al gran desarrollo de su sector agrícola y comercial.

- Chone es una ciudad de paso para quienes se trasladan hacia otros sectores de la geografía manabita y nacional, por lo tanto existe una gran afluencia de personas que por actividades comerciales o particulares visitan esta ciudad diariamente. 


\subsubsection{2.-Micro localización}

Para el presente proyecto la mejor alternativa debe considerar los siguientes aspectos:

- Afluencia de personas.

- Existencia de servicios básicos.

- La infraestructura existente para proporcionar el servicio.

- La ubicación del local.

- La facilidad de parqueo en la zona.

Tabla 31: Factores determinantes de micro localización.

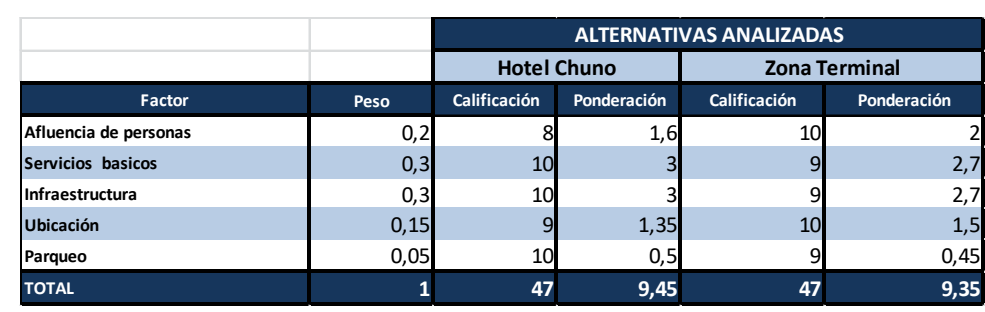

Fuente: Elaboración propia.

Al realizar el análisis correspondiente, se obtuvo que la mejor alternativa para la implementación del proyecto, se encuentra en el Hotel Chuno, ubicado en la Avenida Sixto Durán Ballén, en la ciudad de Chone.

Del análisis de la tabla anterior se desprende que la idoneidad del local se debe básicamente a que el local presenta las características esenciales en lo referente a infraestructura y servicios básicos, además de encontrarse en un sector con una gran afluencia de personas y por ofrecer facilidades para el parqueo de sus clientes.

\subsection{2.-Tamaño de la planta}

\subsubsection{1.-Capacidad de producción}

\subsubsection{1.-Capacidad instalada:}

Para determinar la capacidad instalada del proyecto se consideró la información recabada en el estudio de mercado en lo referente a la demanda insatisfecha y teniendo en cuenta el segmento, de dicha demanda insatisfecha, a la que se pretende llegar con el proyecto ( $10 \%$ de la demanda insatisfecha en cada uno de los periodos).

Con los datos anteriormente expuestos se determinó la cantidad de mesas disponibles para la atención al cliente que permitan cubrir la demanda insatisfecha del proyecto que en este caso debe ser 35. Además se tuvo en consideración la información proporcionada por el estudio de mercado, en la cual se estableció que los consumidores, en promedio, destinan una hora al consumo de los alimentos. De igual manera se estableció que se laborará 8 horas diarias repartidas en dos horarios (medio día y noche) y se laborará 26 días al mes (de lunes a sábado).

De lo anteriormente expuesto se pudo establecer que si se labora 26 días al mes, esto da como resultado que mensualmente se está en capacidad de atender a 7.280 clientes, lo que representa que se posee la capacidad de acoger un total de 87.360 personas al año. 
Tabla 32. Capacidad instalada.

\section{CAPACIDAD INSTALADA}

\begin{tabular}{|l|r|}
\hline $\begin{array}{l}\text { Capacidad/hora } \\
\text { (personas) }\end{array}$ & 35 \\
\hline Horas de atención & 8 \\
\hline $\begin{array}{l}\text { Dias trabajados } \\
\text { Capacidad/mes } \\
\text { (personas) }\end{array}$ & 7280 \\
\hline $\begin{array}{l}\text { Capacidad/año } \\
\text { (personas) }\end{array}$ & $\mathbf{8 7 3 6 0}$ \\
\hline
\end{tabular}

Fuente: Elaboración propia.

\section{Capacidad Utilizada}

En la elaboración del presente proyecto, se consideró que, en sus inicios la capacidad utilizada será del $50 \%$ durante el primer año y esta se incrementará de manera gradual en un porcentaje del $5 \%$ cada año hasta alcanzar el $80 \%$ de la capacidad instalada. Esto se lo hizo considerando que en sus inicios el establecimiento deberá enfrentar, inicialmente, una competencia ya establecida así como otros factores externos que en sus inicios podrían afectar el desarrollo del mismo.
Tabla 33. Capacidad utilizada del proyecto.

\begin{tabular}{|c|c|c|c|c|}
\hline Año & $\begin{array}{l}\text { Demanda } \\
\text { insatisfecha }\end{array}$ & $\begin{array}{l}\text { Demanda del } \\
\text { proyecto } 10 \%\end{array}$ & $\begin{array}{l}\text { Capacidad } \\
\text { instalada }\end{array}$ & $\begin{array}{c}\text { Capacidad } \\
\text { utilizada }\end{array}$ \\
\hline 2015 & 881.518 & 88.152 & 87360 & 43680 \\
\hline 2016 & 895.622 & 89.562 & 87360 & 48048 \\
\hline 2017 & 909.952 & 90.995 & 87360 & 52416 \\
\hline 2018 & 924.512 & 92.451 & 87360 & 56784 \\
\hline 2019 & 939.304 & 93.930 & 87360 & 61152 \\
\hline 2020 & 954.333 & 95.433 & 87360 & 65520 \\
\hline 2021 & 969.602 & 96.960 & 87360 & 69888 \\
\hline 2022 & 985.116 & 98.512 & 87360 & 69888 \\
\hline 2023 & 1.000 .878 & 100.088 & 87360 & 69888 \\
\hline 2024 & 1.016 .892 & 101.689 & 87360 & 69888 \\
\hline
\end{tabular}

Fuente: Estudio de mercado.

\subsubsection{2.-Capacidad Ociosa}

Para determinar la capacidad ociosa del proyecto, de acuerdo a la capacidad instalada y la demanda insatisfecha, se calculó la diferencia entre capacidad instalada anual y la capacidad utilizada anual obteniéndose los siguientes resultados:

Tabla 34. Capacidad ociosa del proyecto.

\begin{tabular}{|c|c|c|c|c|c|}
\hline Año & $\begin{array}{c}\text { Demanda } \\
\text { insatisfecha }\end{array}$ & $\begin{array}{l}\text { Demanda del } \\
\text { proyecto } 10 \%\end{array}$ & $\begin{array}{c}\text { Capacidad } \\
\text { instalada }\end{array}$ & $\begin{array}{c}\text { Capacidad } \\
\text { utilizada }\end{array}$ & $\begin{array}{l}\text { Capacidad } \\
\text { ociosa }\end{array}$ \\
\hline 2015 & 881.518 & 88.152 & 87360 & 43680 & 43680 \\
\hline 2016 & 895.622 & 89.562 & 87360 & 48048 & 39312 \\
\hline 2017 & 909.952 & 90.995 & 87360 & 52416 & 34944 \\
\hline 2018 & 924.512 & 92.451 & 87360 & 56784 & 30576 \\
\hline 2019 & 939.304 & 93.930 & 87360 & 61152 & 26208 \\
\hline 2020 & 954.333 & 95.433 & 87360 & 65520 & 21840 \\
\hline 2021 & 969.602 & 96.960 & 87360 & 69888 & 17472 \\
\hline 2022 & 985.116 & 98.512 & 87360 & 69888 & 17472 \\
\hline 2023 & 1.000 .878 & 100.088 & 87360 & 69888 & 17472 \\
\hline 2024 & 1.016 .892 & 101.689 & 87360 & 69888 & 17472 \\
\hline
\end{tabular}

Fuente: Estudio de mercado. 


\subsubsection{Proceso de elaboración de productos}

Los productos que se elaborarán están divididos en tres categorías:

\section{- Comida rápida.}

- Bebidas.

- Cocteles.

Estos productos serán elaborados para el consumo final de nuestros clientes. El proceso de elaboración empieza con la recepción de las materias primas, las mismas que se buscará sean de la mejor calidad para asegurar una óptima calidad en los productos resultantes.

Una vez receptada la materia prima esta será almacenada en un ambiente adecuado para asegurar su mejor conservación.

Las materias primas previas a su utilización en las órdenes de pedido por parte de los clientes serán lavadas de ser necesario con la final de asegurar que estos no sean nocivos para la salud.

Una vez lavados serán utilizados de manera directa en la preparación de los productos solicitados por los clientes. Para ello de ser necesario serán cocidos para finalmente ser entregados para el consumo directo por parte de los clientes.

A continuación se detalla mediante un diagrama el proceso descrito anteriormente. 
Hamburguesa normal (12 porciones)

\begin{tabular}{|l|l|r|}
\hline Panes & paquete 12 uniddes & 3,50 \\
\hline Carne molida & 1 libra & 3,00 \\
\hline Lechuga & $200 \mathrm{gr}$ & 0,60 \\
\hline Tomate & $500 \mathrm{gr}$ & 0,70 \\
\hline Queso & $0,5 \mathrm{Kg}$ & 2,00 \\
\hline Aderezos & $100 \mathrm{gr}$ & 0,20 \\
\hline
\end{tabular}

Hamburguesa especial (12 porciones)

\begin{tabular}{|l|l|r|}
\hline Panes & paquete 12 uniddes & 3,5 \\
\hline Carne molida & 1 libra & 3 \\
\hline lechuga & $200 \mathrm{gr}$ & 0,6 \\
\hline Tomate & $500 \mathrm{gr}$ & 0,7 \\
\hline Queso & $0,5 \mathrm{Kg}$ & 2 \\
\hline Aderezos & $100 \mathrm{gr}$ & 0,2 \\
\hline Tocino & $300 \mathrm{gr}$ & 3,5 \\
\hline Salsa hawwaiana & $100 \mathrm{gr}$ & 1,5 \\
\hline
\end{tabular}

Papas fritas (10 porciones)

\begin{tabular}{|l|l|r|}
\hline Papas & 5 libras & 2,5 \\
\hline Aceite & 1 litro & 1,5 \\
\hline Chorizo & $1 \mathrm{~kg}$ & 7 \\
\hline Aderezos & mayonesa y salsa & 0,4 \\
\hline Queso & $1 / 2$ libra & 1 \\
\hline
\end{tabular}

Sanduches de pollo (12 porciones)

\begin{tabular}{|l|l|r|}
\hline Pan & Paquete 12 uniddes & 3,5 \\
\hline Lomo de pollo & 1,5 libras & 4 \\
\hline Lechuga & $1 \mathrm{~kg}$ & 0,7 \\
\hline Cebolla & mayonesa y salsa & 0,4 \\
\hline Aceituna & $1 / 2$ libra & 1 \\
\hline Salsas & $100 \mathrm{gr}$ & 0,2 \\
\hline
\end{tabular}

Sanduches de chancho (12 porciones)

\begin{tabular}{|l|l|r|}
\hline Pan & Paquete 12 uniddes & $\$ 3,50$ \\
\hline Lomo de chancho & 1,5 libras & $\$ 5,00$ \\
\hline Leghuga & $1 \mathrm{~kg}$ & $\$ 7,00$ \\
\hline Cebolla & mayonesa y salsa & $\$ 0,40$ \\
\hline Salsas & $100 \mathrm{gr}$ & $\$ 0,50$ \\
\hline
\end{tabular}

Tostadas de queso (12 porciones)

\begin{tabular}{|l|l|r|}
\hline Pan & 20 unidades & $\$ 2,80$ \\
\hline Queso & $1 \mathrm{lbra}$ & $\$ 2,00$ \\
\hline Mantequilla & $1 / 4 \mathrm{ss}$ & $\$ 0,25$ \\
\hline
\end{tabular}

\section{Tostada mixta}

\begin{tabular}{|l|l|r|}
\hline Pan & 20 unidades & $\$ 2,80$ \\
\hline Queso & $1 \mathrm{lbra}$ & $\$ 2,00$ \\
\hline Jamon & $1 / 2 \mathrm{lbra}$ & $\$ 2,00$ \\
\hline Mantequilla & $1 / 4 \mathrm{ss}$ & $\$ 0,25$ \\
\hline
\end{tabular}




\section{Tostada especial (12 porciones)}

\begin{tabular}{|l|l|r|}
\hline Pan & 20 unidades & $\$ 2,80$ \\
\hline Queso & $1 \mathrm{lbra}$ & $\$ 2,00$ \\
\hline Jamon & $1 / 2 \mathrm{lbra}$ & $\$ 2,00$ \\
\hline Mantequilla & $1 / 4 \mathrm{ss}$ & $\$ 0,25$ \\
\hline Tocino & $1 / 4 \mathrm{lbra}$ & $\$ 2,50$ \\
\hline Oregano & 1 cucharada & $\$ 0,20$ \\
\hline Queso amarillo & 1 paquete peq. & $\$ 2,00$ \\
\hline
\end{tabular}

Pizza de jamón y queso ( 8 porciones)

\begin{tabular}{|l|l|r|}
\hline Harina & $0,250 \mathrm{~kg}$ & $\$ 1,00$ \\
\hline Sal & $0,020 \mathrm{~kg}$ & $\$ 0,06$ \\
\hline Levadura & $0,015 \mathrm{~kg}$ & $\$ 0,45$ \\
\hline Aceite & 0,050 Itros & $\$ 0,25$ \\
\hline Agua & 0,100 Itros & $\$ 0,10$ \\
\hline Jamon de cerdo & $1 / 2$ libra & $\$ 2,50$ \\
\hline Queso mozzarella & $1 / 2$ libra & $\$ 4,00$ \\
\hline Salsa de tomate & 200 gr & $\$ 0,85$ \\
\hline Oregano & 1 cucharada & $\$ 0,20$ \\
\hline
\end{tabular}

Pizza hawaiana ( 8 porciones)

\begin{tabular}{|l|l|r|}
\hline Harina & $0,250 \mathrm{~kg}$ & $\$ 1,00$ \\
\hline Sal & $0,020 \mathrm{~kg}$ & $\$ 0,06$ \\
\hline Levadura & $0,015 \mathrm{~kg}$ & $\$ 0,45$ \\
\hline Aceite & $0,050 \mathrm{ltros}$ & $\$ 0,25$ \\
\hline Agua & $0,100 \mathrm{ltros}$ & $\$ 0,10$ \\
\hline Jamon de cerdo & $1 / 2$ libra & $\$ 2,50$ \\
\hline Queso mozzarella & $1 / 2$ libra & $\$ 4,00$ \\
\hline Salsa de tomate & $200 \mathrm{gr}$ & $\$ 0,85$ \\
\hline Salsa hawaiana & $200 \mathrm{gr}$ & $\$ 1,50$ \\
\hline Oregano & $1 \mathrm{cucharada}$ & $\$ 0,20$ \\
\hline
\end{tabular}

Alitas bbq (6 porciones)

\begin{tabular}{|l|l|r|}
\hline Alitas & 1 libra & $\$ 2,00$ \\
\hline Sal & $0,020 \mathrm{~kg}$ & $\$ 0,06$ \\
\hline Salsa BBQ & $10 \mathrm{gr}$ & $\$ 1,50$ \\
\hline Aderesos & $0,50 \mathrm{~kg}$ & $\$ 1,00$ \\
\hline
\end{tabular}

Alitas con salsa de mostaza y miel (6 porciones)

\begin{tabular}{|l|l|r|}
\hline Alitas & 1 libra & $\$ 2,00$ \\
\hline Sal & $0,020 \mathrm{~kg}$ & $\$ 0,06$ \\
\hline Salsa de mostaza y miel & $10 \mathrm{gr}$ & $\$ 1,50$ \\
\hline Aderesos & $0,50 \mathrm{~kg}$ & $\$ 1,00$ \\
\hline
\end{tabular}

Fritadas (5 porciones)

\begin{tabular}{|l|l|r|}
\hline Chifles & 1 funda grande & $\$ 3,00$ \\
\hline Carnes & 1 libra & $\$ 3,00$ \\
\hline Repollo & $1 / 2$ peq. & $\$ 0,50$ \\
\hline Limón & 1 limon & $\$ 0,05$ \\
\hline
\end{tabular}

89 


\section{Lasaña (10 porciones)}

\begin{tabular}{|l|l|r|}
\hline Laminas de lasaña & 1 funda grande & $\$ 3,00$ \\
\hline Cebollas & 1 libra & $\$ 3,00$ \\
\hline Pimiento & $1 / 2$ peq. & $\$ 0,50$ \\
\hline Zanahorias & 1 limon & $\$ 0,05$ \\
\hline Ajo & 1 diente & $\$ 6,55$ \\
\hline Carne molida & $1 \mathrm{~kg}$ & $\$ 1,90$ \\
\hline Pasta de tomate & $500 \mathrm{ml}$ & $\$ 1,50$ \\
\hline Vino tinto o blanco & 1 onza & $\$ 0,50$ \\
\hline Sal & $0,020 \mathrm{~kg}$ & $\$ 0,06$ \\
\hline Pimienta & $0,005 \mathrm{~kg}$ & $\$ 0,06$ \\
\hline Perejil & 1 ramita & $\$ 0,25$ \\
\hline Salsa blanca & 1 taza & $\$ 1,50$ \\
\hline Queso rallado & 1 funda pequeña & $\$ 1,75$ \\
\hline
\end{tabular}

Torta de choclo (4 porciones)

\begin{tabular}{|l|l|r|}
\hline Maíz desgranado & 2 tazas & $\$ 1,50$ \\
\hline Mantequilla derretida & 4 cucharadas & $\$ 0,50$ \\
\hline Queso rallado & 1 taza & $\$ 1,50$ \\
\hline Sal & 1 cucharadita & $\$ 0,06$ \\
\hline Polvo de hornear & 1 cucharadita & $\$ 0,10$ \\
\hline Huevos & 2 & $\$ 0,25$ \\
\hline
\end{tabular}

\subsection{5.-Requerimientos de mano de obra}

La mano de obra necesaria para la producción de los bienes y servicios del presente proyecto, se encuentran disponibles en la zona lo cual permite mejorar la estructura de costos, pues al ser mano de obra local ésta es menos costosa.
El recurso humano es un factor muy importante e indispensable para el funcionamiento de una empresa, ya que este es el que permite que se ejecuten las actividades correspondientes para la puesta en marcha del proyecto.

Teniendo en cuenta lo anteriormente expuesto, el personal necesario para el presente proyecto se detalla en la tabla 35 .

Tabla 35. Proyecto de servicio de comidas rápidas.

\begin{tabular}{|c|c|c|c|c|c|c|c|c|c|}
\hline \multicolumn{10}{|c|}{ PROYECTO DE SERVICIO DE COMIDAS RÁPIDAS } \\
\hline \multicolumn{10}{|c|}{ DETALLE REQUERIMIENTOS MANO DE OBRA } \\
\hline Cargo & Cantidad & $\begin{array}{c}\text { Salario } \\
\text { nominal }\end{array}$ & $\begin{array}{l}\text { 13er } \\
\text { sueldo }\end{array}$ & $\begin{array}{l}\text { 14to } \\
\text { sueldo }\end{array}$ & $\begin{array}{l}\text { Vacacione } \\
\quad s\end{array}$ & $\begin{array}{l}\text { Fondo de } \\
\text { reserva }\end{array}$ & $\begin{array}{c}\text { Aporte } \\
\text { patronal }\end{array}$ & $\begin{array}{l}\text { Costo } \\
\text { Mensual }\end{array}$ & $\begin{array}{l}\text { Costo } \\
\text { Anual }\end{array}$ \\
\hline Gerente & 1 & $\$ 600,0$ & $\$ 50,0$ & $\$ 30,0$ & $\$ 25,0$ & $\$ 50,0$ & $\$ 72,9$ & $\$ 827,9$ & $\$ 9.934,6$ \\
\hline Administrador & 1 & $\$ 400,0$ & $\$ 33,3$ & $\$ 30,0$ & $\$ 16,7$ & $\$ 33,3$ & $\$ 48,6$ & $\$ 561,9$ & $\$ 6.743,0$ \\
\hline Cajeros (2) & 2 & $\$ 360,0$ & $\$ 30,0$ & $\$ 30,0$ & $\$ 15,0$ & $\$ 30,0$ & $\$ 43,7$ & $\$ 508,7$ & $\$ 12.209,5$ \\
\hline Cocineros (2) & 2 & $\$ 400,0$ & $\$ 33,3$ & $\$ 30,0$ & $\$ 16,7$ & $\$ 33,3$ & $\$ 48,6$ & $\$ 561,9$ & $\$ 13.486,1$ \\
\hline Meseros (2) & 2 & $\$ 360,0$ & $\$ 30,0$ & $\$ 30,0$ & $\$ 15,0$ & $\$ 30,0$ & $\$ 43,7$ & $\$ 508,7$ & $\$ 12.209,5$ \\
\hline *Barman & 1 & $\$ 180,0$ & $\$ 15,0$ & $\$ 30,0$ & $\$ 7,5$ & $\$ 15,0$ & $\$ 21,9$ & $\$ 269,4$ & $\$ 3.232,4$ \\
\hline Guardia & 1 & $\$ 360,0$ & $\$ 30,0$ & $\$ 30,0$ & $\$ 15,0$ & $\$ 30,0$ & $\$ 43,7$ & $\$ 508,7$ & $\$ 6.104,7$ \\
\hline & 10 & $\$ 2.660,0$ & $\$ 221,7$ & $\$ 210,0$ & $\$ 110,8$ & $\$ 221,6$ & $\$ 323,2$ & $\$ 3.747,3$ & $\$ 63.919,7$ \\
\hline
\end{tabular}

Fuente: Elaboración propia.

\subsection{6.-Estimación de la inversión}

\subsubsection{1.-Obras físicas}

El local que se tiene previsto para el funcionamiento del proyecto necesita ser adecuado para ofrecer la comodidad tanto para los procesos de producción como para garantizar la comodidad de los clientes. En tal virtud se ha considerado realizar adecuaciones en el mismo.

Estas adecuaciones se detallan a continuación: 
Tabla 36. Detalles de obras físicas

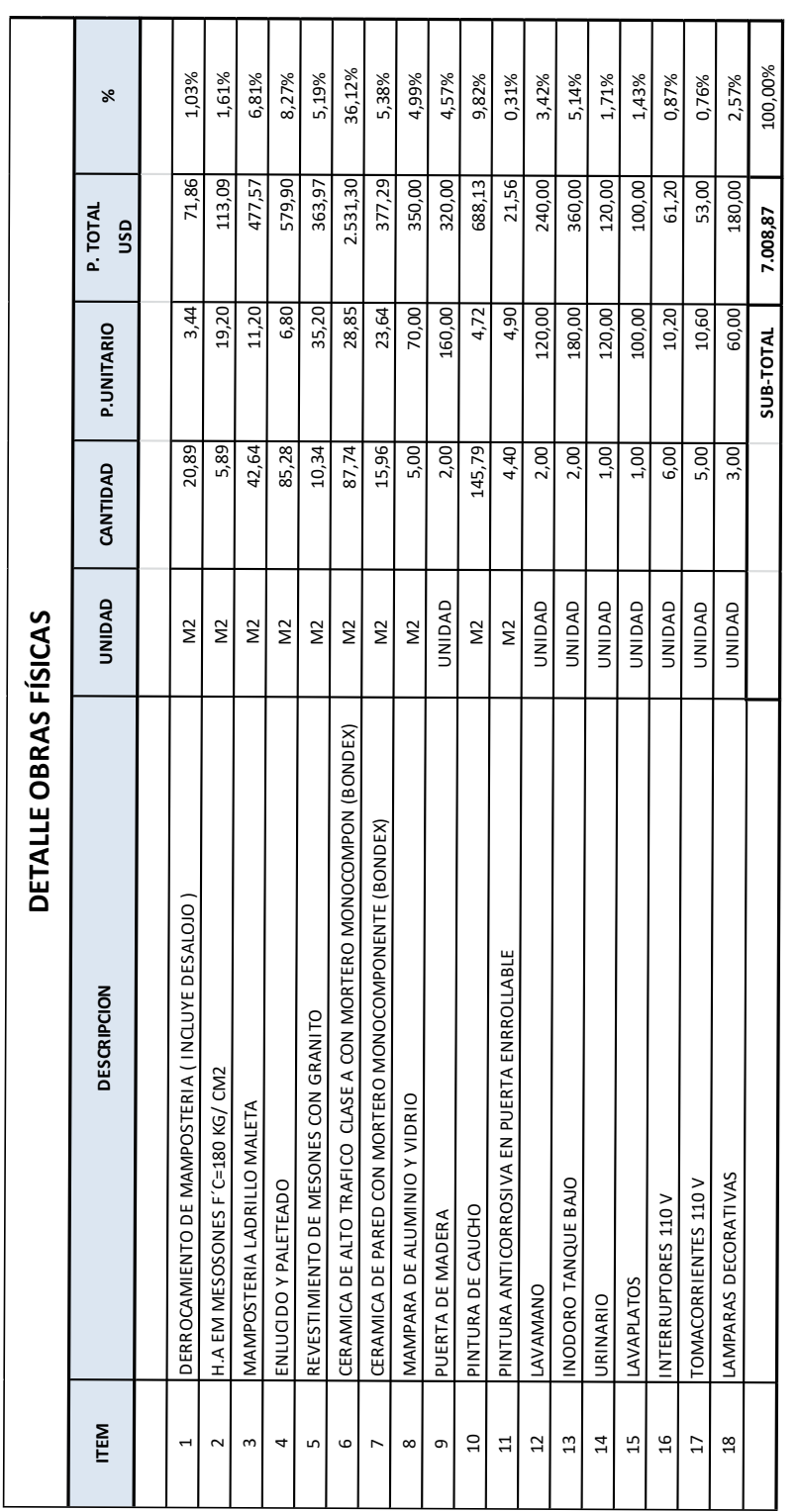

Fuente: Elaboración propia.

\section{Mobiliario}

Tabla 37. Mobiliario

\begin{tabular}{|l|r|r|r|}
\hline \multicolumn{1}{|c|}{ Muebles } & Cantidad & V. Unitario & V. Total \\
\hline Escritorio Gerencial & 1 & 400 & 400 \\
\hline Silla Gerencial & 1 & 120 & 120 \\
\hline Escritorio pequeño & 1 & 180 & 180 \\
\hline Silla Giratoria & 1 & 80 & 80 \\
\hline Mesas de 2 puestos & 2 & 150 & 300 \\
\hline Mesas de 4 puestos & 6 & 250 & 1500 \\
\hline Muebles & 1 & 800 & 800 \\
\hline Bancos para la barra & 4 & 60 & 240 \\
\hline Barra del Bar & 1 & 600 & 600 \\
\hline Sillas para las mesas & 34 & 80 & 2720 \\
\hline Total & $\mathbf{5 2}$ & $\mathbf{2 7 2 0}$ & $\mathbf{6 9 4 0}$ \\
\hline
\end{tabular}

Fuente: Elaboración propia.

Tabla 38. Equipos de oficina

\begin{tabular}{|l|r|r|r|}
\hline \multicolumn{1}{|c|}{ Equipos de oficina } & Cantidad & \multicolumn{1}{c|}{ V. Unitario } & \multicolumn{1}{c|}{ V. Total } \\
\hline Teléfonos & 2 & $\$ 35,00$ & $\$ 70,00$ \\
\hline Total & 2 & $\$ 35,00$ & $\$ 70,00$ \\
\hline
\end{tabular}

Fuente: Elaboración propia. 
Tabla 39. Equipos de cómputo

\begin{tabular}{|l|r|r|r|}
\hline \multicolumn{1}{|c|}{ Equipos de cómputo } & \multicolumn{1}{c|}{ Cantidad } & \multicolumn{1}{c|}{ V. Unitario } & \multicolumn{1}{c|}{ V. Total } \\
\hline Computadora portatil & 2 & $\$ 800,00$ & $\$ 1.600,00$ \\
\hline Impresora & 1 & $\$ 350,00$ & $\$ 350,00$ \\
\hline Total & 3 & $\$ 1.150,00$ & $\$ 1.950,00$ \\
\hline
\end{tabular}

Fuente: Elaboración propia.

\section{Tabla 40. Maquinarias y equipos}

\begin{tabular}{|l|r|r|r|}
\hline \multicolumn{1}{|c|}{ Maquinarias y equipos } & Cantidad & \multicolumn{1}{c|}{ V. Unitario } & \multicolumn{1}{c|}{ V. Total } \\
\hline Cortina de aire & 1 & $\$ 2.000,00$ & $\$ 2.000,00$ \\
\hline Congelador & 1 & $\$ 1.200,00$ & $\$ 1.200,00$ \\
\hline Congelador vitrina & 1 & $\$ 1.000,00$ & $\$ 1.000,00$ \\
\hline Parlantes de audio & 1 & $\$ 400,00$ & $\$ 400,00$ \\
\hline Cocina industrial & 1 & $\$ 800,00$ & $\$ 800,00$ \\
\hline Freidora & 2 & $\$ 400,00$ & $\$ 800,00$ \\
\hline Microondas & 1 & $\$ 250,00$ & $\$ 250,00$ \\
\hline Cafetera electrica & 1 & $\$ 50,00$ & $\$ 50,00$ \\
\hline Campana extractora de oleres & 1 & $\$ 500,00$ & $\$ 500,00$ \\
\hline Tostadora & 1 & $\$ 80,00$ & $\$ 80,00$ \\
\hline Horno & 1 & $\$ 400,00$ & $\$ 400,00$ \\
\hline Licuadora & 1 & $\$ 100,00$ & $\$ 100,00$ \\
\hline Batidora & 1 & $\$ 80,00$ & $\$ 80,00$ \\
\hline Plasma & 2 & $\$ 600,00$ & $\$ 1.200,00$ \\
\hline Extractor de jugo & 1 & $\$ 100,00$ & $\$ 100,00$ \\
\hline Total & 17 & $\$ 7.960,00$ & $\$ 8.960,00$ \\
\hline
\end{tabular}

Fuente: Elaboración propia.

\section{Tabla 41. Equipos varios}

\begin{tabular}{|l|r|r|r|}
\hline \multicolumn{1}{|c|}{ Equipos varios } & Cantidad & V. Unitario & V. Total \\
\hline Vasos & 100 & $\$ 0,50$ & $\$ 50,00$ \\
\hline Juegos de tazas & 20 & $\$ 4,00$ & $\$ 80,00$ \\
\hline Platos ovalados & 100 & $\$ 1,00$ & $\$ 100,00$ \\
\hline Platos redondos & 100 & $\$ 0,80$ & $\$ 80,00$ \\
\hline Copas & 50 & $\$ 1,80$ & $\$ 90,00$ \\
\hline Platos medianos & 50 & $\$ 0,60$ & $\$ 30,00$ \\
\hline Cucharas pequeñas & 50 & $\$ 0,25$ & $\$ 12,50$ \\
\hline Cubiertos & 100 & $\$ 0,80$ & $\$ 80,00$ \\
\hline Cuchillos & 5 & $\$ 2,50$ & $\$ 12,50$ \\
\hline Cernidoras & 4 & $\$ 2,00$ & $\$ 8,00$ \\
\hline Pirex cuadrados & 10 & $\$ 15,00$ & $\$ 150,00$ \\
\hline Cucharetas & 10 & $\$ 2,50$ & $\$ 25,00$ \\
\hline Ollas & 10 & $\$ 25,00$ & $\$ 250,00$ \\
\hline Jarros para batidos & 10 & $\$ 2,50$ & $\$ 25,00$ \\
\hline Cocteleras & 10 & $\$ 2,00$ & $\$ 100,00$ \\
\hline Sorbetes & 8 & $\$ 7,80$ & $\$ 62,40$ \\
\hline Jarras & 100 & $\$ 0,10$ & $\$ 10,00$ \\
\hline Servilleteros & $\$ 3,00$ & $\$ 48,00$ \\
\hline Saleros & $\$ 2,50$ & $\$ 22,50$ \\
\hline Tablas para picar & $\$ 80,15$ & $\$ 1.270,90$ \\
\hline Total & & & $\$ 35,00$ \\
\hline
\end{tabular}

Fuente: Elaboración propia. 
Tabla 42. Suministros de oficina

\begin{tabular}{|l|r|r|r|}
\hline \multicolumn{1}{|c|}{ Suministros de oficina } & Cantidad & V. Unitario & \multicolumn{1}{c|}{ V. Total } \\
\hline Resmas de papel & 20 & $\$ 4,00$ & $\$ 80,00$ \\
\hline Libretas & 20 & $\$ 1,20$ & $\$ 24,00$ \\
\hline Lapiceros & 30 & $\$ 0,50$ & $\$ 15,00$ \\
\hline Saca grapas & 2 & $\$ 1,50$ & $\$ 3,00$ \\
\hline Perforadora & 1 & $\$ 3,00$ & $\$ 3,00$ \\
\hline Grapadoras & 2 & $\$ 3,50$ & $\$ 7,00$ \\
\hline Folders & 2 & $\$ 4,50$ & $\$ 9,00$ \\
\hline Total & $\mathbf{7 7}$ & $\mathbf{\$ 1 8 , 2 0}$ & $\$ 141,00$ \\
\hline
\end{tabular}

Fuente: Elaboración propia.

Tabla 43. Estimación de la inversión inicial

\begin{tabular}{|c|r|r|r|}
\hline \multicolumn{3}{|c|}{$\begin{array}{c}\text { DETALLE INVERSION INCIAL } \\
\text { DESCRIPCION }\end{array}$} \\
\hline \multicolumn{1}{|c|}{ VALOR } & \multicolumn{1}{c|}{$\%$} \\
\hline 1 Local & $\$ 3.600,00$ & $12,0 \%$ \\
\hline 2 Obras físicas & $\$ 7.008,87$ & $23,4 \%$ \\
\hline 3 Muebles & $\$ 6.940,00$ & $23,2 \%$ \\
\hline 4 Equipos de oficina & $\$ 70,00$ & $0,2 \%$ \\
\hline 5 & Equipos de cómputo & $\$ 1.950,00$ & $6,5 \%$ \\
\hline 6 & Maquinarias y equipos & $\$ 8.960,00$ & $29,9 \%$ \\
\hline 7 Equipos varios & $\$ 1.270,90$ & $4,2 \%$ \\
\hline 8 Suministros de oficina & $\$ 141,00$ & $0,5 \%$ \\
\hline \multicolumn{2}{|c|}{ TOTAL INVERSION INICIAL } & $\mathbf{2 9 . 9 4 0 , 7 7}$ & $\mathbf{1 0 0 , 0 \%}$ \\
\hline
\end{tabular}

Fuente: Elaboración propia.

\subsection{7.-Distribución del lugar para la instalación del servicio}

Se debe procurar una distribución óptima del espacio físico donde se ejecutara el proyecto, lo que permitirá aprovechar toda el área que este posee, creando así las condiciones adecuadas para su funcionamiento.

A continuación se plantea la propuesta de la distribución de la planta.

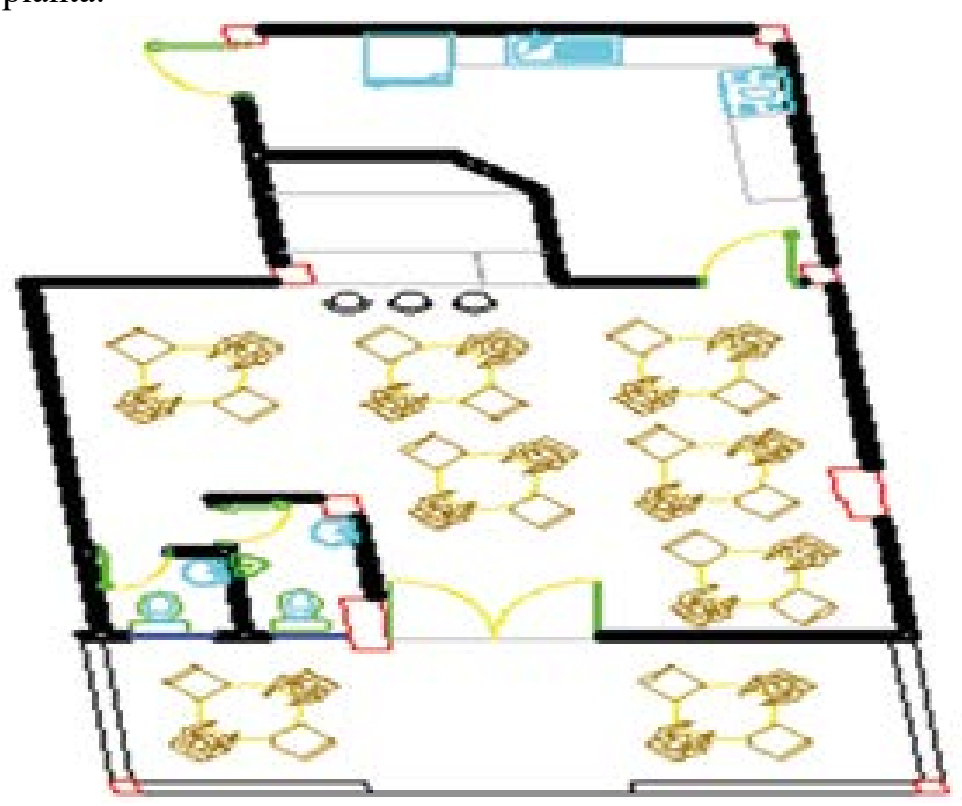

Grafico 19. Propuesta de la distribución de la planta Fuente: Elaboración propia.

\section{2.-Estudio administrativo legal}

Se plantea el estudio administrativo - legal para proponer la estructura administrativa adecuada y el cumplimiento de las normas relacionadas a la actividad del proyecto.

97 


\subsection{1.-La empresa}

La empresa proveedora de servicios de comida rápida, se llamará "El RINCON DEL CHUNO", la misma que tendrá un solo socio, quien será dueño de la totalidad de las acciones de la empresa y ésta se constituirá como una sociedad de hecho. La empresa se legalizará a través de un documento notariado por el dueño de las acciones de la empresa, en dicho documento quedará establecido la nueva razón social de la empresa la cual será: "el rincon del chuno sociedad de hecho"

\subsection{2.-Giro del negocio}

La actividad del negocio será la de ofrecer a su clientela alimentos preparados para el consumo humano, divididos en tres categorías: alimentos, bebidas y cocteles (los cuales se circunscriben dentro de la definición de comidas rápidas), en un ambiente cómodo y agradable para la clientela. Para éste propósito contará con los recursos económicos, humanos y materiales que le permitirá cumplir todas las actividades con eficacia y eficiencia.

Misión: "El rincón del chuno sociedad de hecho" es una empresa que se dedica a ofrecer el servicio de comidas rápidas, en un lugar acogedor, con la mejor calidad, garantizando a nuestros clientes una óptima relación costo-beneficio con la finalidad de mejorar la calidad de vida de sus clientes, empleados y la comunidad en general.

Visión: la empresa ““'el rincon del chuno sociedad de hecho” pretende ser reconocida a nivel local como la mejor organización que se dedica a la venta de comidas rápidas por la calidad de sus productos, el servicio personalizado a sus clientes y los valores que profesa.

Valores: los valores fundamentales en los cuales se fundamenta la empresa "el rincón del chuno sociedad de hecho" son:

- Calidad.

- Eficiencia.

- Servicio.

- Responsabilidad.

- Innovación.

\subsection{3.-Objetivos estratégicos}

Los objetivos estratégicos de la empresa son los siguientes:

- Obtener posicionamiento en el mercado en el corto plazo.

- Alcanzar el uso de su capacidad máxima de operación en el mediano plazo.

- Optimizar los recursos humanos, técnicos y materiales en la preparación y comercialización de los productos que se elaboren.

\subsection{4.-Estrategias}

Para alcanzar los objetivos anteriormente planteados la empresa realizará las siguientes acciones:

- Entregar productos de calidad con novedosas características y atributos.

- Ofrecer un servicio personalizado a su clientela.

- Ofrecer precios bajos en sus productos sin desmedro de la calidad de los mismos. 
- Brindar promociones que incentiven el consumo de los productos ofertados.

\subsection{5.-La organización}

\subsubsection{1.-Organigrama estructural}

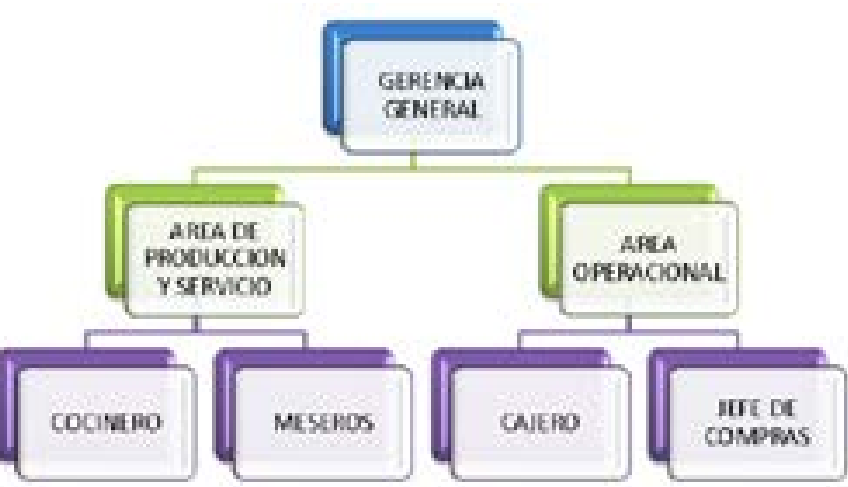

Grafico 20. Organigrama estructural

Fuente: Elaboración propia.

\section{Nivel directivo:}

Está conformado por el dueño y es quien legislará sobre las políticas que deberán seguir en la Empresa, sus funciones serán:

- Normar los procedimientos.

- Redactar los reglamentos internos.

- Resolver asuntos relativos a todos los negocios que sean de acuerdo a la competencia de Ley y el Estatuto.

- Nombrar al Gerente General.

- Nombrar y remover por causa legal a los funcionarios, fijar remuneraciones y sueldos.

- Conocer sobre las cuentas bancarias, informes, documentos que le fueren presentados y dictar las resoluciones correspondientes.

- Resolver sobre el reparto de los beneficios sociales.

- Facultar al Gerente General para que suscriba actos y contratos.

- Elaborar y políticas comerciales de la empresa.

- Fiscalizar el cumplimiento de los planes propuestos.

\section{Nivel ejecutivo}

El Gerente será el representante legal, sus funciones administrativas serán: planificar, organizar y dirigir planes y programas; trasmitir a los órganos operativos y auxiliares para su ejecución.

\section{- Perfil del puesto}

Título Terminal: Ingeniero Comercial o Economista

Edad: 23 a 30 años

Experiencia: 2 años

Objetivo: Supervisar, planificar, coordinar, controlar, dirigir y ejecutar las actividades relacionadas al negocio.

\section{Funciones:}

- Presentar el Plan Operativo y ejecutarlo si es aprobado por el dueño.

- Dirigir, controlar y evaluar las actividades operacionales, administrativas, financieras y judiciales.

- Implementar mecanismos de control interno, calidad y competitividad. 
- Instituir un sistema de selección técnica y capacitación del personal.

- Preparar y presentar anualmente o cuando el dueño lo requiera, los informes de actividades administrativas, económicas y financieras de la empresa.

- Controlar los depósitos y reembolsos.

\section{- Nivel auxiliar}

Ayuda a los otros niveles en la prestación de servicios con oportunidad y eficiencia; las actividades del nivel auxiliar tiene que ver con administración, contabilidad, finanzas, etc.

\section{Departamento administrativo y contable}

- Llevar el Registro del Personal que labora en la Empresa.

- Llevar la contabilidad de la empresa.

- Manejar todo el sistema contable de la empresa y sus estados financieros.

- Evaluar las necesidades de contratar capacitadores de diversos temas, de acuerdo a las necesidades de los miembros de la empresa y de los clientes.

\section{Nivel operativo}

Son los responsables directos de ejecutar las actividades básicas de la empresa, es decir cumplirán las órdenes emanadas por los órganos directivo y administrativo.

\section{Área de producción y servicio}

\section{Cocinero}

- Tendrá la obligación de arreglar de manera general la cocina.
- Elaborará los productos solicitados por los clientes en cada una de sus órdenes.

- Diseñará la presentación de los productos de forma creativa e impactante para el cliente.

- Cuidará del aseo en la preparación y manipulación de los pedidos realizados por los clientes.

- Acordar con el Gerente las propuestas de aprobación, en cuanto, a las materias primas y utensilios requeridos para la producción de los alimentos que se elaboren.

- Llevar de forma ordenada las entradas y salidas de las adquisiciones efectuadas (materia prima, materiales y equipos).

- Será responsable tanto de las materias primas como de las herramientas y utensilios que sean utilizados en el proceso de elaboración de los alimentos.

- Asesorar con materiales y utensilios que servirán para mejorar el proceso de elaboración en la cocina

- Emitirá un informe periódico (mensual), o cuando el gerente lo solicite, de los activos que estén bajo su responsabilidad.

- Determinar los faltantes y/o sobrantes de la materia prima, materiales, equipos de la empresa y demás recursos.

\section{Barman}

- Tendrá la obligación de arreglar de manera general el bar.

- Elaborará los productos solicitados por los clientes en cada una de sus órdenes.

- Diseñará la presentación de los cocteles de forma creativa para el cliente. 
- Cuidará del aseo en la preparación y manipulación de los pedidos realizados por los clientes.

- Acordará con el gerente las materias primas y utensilios requeridos para la producción de los cocteles que se elaboren.

- Llevar de forma ordenada las entradas y salidas de las adquisiciones efectuadas (materia prima, materiales).

- Será responsable tanto de las materias primas como de las herramientas y utensilios que sean utilizados en el proceso de elaboración de los cocteles.

- Emitirá un informe periódico (mensual), o cuando el gerente lo solicite, de los activos que estén bajo su responsabilidad.

- Determinar los faltantes y/o sobrantes de la materia prima y materiales de la empresa y demás recursos.

\section{Mesero}

- Presentarse frente a los clientes de manera debidamente uniformado y aseado.

- Atender de manera oportuna a los clientes con calidad y calidez.

- Ofrecer a los clientes la lista de alimentos fríos y calientes para su consumo.

- Conocer el uso correcto de la terminología derivados de los alimentos y las bebidas.

- Limpiar las mesas u otros utensilios para que los clientes se sientan cómodos.

- Asegurar que en las mesas estén surtidas de insumos que complementan los alimentos servidos.

- Conocer el tiempo aproximado que se demora los alimentos que se elaboran en la cocina.

- Comunicar el pedido del cliente al cocinero para elaborar el o los pedidos de los clientes.

- Solicitar al cajero la factura para presentarle al cliente para su pago.

- Cobrar el dinero y llevarlo al cajero pero sin tocar el dinero con las manos.

\section{Área operacional}

\section{Cajero}

- Se encargará de la atención al cliente, considerando el turno respectivo que le es asignado.

- Mantener en el punto de venta los horarios y días establecidos por la empresa.

- Reportar al gerente la falta de materiales y suministros para el funcionamiento de la caja registradora.

- Emitir la correspondiente factura a cada uno de los clientes a partir de la nota de pedido entregada por los meseros.

- Receptar el dinero de los clientes a través de los meseros.

- Salvaguardar las recaudaciones efectuadas por las ventas.

- Realizar periódicamente arqueos a la caja para la verificación del dinero.

- Otras que resulten de la Gerencia General.

\section{Administrador}

- Supervisar el desempeño de cada una de las áreas de producción el área operacional del negocio. 
- Dirigir y controlar las actividades relacionadas con el personal que labora en la empresa.

- Supervisar la correcta utilización de los recursos en la empresa.

- Velar por el aseo y la pulcritud del negocio.

- Se encargará de escoger las mejores materias primas, que por su calidad y frescura permitan elaborar los mejores productos.

- Cotizará con distintos proveedores las materias primas y los materiales necesarios para la elaboración de los productos que se elaboren en el negocio.

- Tomará decisiones, en función de precios, calidad y formas de pago, que sean las más eficientes al giro del negocio.

- Comprará únicamente productos frescos y de calidad.

- Presentará informes periódicos a la gerencia con la finalidad de evidenciar el inventario de materia primas existentes.

- Receptar los requerimientos originados en el área de la cocina a través del cocinero.

\section{Guardia}

- Presentarse frente a los clientes de manera debidamente uniformado y aseado.

- Atender de manera oportuna a los clientes con calidez.

- Se encargará de la seguridad y comodidad de los clientes al interior del negocio.

- Tendrá la responsabilidad de velar por los vehículos que se encuentren en el parqueadero del negocio.

- Informar inmediatamente al gerente en el caso de presentarse el menor inconveniente.

- Llevar una bitácora con los eventos relevantes que se susciten durante la jornada laboral.

- Otras que resulten, en consenso, de la gerencia general.

\section{3.-Estudio legal}

\subsection{1.-Constitución de la empresa}

En fiel cumplimiento a la normativa vigente: Código de Trabajo, Código Tributario, Derecho Mercantil y Societario, que permitirá poner en marcha el proyecto, la empresa adquirirá la forma jurídica de SOCIEDAD DE HECHO la cual se constituirá mediante escritura pública, la cual le dará personería jurídica y le permitirá operar legalmente para estar en capacidad de contratar y ser contratada.

La empresa se legalizará a través de un documento notariado por el dueño de las acciones de la empresa, en dicho documento quedará establecido la nueva razón social de la empresa la cual será: "el rincón del chuno sociedad de hecho"

\subsection{2.-permisos de funcionamiento}

Los permisos para el funcionamiento del establecimiento, se detallan a continuación:

- Permiso y certificados del Ministerio de Salud Pública.

- Permiso de la Agencia Nacional de Regulación, Control y Vigilancia Sanitaria (ARCSA).

- GAD del cantón Chone (Patente municipal)

- Superintendencia de Compañías.

- Ministerio de Turismo . 
TABLA 44. COSTOS DE CONSTITUCIÓN Y PERMISOS

\begin{tabular}{|l|r|}
\hline \multicolumn{2}{|c|}{ CONSTITUCION DE LA EMPRESA } \\
\hline \multicolumn{1}{|c|}{ Descripción } & \multicolumn{1}{c|}{ Costo } \\
\hline Constitución & $\$ 800,00$ \\
\hline Impuestos & $\$ 100,00$ \\
\hline Permisos & $\$ 200,00$ \\
\hline Total & $\$ 1.100,00$ \\
\hline
\end{tabular}

Fuente: Elaboración propia.

\section{4.-Estudio Financiero}

Se propone la factibilidad financiera del proyecto de creación de la microempresa de comidas rápidas en el cantón Chone, a partir del presupuesto de inversiones, de la realización de la proyección de ingresos y gastos y determinación de la rentabilidad o pérdida económica del proyecto planteado.

\subsection{1.-Presupuesto de inversiones}

\subsubsection{1.-Inversión fija}

En este punto de determinó la inversión fija necesaria para la puesta en marcha del proyecto. Para establecer el monto se utilizó la información recabada en los capítulos anteriores.
Tabla 45. Detalle de inversión fija

\begin{tabular}{|c|r|r|}
\hline \multicolumn{2}{|c|}{ DETALLE INVERSION FIJA } \\
\hline No & \multicolumn{1}{|c|}{ DESCRIPCION } \\
\hline 1 Obras físicas & $\$ 7.008,87$ \\
\hline 2 Muebles & $\$ 6.940,00$ \\
\hline 3 Equipos de oficina & $\$ 70,00$ \\
\hline 4 Equipos de cómputo & $\$ 1.950,00$ \\
\hline 5 Maquinarias y equipos & $\$ 8.960,00$ \\
\hline TOTAL INVERSION INICIAL & $\$ \mathbf{2 4 . 9 2 8 , 8 7}$ \\
\hline
\end{tabular}

Fuente: Elaboración propia.

\subsubsection{2.-Inversiones diferidas}

Tabla 46. Detalle de la inversión diferida

\begin{tabular}{|l|r|}
\hline \multicolumn{2}{|c|}{\begin{tabular}{c} 
DETALLE INVERSION DIFERIDA \\
\multicolumn{1}{|c|}{ Descripción }
\end{tabular}} \\
\hline Constitución & Costo \\
\hline Impuestos & $\$ 800,00$ \\
\hline Permisos & $\$ 100,00$ \\
\hline Total & $\$ 200,00$ \\
\hline
\end{tabular}

Fuente: Elaboración propia.

\subsubsection{3.-Presupuesto de costos}

En este apartado se detallan el análisis realizado para realizar el presupuesto de los costos para de esta manera poder realizar la evaluación financiera del proyecto. 


\subsubsection{4.-Costos de producción}

En el análisis de los costos de producción se consideró:

- Costos de materia prima.

- Costos de mano de obra directa.

- Costos indirectos de fabricación.

\subsubsection{5.-Costos de materia prima}

Para realizar el presupuesto de los costos de materia prima, se tuvieron en consideración los siguientes aspectos:

- El número de requerimientos anuales de cada uno de los productos demandadas por los consumidores en función de la encuesta de preferencias de los productos realizada en el estudio de mercado.

- El incremento de las cantidades solicitadas por los consumidores considerando la proyección de la demanda analizada en el estudio de mercado.

- Se consideró un incremento anual en el precio de las materias primas igual a la inflación promedio del país la cual es del $3 \%$.

Con las consideraciones anotadas anteriormente se procedió a realizar el presupuesto de costos anuales por cada producto. El análisis de costo unitario de cada uno de los productos se detalla en los anexos que acompañan la presente investigación.
Tabla 47.Costo de la materia prima

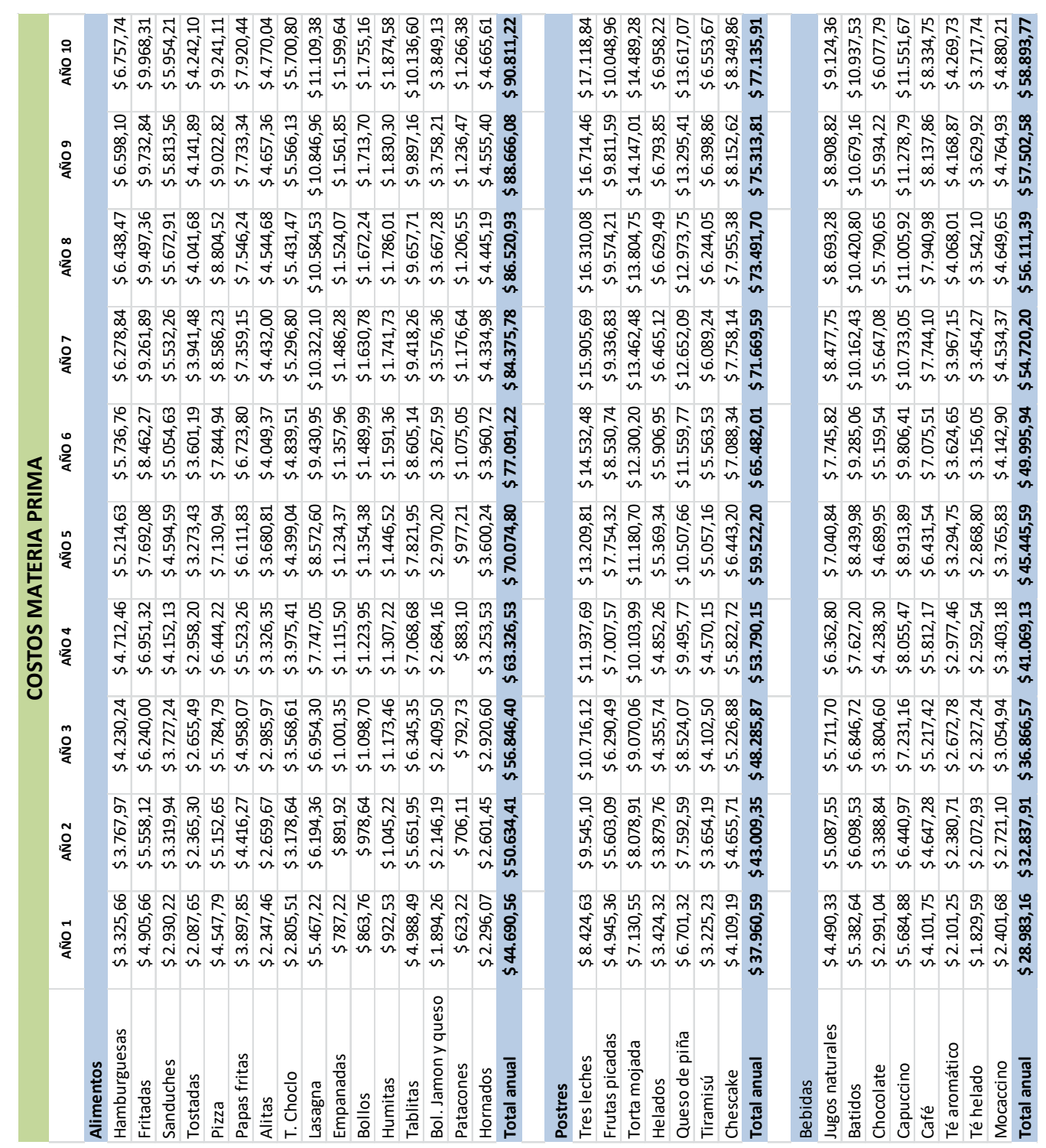

Fuente: Elaboración propia. 


\section{Tabla 48. Costos de mano de obra directa}

DETALLE MANO DE OBRA DIRECTA

\begin{tabular}{|c|c|c|c|c|c|c|c|c|c|c|c|}
\hline \multicolumn{12}{|c|}{ DETALLE MANO DE OBRA DIRECTA } \\
\hline & Cargo & & Cantidad & $\begin{array}{c}\text { Salario } \\
\text { nominal }\end{array}$ & $\begin{array}{l}13 \text { er } \\
\text { sueldo }\end{array}$ & $\begin{array}{l}\text { 14to } \\
\text { sueldo }\end{array}$ & Vacaciones & $\begin{array}{l}\text { Fondo de } \\
\text { reserva }\end{array}$ & $\begin{array}{c}\text { Aporte } \\
\text { patronal }\end{array}$ & $\begin{array}{c}\text { Costo } \\
\text { Mensual }\end{array}$ & $\begin{array}{l}\text { Costo } \\
\text { Anual }\end{array}$ \\
\hline Cocinero & & & 2 & $\$ 400,0$ & $\$ 33,3$ & $\$ 30,0$ & $\$ 16,7$ & $\$ 33,3$ & $\$ 48,6$ & $\$ 561,9$ & $\$ 13.486,1$ \\
\hline & & Total & 10 & $\$ 400,0$ & $\$ 33,3$ & $\$ 30,0$ & $\$ 16,7$ & $\$ 33,3$ & $\$ 48,6$ & $\$ 561,9$ & $\$ 13.486,1$ \\
\hline
\end{tabular}

Fuente: Elaboración propia.

\section{Tabla 49. Costos indirectos}

\section{COSTOS INDIRECTOS}

\begin{tabular}{|c|c|r|}
\hline No & DESCRIPCION & VALOR ANUAL \\
\hline 1 Insumos varios & $\$ 1.270,90$ \\
\hline TOTAL INVERSION INICIAL & $\$ 1.270,90$ \\
\hline
\end{tabular}

Fuente: Elaboración propia.

\subsubsection{6.-Costos de operación}

Dentro de los costos de operación se contemplaron:

- Remuneraciones.

- Materiales de oficina.

- Servicios básicos.

- Otros insumos

- Depreciación de activo fijo.

- Amortización constitución.

Tabla 50. Remuneraciones

\section{REMUNERACIONES}

\begin{tabular}{|c|c|c|c|c|c|c|c|c|c|}
\hline Cargo & Cantidad & $\begin{array}{c}\text { Salario } \\
\text { nominal }\end{array}$ & $\begin{array}{c}\text { 13er } \\
\text { sueldo }\end{array}$ & $\begin{array}{l}\text { 14to } \\
\text { sueldo }\end{array}$ & $\begin{array}{l}\text { Vacacione } \\
\mathrm{s}\end{array}$ & $\begin{array}{l}\text { Fondo de } \\
\text { reserva }\end{array}$ & $\begin{array}{c}\text { Aporte } \\
\text { patronal }\end{array}$ & $\begin{array}{c}\text { Costo } \\
\text { Mensual }\end{array}$ & $\begin{array}{l}\text { Costo } \\
\text { Anual }\end{array}$ \\
\hline Gerente & 1 & $\$ 600,0$ & $\$ 50,0$ & $\$ 30,0$ & $\$ 25,0$ & $\$ 50,0$ & $\$ 72,9$ & $\$ 827,9$ & $\$ 9.934,6$ \\
\hline Administrador & 1 & $\$ 400,0$ & $\$ 33,3$ & $\$ 30,0$ & $\$ 16,7$ & $\$ 33,3$ & $\$ 48,6$ & $\$ 561,9$ & $\$ 6.743,0$ \\
\hline Cajeros & 2 & $\$ 360,0$ & $\$ 30,0$ & $\$ 30,0$ & $\$ 15,0$ & $\$ 30,0$ & $\$ 43,7$ & $\$ 1.017,5$ & $\$ 12.209,5$ \\
\hline Meseros & 2 & $\$ 360,0$ & $\$ 30,0$ & $\$ 30,0$ & $\$ 15,0$ & $\$ 30,0$ & $\$ 43,7$ & $\$ 1.017,5$ & $\$ 12.209,5$ \\
\hline "Barman & 1 & $\$ 180,0$ & $\$ 15,0$ & $\$ 30,0$ & $\$ 7,5$ & $\$ 15,0$ & $\$ 21,9$ & $\$ 269,4$ & $\$ 3.232,4$ \\
\hline Guardia & 1 & $\$ 360,0$ & $\$ 30,0$ & $\$ 30,0$ & $\$ 15,0$ & $\$ 30,0$ & $\$ 43,7$ & $\$ 508,7$ & $\$ 6.104,7$ \\
\hline Total & 8 & $\$ 2.260,0$ & $\$ 188,3$ & $\$ 180,0$ & $\$ 94,2$ & $\$ 188,3$ & $\$ 274,6$ & $\$ 4.202,8$ & $\$ 50.433,6$ \\
\hline
\end{tabular}

* La labor del barman se realiza únicamente los fines de semana.

Fuente: Elaboración propia.

Tabla 51. Materiales de oficina

\begin{tabular}{|l|r|r|r|}
\hline \multicolumn{1}{|c|}{ SUMINISTROS DE OFICINA } & $\begin{array}{c}\text { CANT. } \\
\text { ANUAL }\end{array}$ & \multicolumn{1}{c|}{ V. Unitario } & \multicolumn{1}{l|}{ V. Total } \\
\hline Resmas de papel & 20 & $\$ 4,00$ & $\$ 80,00$ \\
\hline Talonario de facturas & 24 & $\$ 10,00$ & $\$ 240,00$ \\
\hline Libretas & 24 & $\$ 1,20$ & $\$ 28,80$ \\
\hline Lapiceros & 30 & $\$ 0,50$ & $\$ 15,00$ \\
\hline Saca grapas & 2 & $\$ 1,50$ & $\$ 3,00$ \\
\hline Perforadora & 1 & $\$ 3,00$ & $\$ 3,00$ \\
\hline Grapadoras & 2 & $\$ 3,50$ & $\$ 7,00$ \\
\hline Folders & 2 & $\$ 4,50$ & $\$ 9,00$ \\
\hline Total & 105 & $\mathbf{\$ 2 8 , 2 0}$ & $\$ 385,80$ \\
\hline
\end{tabular}

Fuente: Elaboración propia. 


\section{Tabla 52. Servicios básicos}

\begin{tabular}{|c|l|r|r|}
\hline \multicolumn{3}{|c|}{ SERVICIOS BASICOS } \\
\hline $\mathbf{N o}$ & \multicolumn{1}{|c|}{ DESCRIPCION } & VALOR MES (\$) & V. ANUAL (\$) \\
\hline $\mathbf{1}$ & Arriendo Local & 300 & $3.600,00$ \\
\hline $\mathbf{2}$ & Suministro de agua & $\$ 30,00$ & 360,00 \\
\hline $\mathbf{3}$ & Energía eléctrica & $\$ 100,00$ & $1.200,00$ \\
\hline $\mathbf{4}$ & Teléfono & $\$ 35,00$ & 420,00 \\
\hline $\mathbf{5}$ & Televisión por cable & $\$ 40,00$ & 480,00 \\
\hline & TOTAL SERVICIOS BASICOS & $\mathbf{\$ 5 0 5 , 0 0}$ & $\mathbf{2 . 4 6 0 , 0 0}$ \\
\hline
\end{tabular}

Fuente: Elaboración propia.

Tabla 53. Depreciación activos fijos

\begin{tabular}{|c|c|c|c|c|c|}
\hline \multicolumn{6}{|c|}{ DEPRECIACION ACTIVOS FIJOS } \\
\hline No & DESCRIPCION & VIDA UTIL AÑOS & $\begin{array}{l}\text { VALOR DE } \\
\text { COMPRA }\end{array}$ & $\begin{array}{c}\text { DEPRECIACION } \\
\%\end{array}$ & TOTAL ANUAL \\
\hline & Muebles & 10 & $6.940,00$ & $10 \%$ & 694,00 \\
\hline & Equipos de oficina & 10 & 70,00 & $10 \%$ & 7,00 \\
\hline & Equipos de cómputo & 3 & $1.950,00$ & $33 \%$ & 650,00 \\
\hline & Maquinarias y equipos & 10 & $8.960,00$ & $10 \%$ & 896,00 \\
\hline & TOTAL DEPRECIACION & & & & $2.247,00$ \\
\hline
\end{tabular}

Fuente: Elaboración propia.

Tabla 54. Amortización por constitución

\begin{tabular}{|c|c|c|c|c|c|}
\hline \multicolumn{6}{|c|}{ AMORTIZACION DE CONSTITUCION } \\
\hline No & DESCRIPCION & VIDA UTIL AÑoS & $\begin{array}{l}\text { VALOR DE } \\
\text { COMPRA }\end{array}$ & AMORTIZ. \% & TOTAL ANUAL \\
\hline \multicolumn{2}{|c|}{1 Constitución } & 5 & $\$ 800,00$ & $20 \%$ & $\$ 160,00$ \\
\hline \multicolumn{2}{|c|}{2 Permisos e impuestos } & 5 & $\$ 300,00$ & $20 \%$ & $\$ 60,00$ \\
\hline \multicolumn{4}{|c|}{ TOTAL DEPRECIACION } & & $\$ 220,00$ \\
\hline
\end{tabular}

Fuente: Elaboración propia.

\subsubsection{7.-Capital de operación}

En el presente proyecto se ha considerado la posibilidad que durante los tres primeros meses de funcionamiento éste no genere los ingresos previstos y por lo tanto de la necesidad de contar con un capital inicial que permita cubrir los costos de producción y de operación durante los tres primeros meses del proyecto.

Tabla 55. Costo producción 3 meses.

\begin{tabular}{|l|r|r|}
\hline Alimento & $\begin{array}{c}\text { C. Prod. } \mathbf{x} \\
\text { mes }\end{array}$ & \multicolumn{1}{c|}{$\begin{array}{c}\text { Costo } 3 \\
\text { meses }\end{array}$} \\
\hline Hamburguesas & $\$ 138,57$ & $\$ 415,71$ \\
\hline Fritadas & $\$ 204,40$ & $\$ 613,21$ \\
\hline Sanduches & $\$ 122,09$ & $\$ 366,28$ \\
\hline Tostadas & $\$ 86,99$ & $\$ 260,96$ \\
\hline Pizza & $\$ 189,49$ & $\$ 568,47$ \\
\hline Papas fritas & $\$ 162,41$ & $\$ 487,23$ \\
\hline Alitas & $\$ 97,81$ & $\$ 293,43$ \\
\hline T. Choclo & $\$ 116,90$ & $\$ 350,69$ \\
\hline Lasagna & $\$ 227,80$ & $\$ 683,40$ \\
\hline Empanadas & $\$ 32,80$ & $\$ 98,40$ \\
\hline Bollos & $\$ 35,99$ & $\$ 107,97$ \\
\hline Humitas & $\$ 38,44$ & $\$ 115,32$ \\
\hline Tablitas & $\$ 207,85$ & $\$ 623,56$ \\
\hline Bolones Jamon y queso & $\$ 78,93$ & $\$ 236,78$ \\
\hline Patacones & $\$ 25,97$ & $\$ 77,90$ \\
\hline Hornados & $\$ 95,67$ & $\$ 287,01$ \\
\hline Total parcial & $\$ 1.862,11$ & $\$ 5.586,32$ \\
\hline
\end{tabular}




\begin{tabular}{|l|r|r|}
\hline Postres & & \\
\hline Tres leches & $\$ 351,03$ & $\$ 1.053,08$ \\
\hline Frutas picadas & $\$ 206,06$ & $\$ 618,17$ \\
\hline Torta mojada & $\$ 297,11$ & $\$ 891,32$ \\
\hline Helados & $\$ 142,68$ & $\$ 428,04$ \\
\hline Queso de piña & $\$ 279,22$ & $\$ 837,66$ \\
\hline Tiramisú & $\$ 134,38$ & $\$ 403,15$ \\
\hline Chescake & $\$ 171,22$ & $\$ 513,65$ \\
\hline Total parcial & $\$ \mathbf{1 . 5 8 1 , 6 9}$ & $\mathbf{\$ 4 . 7 4 5 , 0 7}$ \\
\hline
\end{tabular}

\begin{tabular}{l|r|r}
\hline Bebidas & $\$ 187,10$ & $\$ 561,29$ \\
\hline Jugos naturales & $\$ 224,28$ & $\$ 672,83$ \\
\hline Batidos & $\$ 124,63$ & $\$ 373,88$ \\
\hline Chocolate & $\$ 236,87$ & $\$ 710,61$ \\
\hline Capuccino & $\$ 170,91$ & $\$ 512,72$ \\
\hline Café & $\$ 87,55$ & $\$ 262,66$ \\
\hline Té aromstico & $\$ 76,23$ & $\$ 228,70$ \\
\hline Té helado & $\$ 100,07$ & $\$ 300,21$ \\
\hline Mocaccino & $\$ 1.207,63$ & $\$ 3.622,89$ \\
\hline Total parclal & & \\
\hline & TOTAL & $\$ 13.954,29$ \\
\hline
\end{tabular}

Fuente: Elaboración propia.
Tabla 56. Costo producción.

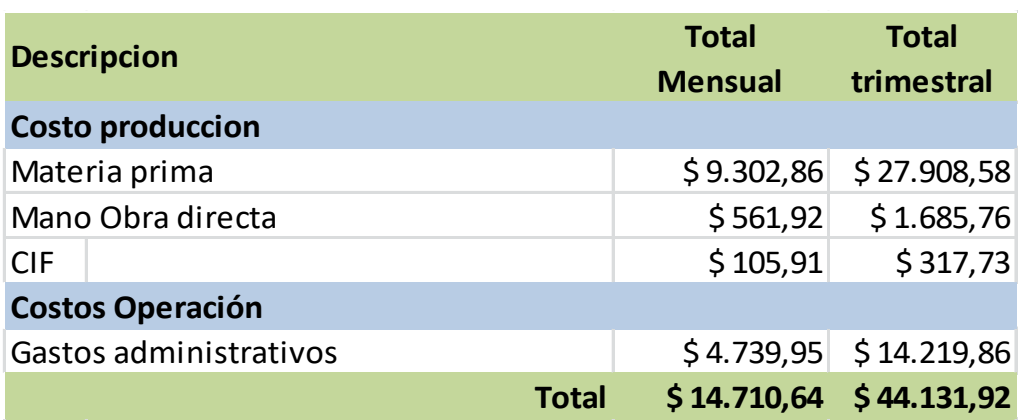

Fuente: Elaboración propia.

Tabla 57. Inversión del proyecto

\begin{tabular}{|l|r|}
\multicolumn{1}{|c|}{ DESCRIPCION } & \multicolumn{1}{c|}{ VALOR } \\
\hline Inversion Fija & $\$ 24.928,87$ \\
\hline Capital Operacional & $\$ 44.131,92$ \\
\hline Inversión diferida & $\$ 1.100,00$ \\
\hline Total & $\$ 70.160,80$ \\
\hline
\end{tabular}

Fuente: Elaboración propia.

\subsubsection{8.-Financiamiento}

El presente proyecto de inversión no utilizará financiamiento pues prevé utilizar $100 \%$ capital propio.

\subsubsection{9.-Presupuesto de ingresos}

En el caso del presupuesto de ingresos se consideraron los siguientes aspectos:

- Las cantidades requeridas de cada uno de los productos de- 
mandados por los consumidores en función de la encuesta de preferencias de los productos realizada en el estudio de mercado.

- El incremento de las cantidades solicitadas por los consumidores considerando la proyección de la demanda analizada en el estudio de mercado.

- Se consideró un incremento anual en el precio de venta de los productos, el mismo que por motivos de promoción se aplicara a partir del tercer año del proyecto. Este incremento será igual a la inflación promedio del país la cual es del 3\%.

Con las consideraciones anotadas anteriormente se procedió a realizar el presupuesto de ingresos por la venta de productos por cada producto de forma anual.

Tabla 58. Ingresos por venta de productos (Anual)

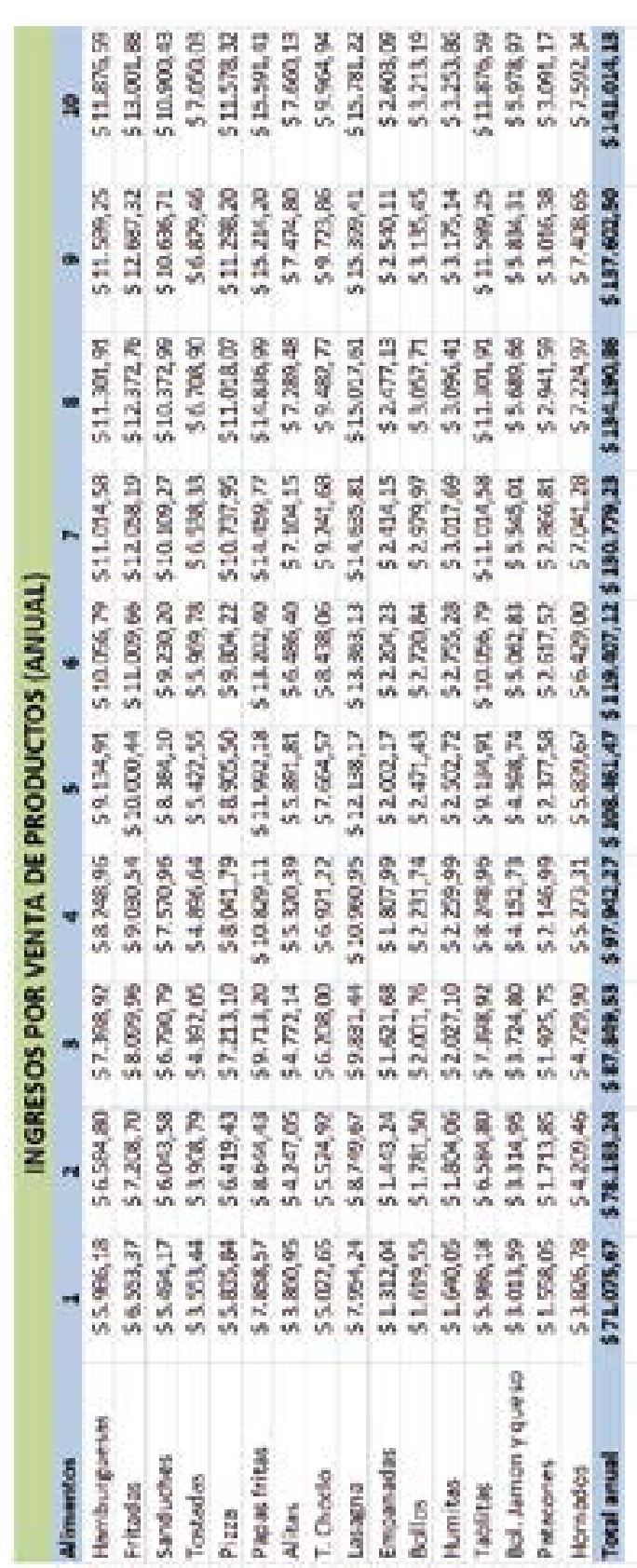




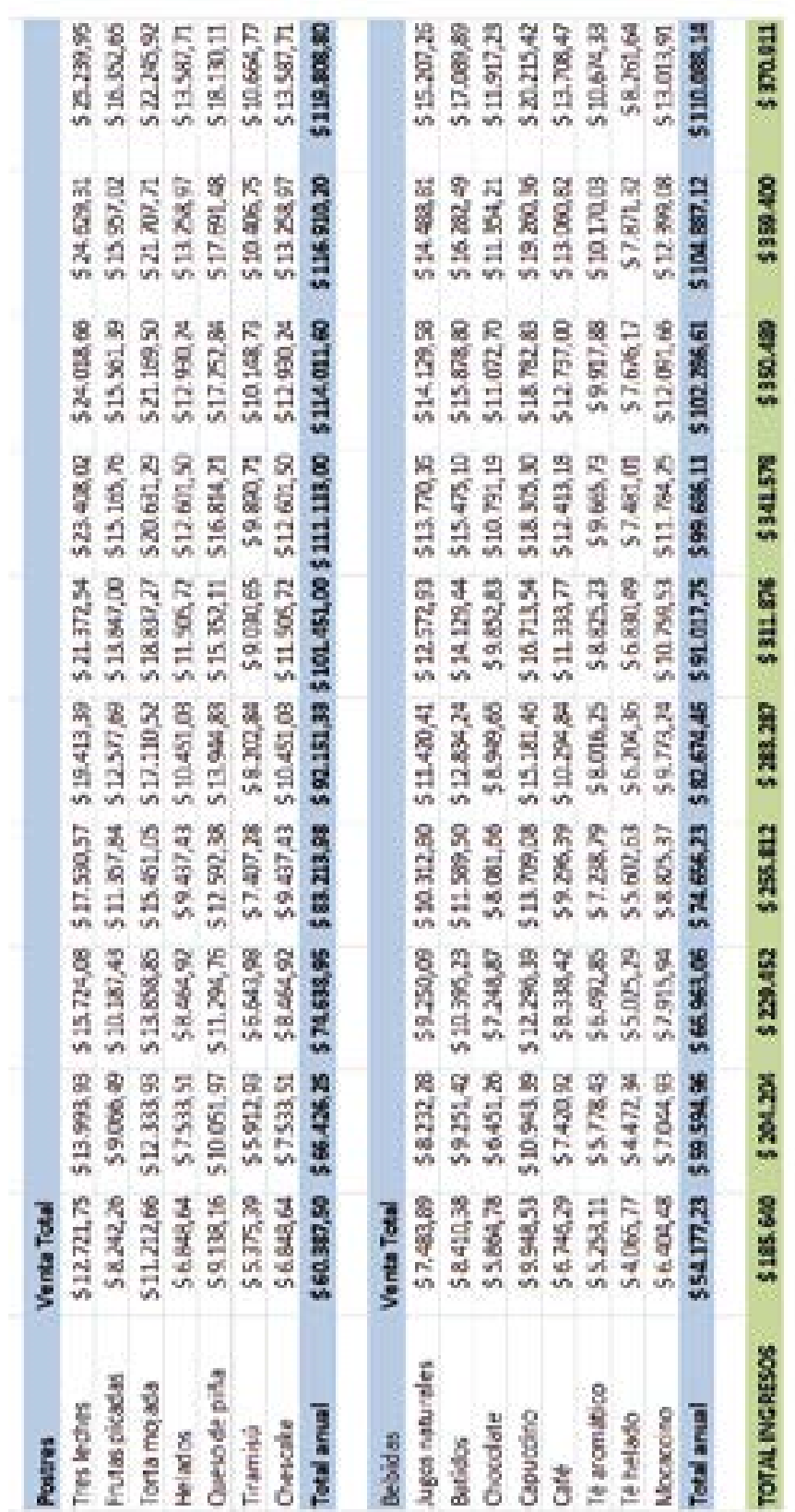

Fuente: Elaboración propia.

\subsubsection{0.-Estados financieros}

Tabla 58. Estado de resultados

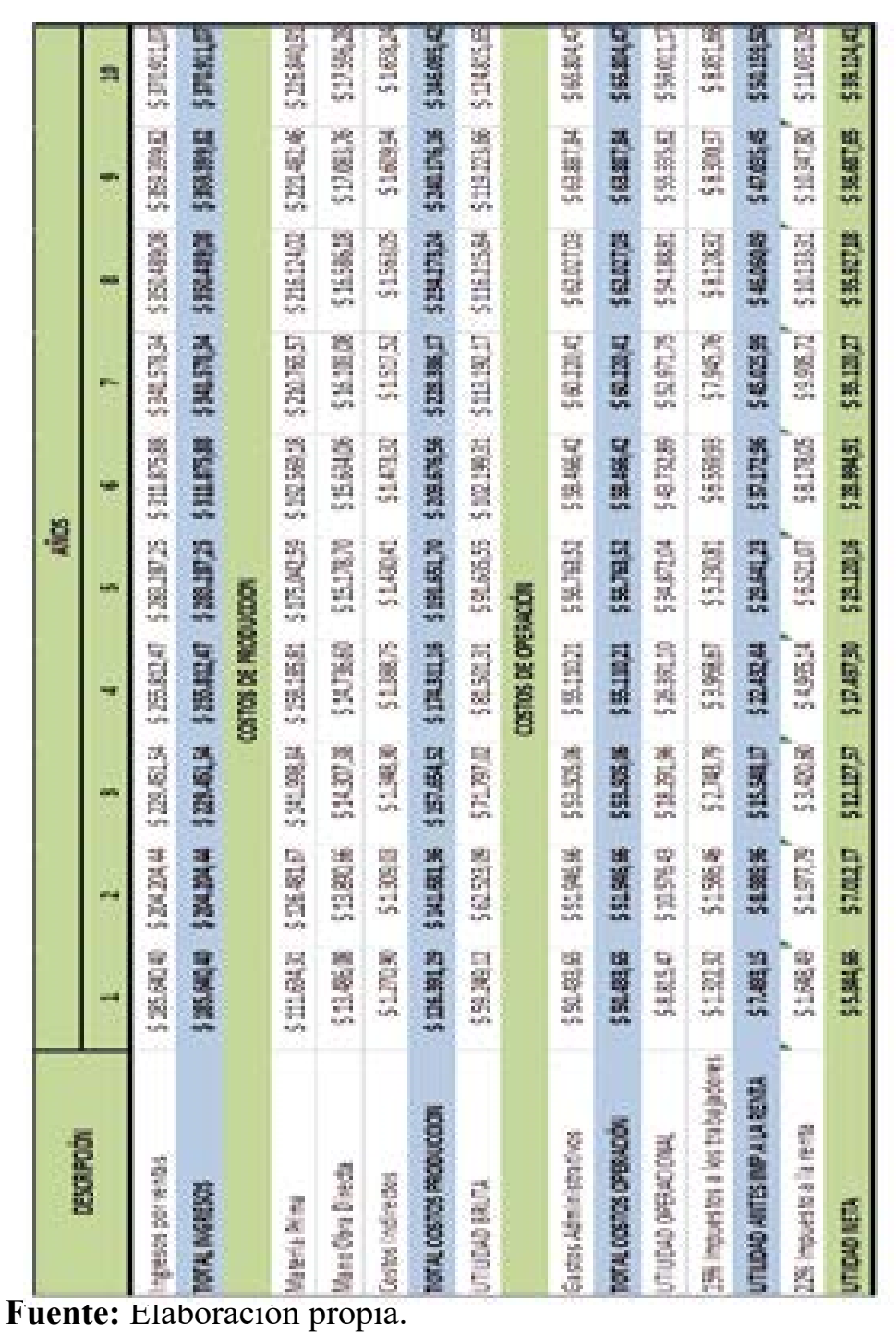

121 
Tabla 59. Flujo de caja

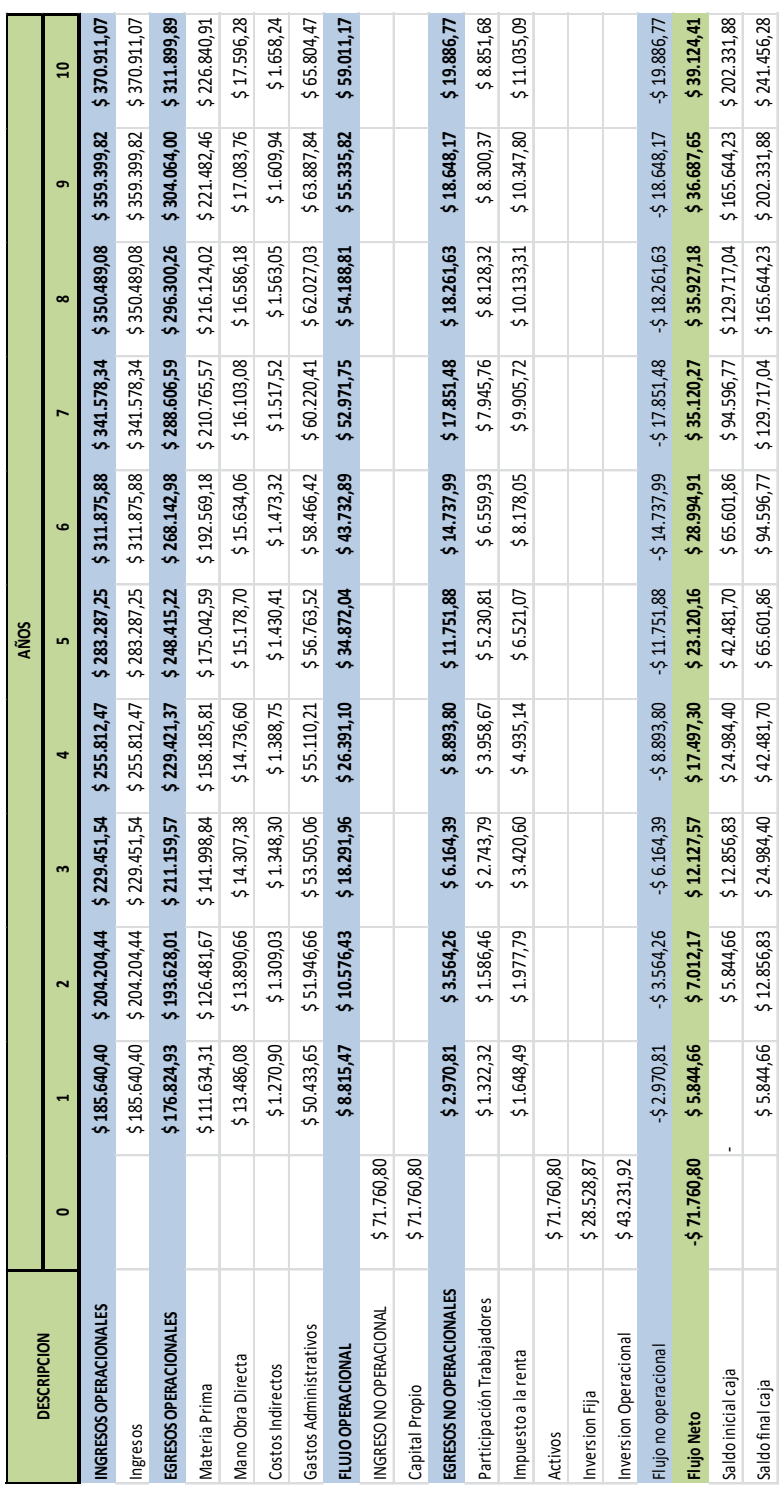

Fuente: Elaboración propia.

\subsubsection{1.-Balance general}

Tabla 60. Balance general 2016

\section{BALANCE GENERAL 2016}

\begin{tabular}{|c|c|c|c|c|c|c|}
\hline \multirow{2}{*}{\multicolumn{3}{|c|}{$\begin{array}{l}\text { ACTIVO } \\
\text { ACTIVO CORRIENTE }\end{array}$}} & \multirow[b]{2}{*}{$\$ 53.243,58$} & \multicolumn{3}{|l|}{ PASIVO } \\
\hline & & & & PASIVO CORRIENTE & & $\$ 70.160,80$ \\
\hline $\begin{array}{l}\text { Caja y Bancos } \\
\text { Inventarios }\end{array}$ & $\begin{array}{r}\$ 5.844,66 \\
\$ \$ 73092\end{array}$ & $\begin{array}{l}\$ 5.844,66 \\
57200\end{array}$ & & Pasivo Largo Plazo & $\$ 70.160,80$ & \\
\hline ACTIVO FIJO & & & $\$ 22.681,87$ & PATRIMONIO & & $\$ 6.644,66$ \\
\hline Obras fisicas & $\$ 7.008,87$ & $\$ 7.008,87$ & & Capital social & $\$ 800,00$ & \\
\hline Maquinarias y equipos & $\$ 8.960,00$ & $\$ 8.064,00$ & & Utilidad del ejercicio & $\$ 5.844,66$ & \\
\hline Deprec. Maquin & $\$ 896,00$ & & & & & \\
\hline Muebles y enseres & $\$ 6.940,00$ & $\$ 6.246,00$ & & & & \\
\hline Deprec. Muebles & $\$ 694,00$ & & & & & \\
\hline Equipos de Computación & $\$ 1.950,00$ & $\$ 1.300,00$ & & & & \\
\hline Deprec. Equipos comp. & $\$ 650,00$ & & & & & \\
\hline Equipos de Oficina & $\$ 70,00$ & $\$ 63,00$ & & & & \\
\hline Deprec. Equip oficina & $\$ 7,00$ & & & & & \\
\hline ACTIVO DIFERIDO & & & $\$ 880,00$ & & & \\
\hline Gasto Constitucion & $\$ 800,00$ & $\$ 640,00$ & & & & \\
\hline Amortizacion Gast Const & $\$ 160,00$ & & & & & \\
\hline Permisos e Impuestos & $\$ 300,00$ & $\$ 240,00$ & & & & \\
\hline Amorti. Impuestos & $\$ 60,00$ & & & & & \\
\hline
\end{tabular}

TOTALACTIVOS

Fuente: Elaboración propia.

\subsubsection{2.-Evaluación financiera}

\section{Tasa de descuento del proyecto}

En el presente proyecto el costo de oportunidad se ha establecido en el $20 \%$.

\section{Determinación tasa de descuento del inversionista}

En virtud de que el presente proyecto no posee financiamiento se ha considerado una tasa de descuento del inversionista igual 
a la tasa de oportunidad del $20 \%$.

\subsubsection{3.-Criterios de evaluación}

\section{Valor actual neto (van) y tasa interna de retorno}

Para el cálculo del Valor Actual Neto (VAN) se utilizó la tasa de oportunidad del $20 \%$, por considerar que cubre las expectativas del inversionista.

La fórmula para el cálculo de la misma se muestra a continuación:

$V A N=-I_{0}+\sum_{t=1}^{N} \frac{Q_{t}}{(1+i)^{t}} ;$ Dónde:

$I_{0}=$ Inversión inicial

$t=$ Periodo observado

$Q_{t}=$ Flujo neto en el periodo

$i=$ Tasa de oportunidad del inversionista

Tal como se muestra en la tabla siguiente, al aplicar la fórmula para el cálculo del mismo se obtuvo un valor de: $\$ 4.013,58$, el cual al ser positivo implica que es rentable, considerando la tasa de oportunidad del inversionista.
Tabla 61. Tasa de oportunidad del inversionista

\begin{tabular}{|c|c|c|c|c|}
\hline PERIODOS & FLUJOS NETO & $\frac{Q_{t}}{(1+0,2)^{t}}$ & $\begin{array}{c}\text { F. NETO DESC. } \\
21 \%\end{array}$ & $\begin{array}{c}\text { F. NETO DESC. } \\
23 \%\end{array}$ \\
\hline Inversión inicial & $-\$ 71.760,80$ & $-\$ 71.760,80$ & $-\$ 71.760,80$ & $-\$ 71.760,80$ \\
\hline Año 1 & $\$ 5.844,66$ & $\$ 4.870,55$ & $\$ 4.830,29$ & $\$ 4.790,70$ \\
\hline Año 2 & $\$ 7.012,17$ & $\$ 4.869,56$ & $\$ 4.789,41$ & $\$ 4.711,21$ \\
\hline Año 3 & $\$ 12.127,57$ & $\$ 7.018,27$ & $\$ 6.845,70$ & $\$ 6.678,74$ \\
\hline Año 4 & $\$ 17.497,30$ & $\$ 8.438,13$ & $\$ 8.162,62$ & $\$ 7.898,27$ \\
\hline Año 5 & $\$ 23.120,16$ & $\$ 9.291,47$ & $\$ 8.913,82$ & $\$ 8.554,44$ \\
\hline Año 6 & $\$ 28.994,91$ & $\$ 9.710,34$ & $\$ 9.238,67$ & $\$ 8.793,52$ \\
\hline Año 7 & $\$ 35.120,27$ & $\$ 9.801,42$ & $\$ 9.248,27$ & $\$ 8.730,50$ \\
\hline Año 8 & $\$ 35.927,18$ & $\$ 8.355,51$ & $\$ 7.818,80$ & $\$ 7.320,56$ \\
\hline Año 9 & $\$ 36.687,65$ & $\$ 7.110,31$ & $\$ 6.598,60$ & $\$ 6.127,47$ \\
\hline Año 10 & $\$ 39.124,41$ & $\$ 6.318,81$ & $\$ 5.815,59$ & $\$ 5.356,11$ \\
\hline \multicolumn{2}{|l|}{ TASA OPORTUNIDAD } & 0,20 & 0,21 & 0,22 \\
\hline & VAN = & $\$ 4.023,58$ & $\$ 501$ & $-\$ 2.799$ \\
\hline
\end{tabular}

Fuente: Elaboración propia.

\section{Tasa interna de retorno (TIR)}

En lo que respecta a la Tasa Interna de Retorno (TIR), se obtuvo que la tasa de rentabilidad del proyecto es de $21,15 \%$, la cual es mayor a la tasa de oportunidad del inversionista, lo cual indica que el proyecto es rentable.

$$
T I R=0,21+(0,22-0,21) \frac{501}{501-(-2.799)}=0,2015=21,15 \%
$$

\section{Evaluación económica}

Para realizar la evaluación económica del proyecto se consideraron los siguientes aspectos: 
- Generación de empleo.

- Aporte a PIB del cantón.

- Aporte al erario público a través de impuestos.

En lo referente a la generación de empleo, éste emprendimiento creará diez fuentes de empleo, lo cual repercutirá en 10 familias de la localidad que mejorarán su bienestar socio económico.

Por otra parte el servicio de comidas rápidas proporcionado por la empresa El Rincón del Chuno, generará, en el transcurso de su vida útil, una facturación de $\$ 2^{\prime} 892.650,29$ siendo por tanto un valioso aporte al PIB del cantón Chone.

\section{Tabla 62. Tasa}

\begin{tabular}{|l|r|}
\hline \multicolumn{1}{|c|}{ PERIODOS } & FACTURACION \\
\hline Año 1 & $\$ 185.640,40$ \\
\hline Año 2 & $\$ 204.204,44$ \\
\hline Año 3 & $\$ 229.451,54$ \\
\hline Año 4 & $\$ 255.812,47$ \\
\hline Año 5 & $\$ 283.287,25$ \\
\hline Año 6 & $\$ 311.875,88$ \\
\hline Año 7 & $\$ 341.578,34$ \\
\hline Año 8 & $\$ 350.489,08$ \\
\hline Año 9 & $\$ 359.399,82$ \\
\hline Año 10 & $\$ 370.911,07$ \\
\hline APORTE PIB & $\$ \mathbf{2 . 8 9 2 . 6 5 0 , 2 9}$ \\
\hline
\end{tabular}

Fuente: Elaboración propia.
Así mismo en virtud de la actividad económica realizada por la empresa, ésta generará al estado ecuatoriano un valor de: \$ $68.103,05$ por concepto de pago de impuesto a la renta durante el horizonte analizado del proyecto.

Tabla 63. Pagos de impuestos

\begin{tabular}{|l|r|}
\hline \multicolumn{1}{|c|}{ PERIODOS } & IMP. RENTA \\
\hline Año 1 & $\$ 1.648,49$ \\
\hline Año 2 & $\$ 1.977,79$ \\
\hline Año 3 & $\$ 3.420,60$ \\
\hline Año 4 & $\$ 4.935,14$ \\
\hline Año 5 & $\$ 6.521,07$ \\
\hline Año 6 & $\$ 8.178,05$ \\
\hline Año 7 & $\$ 9.905,72$ \\
\hline Año 8 & $\$ 10.133,31$ \\
\hline Año 9 & $\$ 10.347,80$ \\
\hline Año 10 & $\$ 11.035,09$ \\
\hline TOTAL IMPUESTOS & $\$ 68.103,05$ \\
\hline
\end{tabular}

Fuente: Elaboración propia. 


\section{5.-Consideraciones finales}

- En el estudio de mercado del presente proyecto se determinó que existe una gran demanda insatisfecha en la ciudad de Chone en lo que respecta al servicio de comidas rápidas, de la cual el presente proyecto solo pretende cubrir un $10 \%$ de la misma.

- La evaluación financiera mostró que el proyecto planteado en rentable, pues permitirá obtener un margen de utilidad así como también cubrir las inversiones realizadas por los inversionistas.

- Considerando una tasa de oportunidad del $20 \%$ el proyecto mostro un VAN de $\$ 4.023,58$, el cual al ser positivo refleja que es rentable si se considera la tasa de oportunidad indicada anteriormente.

- La evaluación del proyecto mostró una tasa interna de retorno igual al 21,15\%, la cual es mayor a la tasa de oportunidad del inversionista.

\section{Por lo que se recomienda}

- Poner en marcha el proyecto, dado que su evaluación financiera y económica indicaron rentabilidad.

- La ejecución del proyecto, pues contribuye a la generación de empleo, lo que se transforma en bienestar social de las personas y de las familias de las personas que intervengan en el proyecto.

- Finalmente la puesta en marcha del proyecto planteado contribuirá al crecimiento económico de la ciudad, pues permite un incremento de su PIB, así como también genera ingresos al estado por concepto de impuestos.

\section{Bibliografía}

Andersen, A. (1999). Diccionario de economía y negocios. Madrid: Espasa Calpe S.A.

Baca Urbina, G. (2001). Evaluación de proyectos. Mexico D.F.: MacGraw-Hill.

Castro Solórzano, M. (2012). SlideShare. Recuperado el 11 de 2015, de http://es.slideshare.net/masolc/los-costos-y-losgastos-definicin-y-calsificacin

COCA COLA. (2015). www.coca-cola.com. Recuperado el 21 de 8 de 2015, de http://www.coca-cola.com.ec/es/productos/

Emprende PYME. (2015).www.emprendepyme.net. Recuperado el 21 de 8 de 2015, de http://www.emprendepyme.net/clavespara-elegir-proveedores.html

Gutierrez Castro, J. P. (2014). Proyecto de inversión para la creación del Centro Recreativo Infantil de juegos inflables "Chiquititos". Manta: ULEAM.

Haime, L. (1995). Planeacion financiera de la empresa moderna. Mexico D.F.: ISEF S.A.

INEC. (2010). Censo de población y vivienda. Quito: INEC.

INEC. (2010). Censo Nacional Económico 2010. Quito: INEC.

Mochón, F. (2001). Principos de economía. Madrid: MacGrawHill Interamericana de España. 
PRONACA. (2015). www.pronaca.com. Recuperado el 21 de 8 de 2015, de http://www.pronaca.com/site/principalFood. jsp?arb $=1123 \&$ cat $=84 \&$ prod $=140$

Sapag Chain, N. (2008). Preparación y Evaluación de Proyectos. Mexico D.F.: Mc Graw Hill. 